\title{
The Production of Sulfate Particles Through the Radiolytic Oxidation of Sulfur Dioxide
}

\author{
A Report \\ by \\ Kim Karpen-Hayes \\ Department of Chemistry
}

Submitted in partial fulfillment of the requirements

for the degree of

Master of Science

Chemistry

September 13, 1991

\section{DISCLAIMER}

This report was prepared as an account of work sponsored by an agency of the United States Government. Neither the United States Government nor any agency thereof, nor any of their employees, makes any warranty, express or implied, or assumes any legal liability or responsibility for the accuracy, completeness, or usefulness of any information, apparatus, product, or process disclosed, or represents that its use would tist infringe privately owned rights. Reference herein to any specific commercial product, procers, or service by trade name, trademark, manufacturer, or otherwise does not necessarily constitute or imply its endorsement, recommendation, or favoring by the United States Governmert or any agency thereof. The views and opinions of authors expressed herein do not necess.arily state or reflect those of the United States Governme it or any agency thereof. 
The undersigned have examined the report entitled

The Production of Sulfate Particles Through the Radiolytic Oxidation of Sulfur Dioxide presented by Kim Karpen-Hayes, a candidate for the degree of Master of Science, and hereby certify that it is worthy of acceptance.

September 13, 1991

Date

Advisor $\quad$ Prof. Philip K. Hopke 


\begin{abstract}
The production of hydroxyl radicals by the radiolytic decomposition of water vapor following alpha decay of ${ }^{22} \mathrm{Rn}$ can be used to produce an ultrafine sulfuric acid aerosol in the presence of $\mathrm{SO}_{2}$. In the past, the production of this aerosol appeared to have a limiting threshold in as much as sufficient conversion of $\mathrm{SO}_{2}$ to $\mathrm{SO}_{4}$ must be attained to achieve the concentration required for nucleation. This appeared to occur when the bulk average acidity reached an adequately high value. Recent studies have indicated that an ultrafine molecular cluster aerosol in the $0.5-3 \mathrm{~nm}$ diameter range is initially formed. This highly diffusive aerosol then rapidly coagulates to form the observed condensation nuclei. Due to the decreased detection efficiencies for particles less than $5 \mathrm{~nm}$ in diameter, particle detection instruments such as condesation nuclei counters (CNCs) have been unable to detect this size mode in the past.

The threshold curve for the onset of the sulfuric acid aerosol formation is a function of the $\mathrm{H}_{2} \mathrm{O}, \mathrm{SO}_{2}$ and $\mathrm{Rn}$ concentrations. The hydroxyl radical formation is dependant on the $\mathrm{H}_{2} \mathrm{O}$ and $\mathrm{Rn}$ concentrations. The mass conversion rate of $\mathrm{SO}_{2}$ to $\mathrm{H}_{2} \mathrm{SO}_{4}$ has been studied by measuring the airborne $\mathrm{H}_{2} \mathrm{SO}_{4}$ concentration by ion chromotography after it has been collected on a filter and leached into solution. The mass conversion rate of $\mathrm{SO}_{2}$ to form $\mathrm{H}_{2} \mathrm{SO}_{4}$ was calculated at $30 \%$ relative humidity. The amount of sulfate produced depended linearly on the amount of $\mathrm{SO}_{2}$ present.

The activity size distributions of the sulfuric acid aerosols are measured through their association with radioactive ${ }^{218} \mathrm{Po} / \mathrm{PoO}_{2}$ following their formation. A modified approach to wire screen penetration theory detailed by Ramamurthi (1989) and the use of graded screen arrays have been used to characterize the activity size distribution of these aerosols. The total particle concentration was measured using a TSI ultrafine condensation particle counter Moi 313025.
\end{abstract}




\section{ACKNOWLEDGMENTS}

I would like to thank my advisor, Dr. Philip Hopke, for his guidance, motivation and support throughout this research project. I would also like to express my thanks and appreciation to Eleanor Hopke for her time and assistance in running the Ion

Chromatograph. I would have been lost without her help in troubleshooting through the problems inherent with the instrument.

I would like to sincerely thank the members of the Hopke group for their support and camaraderie. I feel very privileged to have been part of this family atmosphere. I would especially like to thank Piotr Wasiolek, Dave Glover, and Mengdawn Cheng who helped me in more ways then I can mention. Of course many thanks go to Annette Green for her cheerful administrative assistance, computer expertise, and her companionship. It has been a real joy working with her!

I would not have considered graduate school much less finished my undergraduate degree had it not been for the unending support, encouragement, and friendship of Dr. Phill Christiansen, his wife Vickie, and sons Sam and Lewis. I owe them much more than a simple thank-you can satisfy. I'm truly blessed to have them as friends.

Finally, I must thank the most important man in my life, my husband Peter. He has been the wind beneath my wings. The sacrifices he made and the support and encouragement given are too numerous to detail here. I could not have succeeded without him. 


\section{TABLE OF CONTENTS}

CHAPTER

Page

1. INTRODUCTION $\ldots \ldots \ldots \ldots \ldots \ldots \ldots \ldots \ldots \ldots \ldots \ldots \ldots \ldots \ldots \ldots$

1.1 Radiological Background $\ldots \ldots \ldots \ldots \ldots \ldots \ldots \ldots \ldots \ldots$

1.2 Radiolytic Nuclei Formation $\ldots \ldots \ldots \ldots \ldots \ldots \ldots \ldots \ldots \ldots$

2. ION-INDUCED CLUSTER FORMATION AND NUCLEATION $\ldots \ldots .6$

2.1 Background $\ldots \ldots \ldots \ldots \ldots \ldots \ldots \ldots \ldots \ldots \ldots \ldots \ldots \ldots \ldots \ldots \ldots \ldots \ldots$

3. WIRE SCREEN PENETRATION THEORY AND TECHNIQUES . . . 15

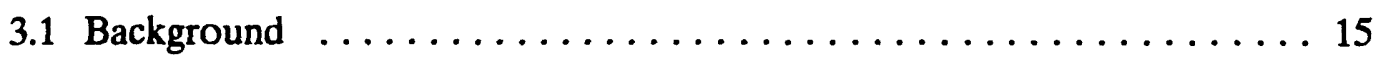

3.2 Wire Screen Penetration Theory $\ldots \ldots \ldots \ldots \ldots \ldots \ldots \ldots \ldots$

3.3 Size Distribution Reconstruction Algorithms ............. 17

3.4 Grab Sampling and The Total Alpha 3-count Method ......... 20

4. EXPERIMENTAL DESIGN AND PROCEDURES $\ldots \ldots \ldots \ldots \ldots 22$

4.1 The Illinios-Clarkson Radon Chamber $\ldots \ldots \ldots \ldots \ldots \ldots \ldots \ldots \ldots$

4.2 Sampling and Counting Equipment $\ldots \ldots \ldots \ldots \ldots \ldots \ldots \ldots \ldots \ldots \ldots \ldots$

4.3 Ion Chromatography $\ldots \ldots \ldots \ldots \ldots \ldots \ldots \ldots \ldots \ldots \ldots \ldots \ldots \ldots \ldots \ldots$

5. RESULTS AND DISCUSSION $\ldots \ldots \ldots \ldots \ldots \ldots \ldots \ldots \ldots \ldots$

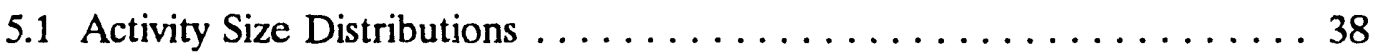

5.2 Mass Conversion Rate Results . . . . . . . . . . . . . . . 44

5.3 Estimate of the Amount of $\mathrm{OH}$ rerriuced $\ldots \ldots \ldots \ldots \ldots \ldots$

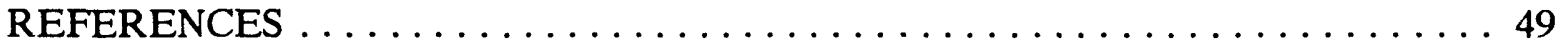

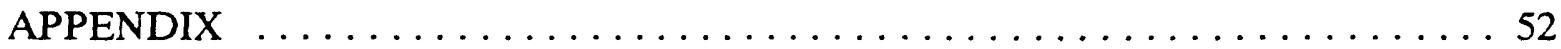

A1.1 Activity Size Distributions $\ldots \ldots \ldots \ldots \ldots \ldots \ldots \ldots \ldots \ldots \ldots \ldots \ldots \ldots \ldots \ldots$

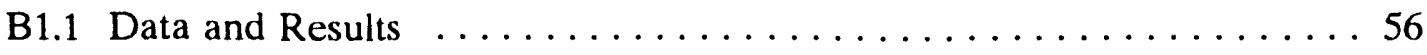


B1.2 Data and Results ......................60

B1.3 Data and Results $\ldots \ldots \ldots \ldots \ldots \ldots \ldots \ldots \ldots \ldots \ldots \ldots \ldots \ldots \ldots$

C1.1 Experimental Conditions $\ldots \ldots \ldots \ldots \ldots \ldots \ldots \ldots \ldots \ldots \ldots \ldots \ldots \ldots$

D1.1 Graded Screen Parameters $\ldots \ldots \ldots \ldots \ldots \ldots \ldots \ldots$

E1.1 15 August 1990 IC Results $\ldots \ldots \ldots \ldots \ldots \ldots \ldots \ldots \ldots \ldots \ldots \ldots$

E1.2 17 September 1990 IC Results $\ldots \ldots \ldots \ldots \ldots \ldots \ldots \ldots \ldots \ldots \ldots$

E1.3 28 January 1991 IC Results $\ldots \ldots \ldots \ldots \ldots \ldots \ldots \ldots \ldots \ldots \ldots \ldots$

E1.4 I March 1991 IC Results . . . . . . . . . . . . . . . . 75

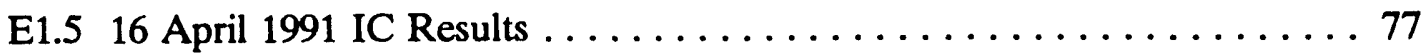

E1.6 16 May 1991 IC Results $\ldots \ldots \ldots \ldots \ldots \ldots \ldots \ldots \ldots \ldots \ldots \ldots$ 


\section{LIST OF FIGURES}

$\begin{array}{lll}\text { Figure } & \text { Page }\end{array}$

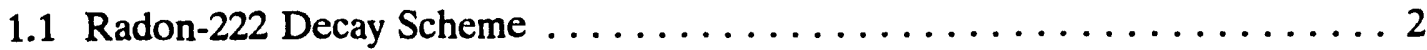

4.1 Set-up of the Illinios/Clarkson Radon-Aerosol Chamber $\ldots \ldots \ldots \ldots 23$

4.2 Sampler Holder and Screen Combinations used in Activity

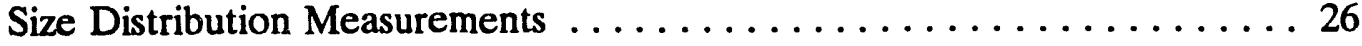

4.3 Typical Dionex Ion Chromatograph Configuration . . . . . . . . . . . . . 29

4.4 Pictorial Representation of Anion Separator Resin $\ldots \ldots \ldots \ldots \ldots \ldots$. . . 31

4.5 Pictorial Representation of Anion Exchange $\ldots \ldots \ldots \ldots \ldots \ldots \ldots \ldots$

5.1 Activity Size Distributions at $695 \mathrm{pCi} / 1 \mathrm{Rn}$, various $\%$ R.H., and various $\mathrm{SO}_{2} \ldots \ldots \ldots \ldots \ldots \ldots \ldots \ldots \ldots \ldots$

5.2 Activity Size Distributions at 695 and $388 \mathrm{pCi} / 1 \mathrm{Rn}$, various \% R.H., and various $\mathrm{SO}_{2}$ concentrations 


\section{CHAPTER 1}

\section{INTRODUCTION}

In the past, radon gas and its decay products were viewed as a health threat only to underground miners or to the small population of people living in homes built with uranium - or radium - contaminated materials. There is considerable epidemiological evidence of lung cancer induction in miners by breathing high levels of airborne radioactivity from radon and its decay products (NAS/NRC, 1988). Recent evidence has suggested that radon poses a health threat to the general public as well (Puskin et al. 1989) (NAS/NRC, 1991). Although ambient atmospheric concentrations of radon (0.1 $\mathrm{pCi} / \mathrm{l}$ at ground level) pose little health risk, indoor airborne concentrations in many residences in the United States are potentially dangerous. Natural soils can effect the indoor radon levels and are thought to contribute the major fraction of average radiation dose to the general public. The health threat stems from the inhalation of the radon decay products, their deposition onto the sensitive cells of the bronchial epithelium, and the subsequent dose of energy imparted.

\subsection{Radiological Background}

Radon is chemically inert under normal environmental conditions. The radiation health hazard is not attributed to radon itself, but rather to the solid, radioactive, chemically active decay products that follow the radon decay. These decay products are well dispersed by gaseous radon. The radioactive decay scheme of radon-222 is shown in Figure 1.1. Radon-222 has a half-life of 3.825 days and decays via alpha emission to polonium-218 (RaA). Polonium-218 has a half life of 3.11 minutes and decays via 


\section{RADON DECAY PRODUCTS}

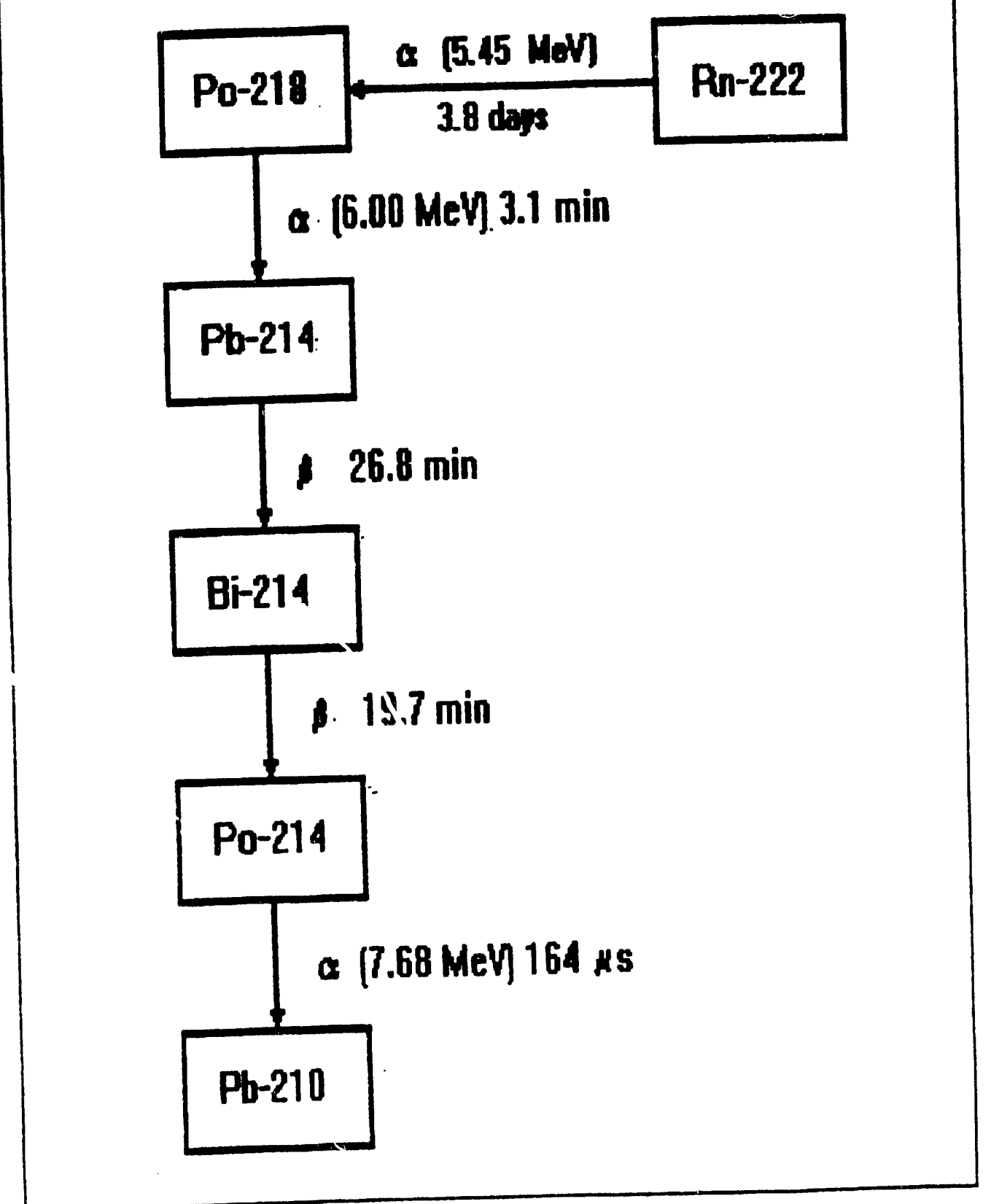

Figure 1.1 Radon-222 Decay Scheme 
alpha emission to lead-214 ( $\mathrm{RaB})$. Lead-214 has a half-life of 19.8 minutes and decays via beta emission to bismuth-214 $(\mathrm{RaC})$. Bismuth-214 has a half-life of 26.8 minutes and decays via beta emission to polonium-214 ( $\left.\mathrm{RaC}^{\prime}\right)$. Polonium-214 decays rapidly (162 usec) via alpha emission to lead-210 which has a comparably long half-life of 22.3 years and effectively ends the decay chain of radon-222. The short lived radon progeny are responsible for the health hazard due to the ionizing radiation they impart while decaying if deposited on the lung tissues.

In dose models commonly used to relate tissue dose to airborne radioactivity concentrations (James, 1990), a substantially increasing effective dose to the target tissue is predicted with decreasing particle size down to a few nm. Particles that approach the free molecular region become much more diffusive, and therefore, more effective in depositing the energy dose into the respiratory tract. However, at the smallest sizes, nasal deposition may limit the amount of activity reaching the tracheobronchial tree (Cheng $e t$ al., 1988). Since the health effects of the radon decay products are strongly dependent on the size distributions of the particles they may attached to, the formation of ultrafine particles in connection with the growth and evolution of radon progeny has been a topic of considerable concern. Before more accurate dose estimates can be determined, the mechanisms of particle formation and radioactivity/particle interaction must be understood.

As radon decays to Po-218, the alpha particle and the Po-218 nucleus detach, the polonium-218 atom dissipates about $117 \mathrm{keV}$ of energy during recoil in which the atom travels about $100 \mathrm{um}$ in air at STP (Lind. 1961). The Po-218 is found to have a +1 charge $88 \%$ of the time and neutral the remaining $12 \%$ of the time (Wellisch, 1913; Porstendörfer and Mercer, 1979 ). The subsequent neutralization of the Po-218 ion occurs quickly even in clean, dry air and has been well investigated and reported recently 
(Chu and Hopke, 1988).

\subsection{Radiolytic Nuclei Formation}

The abilitiy of ionizing radiation to produce condensation nuclei in clean filtered air was first reported by Chamberlain et al. (1957) and Megaw and Wiffen (1961). The passage of both the recoiling Po-218 nucleus and the alpha particle through air generates a substantial local concentration of hydroxyl radicals through the radiolysis of water vapor (Chu and Hopke, 1988). When trace amounts of oxidizable gases like $\mathrm{SO}_{2}$ are present, this ionization radiation can lead to the oxidation of $\mathrm{SO}_{2}$ to produce $\mathrm{H}_{2} \mathrm{SO}_{4}$ by reactions with hydroxyl radicals generated through the radiolysis of water. The lower vapor pressure species formed will cluster around ions (Chu et al., 1987). Due to the hygroscopic nature of $\mathrm{H}_{2} \mathrm{SO}_{4}$, it will gather water molecules leading to the formation of $\mathrm{H}_{2} \mathrm{SO}_{4}-\mathrm{H}_{2} \mathrm{O}$ clusters. Coagulation and condensation following homogeneous-heteromolecular and heterogeneous ion-induced nucleation then leads to the formation of an ultrafine aerosol. This aerosol can be studied through its incorporation of the radioactive Po-218.

Depending on the composition of the trace gases, the particles may form a continuous size range that reaches from molecular clusters to ultrafine particles. Radon decay products may attach to these aerosols resulting in a multi-modal activity size distribution that is typically in the $0.5-500 \mathrm{~nm}$ size range. Traditionally, a distinction has been made on the state of the daughter atoms in the ambient air based on their apparent attachment to aerosol particles (Ramamurthi and Hopke, 1989). The "unattached" fraction was defined as radioactivity associated with free molecular clusters and "attached" forms were those combined with preexeisting aerosol particles. These definitions were primarily due to the inability of typical condensation nuclei counters (CNC's) that were 
coupled with diffusion batteries to detect particles below $5 \mathrm{~nm}$. This was due to sharply decreasing detection efficiency below $10 \mathrm{~nm}$ (Agarwal and Sem, 1980). Ramamurthi and Hopke (1989) reviewed the prior use of wire screens for the separation of the "unattached" fraction. The activity size distributions in the range of $0.5-500 \mathrm{~nm}$ can be measured by the penetrability of activity through single wire mesh screens. The measurement systems employed are called graded screen arrays and are described by Ramamurthi and Hopke (1991).

Previous qualitative measurements on the mass conversion rate of $\mathrm{SO}_{2}$ to $\mathrm{H}_{2} \mathrm{SO}_{4}$ have been made using the University of Illinois radon aerosol chamber designed by Ramamurthi (1989) and detailed in his Ph.D. Thesis. These studies determined that the mass conversion rate of $\mathrm{SO}_{2}$ to $\mathrm{H}_{2} \mathrm{SO}_{4}$ increased as the relative humidity, $\mathrm{SO}_{2}$, and radon concentrations increased.

It was the object of this thesis to produce ultrafine sulfuric acid aerosols through the radiolytic oxidation of sulfur dioxide, and quantify the mass conversion rate of $\mathrm{SO}_{2}$ to $\mathrm{H}_{2} \mathrm{SO}_{4}$ as a function of radon gas, relative humididty, and $\mathrm{SO}_{2}$ concentrations. Sulfuric acid aerosols were collected on a filter, leached from the filter into solution, and analyzed using a Dionex Series 4000i Ion Chromatograph. Activity size distributions and diffussion coefficients of each set of conditions were determined using the modified graded screen array technique (Ramamurthi, 1989). Total aerosol number concentrations were measured using a TSI Model 3025 Condensation Particle Counter. The airborne sulfuric acid aerosol concentration for each set of conditions was then determined. 


\section{CHAPTER 2}

\section{Ion-induced Cluster Formation and Nucleation}

To understand the formation mechanisms of the $\mathrm{H}_{2} \mathrm{SO}_{4}-\mathrm{H}_{2} \mathrm{O}$ aerosols created in the Illinios-Clarisson Radon chamber a brief review of the theory of ion-induced nucleation follows. Prior experimental studies are also presented in this chapter.

\subsection{Background}

The most frequently considered mechanisms for formation of the binary system $\mathrm{H}_{2} \mathrm{SO}_{4}-\mathrm{H}_{2} \mathrm{O}$ droplets are homogeneous and heterogeneous nucleation, of which ioninduced nucleation is the simplest example of the later. In this thesis, aerosols are defined as a two phase system sonsisting of the condensed phase tia. terials, either liquid or solid, in contact with a supporting gas.

Nucleation is the initial phase transition process in which these particles are formed. This process occurs by the coalescence of gaseous materials into a condensed pruduct. There are two main types of nucleation processes, homogeneous or heterogeneous. In homogeneous nucleation, the process does not depend on the preexistance of other particles and occurs at supersaturated vapor pressures. Heterogeneous nucleation occurs when deposition of material takes place on pre-existing particles or ions. The nucleation process may occur between the same pure species (homomolecular) or between different species (heteromolecular).

Gases or vapors are converted to submicron - sized particles resulting in a dynamic particle size spectrum that goes through 3 successive stages, dominated by nucleation, coagulation, and heterogeneous condensation (Warneck, 1988). The aerosols are considered to be spherical and their size can be described by radius. Condensation is 
defined as aerosol particle formation and growth at saturation vapor pressure. If the vapor pressure of the condensable product in the gas phase is higher than the equilibrium vapor pressure over the droplet, there will be a net flux of vapor molecules towards the aerosol droplet and condensational growth will occur (Van Dingenen, 1990). Evaporation is the opposite process. Coagulation occurs between two aerosol particles of similiar composition. These particles collide due to their Brownian motion and combine to become one larger particle.

The pre-existence of particles and ions promote nucleation by effectively lowering the Gibbs free energy of formation and can cause nucleation to occur at a smaller supersaturation compared to homogeneous nucleation. When an ion is present, its local electric field polarizes the nucleating molecules (Strydom, 1989). Nucleating molecules are more strongly bound to an ion through an attractive force that exists between the ion and the induced dipole on the molecule. The Gibbs free energy of formation of the cluster is reduced and ion-induced nucleation occurs through the clustering of molecules of a condensable species around the ion. Depending on the environmental conditions, these clusters can grow to ultrafine aerosol particles.

Many papers have been devoted to the subject of nucleation enhancement through ions since Wilson's cloud chamber experiments (Wilson, 1897). Compared with homomolecular nucleation which normally requires supersaturation vapor pressures, hetermolecular nucleation on ions involves additional forces among the molecules participating in the formation of the pre-nucleation clusters (Chan and Mohnen, 1980). The theoretical processes of nucleation are mainly based on statistical mechanics and assumes that thermodynamic properties that are determined for macroscopic quantities such as surface tension, hold for microscopic quantities. 
The first attempt to calculate the free energy of a charged cluster was by Thomson in 1888 (Chan and Mohnen, 1980). The mechanism he considered was the growth of clusters on an ion until reaching a critical size. He suggested that ions promote nucleation by reducing the supersaturation of gaseous molecules required and by lowering the Gibbs free energy barier by providing an attractive center on which nucleation can readily occur. The free energy required to form a droplet depends on the radius of the ion core and is given by (Rabeony and Mirabel, 1986):

$$
\Delta G(n)=-n R T \ln S+4 \pi r^{2}+\frac{1}{2} q^{2}\left(1-\frac{1}{\epsilon}\right)\left(\frac{1}{r}-\frac{1}{r_{1}}\right)
$$

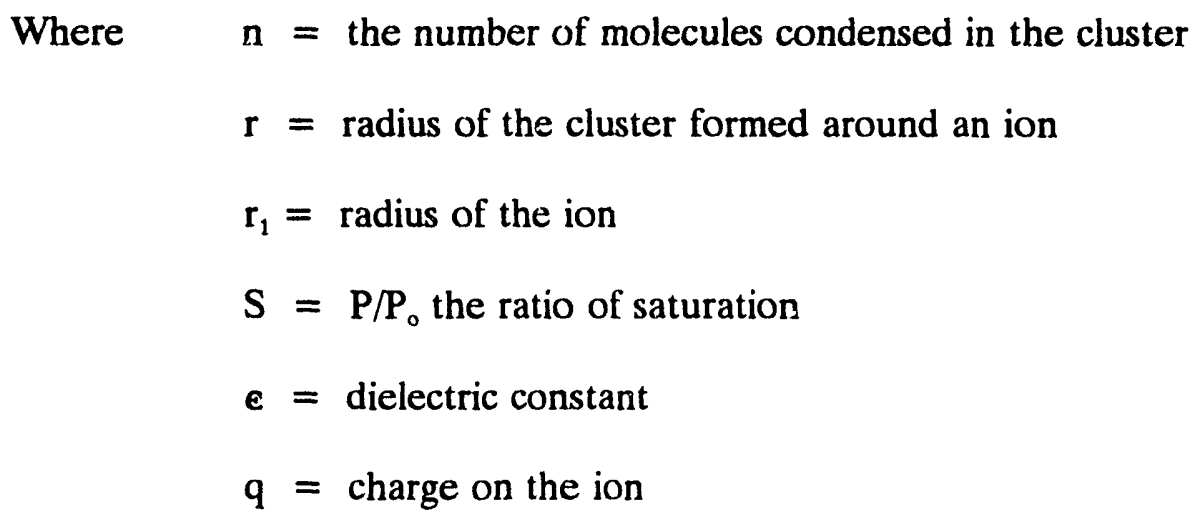

The first term is the free energy assuming an ideal gas. The second and third terms lower the free energy compared to an ideal gas by taking into account the raulius size of the charged droplet and the ionic charge. If the free energy as a function of the droplet radius is calculated and plotted, a minimum and a maximum are evident. The minimum corresponds to the onset of nucleation where stable pre-nucleation embryos are dominant and the maximum corresponds to the state in which an unstable equilibrium exists between 
the critical cluster and the vapor. This difference in the free energy $(\Delta \phi)$ represents the barrier to nucleation and is the derivative of equation 1 . The nucleation rate is dependent on this energy barrier and is given by Rabeony and Mirabel (1986) as:

$$
J=N_{i} C \exp (-\Delta \phi / k T)
$$

$$
\text { where } \quad \begin{aligned}
& \mathrm{N}_{\mathrm{i}}=\text { number density of the ionic species } \\
& \mathrm{C}=\text { slowly varying, mostly kinetic frequency factor } \\
& \mathbf{k}=\text { Boltzmann constant }
\end{aligned}
$$

When compared with experimental results obtained from ion-induced nucleation occurring in cloud chambers, Thomson's model underestimates the rate of nucleation by about $20 \%$ in the approximation of the free energy barrier. The shortcomings of Thoinson's model can be summarized as follows: 1) it is based on macroscopic continuum thermodynamics and contains no consideration of the structure of a small droplet; and 2) it does not consider that the ion itself may perturb the configurations of the molecules in the drop due to its charge (Chan and Mohnen, 1980).

To overcome this inaccuracy in the free energy barrier, many correction theories have arisen. Rabeony and Mirabel (1986) examine a few of these theories and compare their predictions with the available experimantal results. Suck's theory is one in which the effects of dipole moments and polarization energy are incorporated into Thomson's equation (Rabeony and Mirabel, 1986). Suck concluded that nucleation is indeed enhanced by ions, but differences in that effect depend on the radius of the central ion and upon the polarizability. However, when Suck's theory is applied to a just saturated 
vapor sustem, no maximum occurs in the free energy curve. The vapor must be supersaturated before a minimum and a maximum are present in the curve and nucleation is able to occur. Rabeony and Mirabe' conclude that Suck's model seems inadequate as the theoretical predictions in the change in nucleation rate do not correspond to the experimental evidence seen elsewhere and that the magnitude of the free energy barrier $\Delta \phi$ is independent of the nature of the central ion for a given supersaturation. Also, the small diffe iences noted in $\Delta \phi$ values were not responsible for notable variation in the rate of nucleation.

Chan and Mohnen (1980) propose an empirical-analytical semi-molecular theory to the nucleation of water on ions. Their model basically adds a surface dipole-dipole interaction to Thomson's model and also accounts for the variation of surface tension and dielectric constant with curvature of the aerosol droplet. The nucleating species will orient itself one way or another depending on the sign of the ion. The energy barrier to nucleation is then increased or decreased depending on the additional expense in energy (if any) a molecule will have to exert to orient itself so that opposite dipoles are paired. Chan and Mohnen assumed that nucleation of a protonated species will occur more readily on a negative ion and the protons will be oriented toward the inside of the droplet (Chan and Mohnen, 1980). This predicted behavior is opposite to the results seen in cloud chamber experiments in which the protons are oriented outward from the surface.

Rabeony and Mirabel conclude that overall Thomson's model still provides the best predictions of the free energy barrier to nucleation when compared to experimental results. They suggest that ion sign effects on the free energy barrier and nucleation rate are inconclusive overall and that more experimential evidence is needed to verify the theories. 
Raes and Janssens (1984) extend the classical theory of ion-induced nucleation in the $\mathrm{H}_{2} \mathrm{SO}_{4}-\mathrm{H}_{2} \mathrm{O}$ system for use in a larger range of environmental conditions such as nonsupersaturated vapor pressures. From the theory derived, they set up a continuously stirred tank reactor experiment where $\mathrm{SO}_{2}$ could be irradiated with u.v. and ionizing radiation to demonstrate the aerosol formation from the photolytic transformation of $\mathrm{SO}_{2}$. From their theory and experimental results, they conclude that ion-induced nucleation predominates when the relative acidiy (same as relative humidity but for acid vapor) is low and the mixture is irradiated with ionizing radiation. However, the ionizing radiation may also enhance the production of $\mathrm{H}_{2} \mathrm{SO}_{4}$ molecules due to radiolytic reactions, resulting in a higher homogeneous nucleation rate. Hence, the increase in particle formation in this system due to ionizing radiation can not be attributed unambiguously to ion-induced nucleation (Raes et al., 1984).

Ion-induced nucleation in the $\mathrm{SO}_{2}-\mathrm{H}_{2} \mathrm{O}$ system by various sources such an alpha emitters, corona, and spray ions were studied experimentally be Diamond et al. (1984). Experiments were carried out in a contiuously flowing system where the ion sources and polarity of the ions, the flow of $\mathrm{SO}_{2}$, and the relative humidity could be controlled. The gas flows were then delivered to a mixing chamber where nucleation occured in steady state conditions. The aged mixture then flowed through a diffusion battery to measure the size distribution and then to a condensation nuclei counter (CNC). The possibilities being investigated were whether $\mathrm{SO}_{2}$ oxidation occured before nucleation or if it occured on the ion cluster by a chemical reaction. They examined the question of whether the effect of the excitation energy of the ions is on the oxidation of $\mathrm{SO}_{2}$ by direct interaction or through secondary interactions where $\mathrm{OH}$ and $\mathrm{HO}_{2}$ radicals are produced and the free radicals were then responsible for the oxidation. Also studied was if ions participate as 
nucleating agents in either the $\mathrm{H}_{2} \mathrm{SO}_{4}-\mathrm{H}_{2} \mathrm{O}$ or the $\mathrm{SO}_{3}-\mathrm{H}_{2} \mathrm{O}$ system. The experimental conditions were given in detail but will not be thoroughly examined here.

The experimental results for various conditions were shown as plots of the particle number concentration $(\mathrm{N})$, as a function of the $\mathrm{SO}_{2}$ concentration in ppm. Under steady state conditions, $\mathrm{N}$ gives a measure of the nucleation rate in the active region (Diamond $e t$ al., 1985). In one experiment, a $100 \mu \mathrm{Ci} \mathrm{Am}-241$ foil source was used as the ion source. By varying the relative humidity, a threshold from a fraction to a few $\mathrm{ppm} \mathrm{SO}_{2}$ occurs before nucleation becomes fast enough to give concentrations detectable by the CNC. A plateau occurs on all curves at about $10-20 \mathrm{ppm} \mathrm{SO}_{2}$ where nucleation is limited by some factor other than the $\mathrm{SO}_{2}$ concentration. The height of these plateaus are functions of the relative humidity and no nucleation is evident in the absence of water vapor.

The ion charge effects were determined using an electric field to establish the charge on the ion after passing the carrier gas $\left(\mathrm{N}_{2}\right)$ through two $100 \mu \mathrm{Ci} \mathrm{Am}-241$ sources. The effect of the ion charge was noted to be only slightly stronger for positive ions than for negative ions at constant relative humidity. No nucleation occured in the absence of ions at 1-40 $\mathrm{ppm} \mathrm{SO}_{2}$. Am-241 also produces $\mathrm{OH}$ radicals through the radiolysis of water vapor.

When varying the placement of $\mathrm{SO}_{2}$ and the $\mathrm{H}_{2} \mathrm{O}$ addition to either before or after the ion source, the dominant rate of nucleation occurred when $\mathrm{SO}_{2}$ passed through the ion source and $\mathrm{H}_{2} \mathrm{O}$ was added downstream. Nucleation also occurred when $\mathrm{H}_{2} \mathrm{O}$ was added upstream to the ion source ard $\mathrm{SO}_{2}$ added downstream but at a much lower rate. The aerosol particles produced were found to be neutral and did not deflect when passing through a $250 \mathrm{~V} / \mathrm{cm}$ electric field.

The authors concluded from the experimental results that ions from nuclear or 
energetic sources induced nucleation as opposed to $\mathrm{OH}$ or $\mathrm{HO}_{2}$ radicals. Since the ions did not remain in the aerosol produced, they concluded that a mechanism for forming embryos around an ion is not necessary. Ions did not seem to act in the "physical" nucleation phase, but they do act in the "chemical" oxidation phase through a transfer of excitation energy with little change in efficiency due the the sign of the ion. The oxidation mechanism of $\mathrm{SO}_{2}$ by energetic ions is purported to be:

$$
\begin{gathered}
\mathrm{I}^{*}+\mathrm{SO}_{2}-->\mathrm{I}+\mathrm{SO}_{2}^{*} \\
\mathrm{SO}^{2^{*}}+\mathrm{SO}_{2}-\mathrm{SO}_{3}+\mathrm{SO}
\end{gathered}
$$

where ${ }^{\bullet}$ represents an excited electronic transition state. If $\mathrm{H}_{2} \mathrm{O}$ is present, it will react with $\mathrm{SO}_{3}$ to produce $\mathrm{H}_{2} \mathrm{SO}_{4}$ and nucleation of the low vapor pressure species and water vapor will follow. Considering this mechanism is dominant seems controversial in light of other experimental studies. The alpha ionization process also produces $\mathrm{N}_{2}{ }^{+}$ions. These will react with water vapor to produce $\mathrm{OH}$ radicals:

$$
\mathrm{N}_{2}^{+}+\mathrm{H}_{2} \mathrm{O}-\cdots-\mathrm{N}_{2} \mathrm{H}^{+}+\mathrm{OH} \text {. }
$$

Consequently, even though the water vapor was added downstream of the ion source, the $\mathrm{N}_{2}{ }^{+}$ions present in the stream at the point where the $\mathrm{H}_{2} \mathrm{O}$ is introduced would still yield a substantial concentration of $\mathrm{OH}$ radicals. Therefore, the oxidation mechanism suggested by Diamond et al. (1985) seems improbable.

The rate of ion-induced n ncleation on the radiolytic oxidation of $\mathrm{SO}_{2}$ to $\mathrm{H}_{2} \mathrm{SO}_{4}$ was not measured in this thesis. Background on ion-induced nucleation theory was given to provide a basic understanding of events that occur in the radon chamber leading the the formation of ultrafine $\mathrm{H}_{2} \mathrm{SO}_{4}$ particles. The rate of ion-induced nucleation for this and other systems will be measured in the future by others. A thermal diffusion cloud chamber is being built at the present time by other members of our research group and 
will be used to carry out this study. Studies are also on-going to directly measure the $\mathrm{OH}$ production rate. 


\section{CHAPTER 3}

\section{Wire Screen Penetration Theory and Techniques}

This chapter will provide background information on wire screen penetration theory will be given. Various size distribution reconstruction algorithms such as the Twomey (Twomey, 1975) and the Expectation-Maximization (Maher and Laird, 1985) are also briefly described. Graded Screen Array (GSA) systems which are modified diffusion batteries, have been used for the measurement of the activity size distributions and will be briefly described.

\subsection{Background}

Particle size distributions for fine particles $(<500 \mathrm{~nm})$ are commonly determined using diffusion-based techniques such as wire screen diffusion batteries (DB) or graded screen array systems (GSA). Diffusion batteries consist of groups of high mesh number wire screens in a segmented stage sequence. The number of screens per group increases geometrically with the direction of flow. The aerosol is drawn through the DB by means of a pump and at any stage, the activity or particle concentration can ıe measured. As the stages increase, the particle concentration decreases due to particle removal by the wire screens. Brownian diffusion is the dominant removal mechanism for particles with a $d_{p}<0.1 \mu \mathrm{m}(100 \mathrm{~nm})$. The degree of particle penetration, $P=(1-$ fractional collection $)$, through each stage is dependent upon the particle size, wire screen parameters and sampling face velocity (Ramamurthi, 1989). Particle sizes with $a d_{p}>0.5 \mu \mathrm{m}$ are collected by inertial impaction and interception by the wire screens and DB measurements are no longer useful.

Computer fitting techniques such as the Twomey (Twomey, 1975) and Expectation 
Maximization (Maher and Laird, 1986) are used to reconstruct the size distribution from the measured particle concentrations at each DB stage.

The DB is typically coupled with a condensation nuclei counter (CNC) to measure particle size distributions. There are inherent drawbacks to this method for the purpose of characterizing our system of ultrafine $(0.5-150 \mathrm{~nm})$ radioactive sulfate particles. The 635 mesh screens utilized in the DB have a high collection efficiency for particles with a $d_{p}$ $<10 \mathrm{~nm}$ and CNC's suffer from low intrinsic detection efficiency and high diffusional losses for ultrafine particles.

Newly developed wire screen techniques now permit adequate resolution in the $d_{p}$ 0.5 - $10 \mathrm{~nm}$ size range and the use of $\mathrm{ZnS}(\mathrm{Ag})$ coated disks and photomultiplier tubes (PMT) allow detection of the radon decay products activity associated with this size mode (Ramamurthi, 1989).

\subsection{Wire Screen Penetration Theory}

Cheng and Yeh (1980) and Cheng et al (1980) developed and verified a theoretical equation from fan model filtration theory to describe particle penetration through a wire screen. The theory has permitted the calculation of the particle size versus penetrability characteristics of the various stages of a DB depending on the screen parameters and sampling face velocity (Ramamurthi and Hopke, 1989).

Many investigators have verified the fan model filtration equation for various characteristics such as; particle sizes $d_{p}>4 \mathrm{~nm}$, solid volume fractions, and 30 mesh wire screens (Scheibel and Porstendörfer, (1984), Yeh et al. (1982), Reineking and Porstendörfer (1986) and Yamada et al. (1988). Ramamurthi et al. (1990) verified the Cheng-Yeh penetration theory for 30 and 145 mesh wire screens using radioactive Po-218 by inhibiting cluster formation and ensuring complete neutralization of Po-218 formed 
from the decay of $\mathrm{Rn}-222$.

Since diffusional collection predominates in the particle size range of interests to evaluate the particle size versus penetration characteristics, Ramamurthi and Hopke (1989) examined the relationship between particle size and diffusion coefficient. Various diffusivity equations such as the Einstein-Cunningham equation that overestimates the diffusion coefficient in the $0.5-1.75 \mathrm{~nm}$ range, and the kinetic theory equation for uncharged clusters (Leob, 1961) were compared to determine the diffusion coefficient of particles in the size range of 0.5 to $2.5 \mathrm{~nm}$.

Ramamurthi (1989) examined the penetration characteristics and optimum parameters for GSA stages and derived a closed form equation that can be used to calculate the penetration of particles through a stage for a range of particles from $0.5-100$ $\mathrm{nm}$, where diffusion is the dominant collection mechanism. The equation can be extended with less than a $10 \%$ error up to a particle diameter of $150 \mathrm{~nm}$. This is the upper limit of the size distributions measured in this work.

\subsection{Size Distribution Reconstruction Algorithms}

Once the particle concentrations penetrating past each stage of a DB or GSA are measured, these data are processed and interpreted to obtain information on the sampled size distribution. Maher and Laird (1985) found the measured particle penetration, $Z_{i}$, could by determined using the following integral:

$$
Z(i)=\int P(i, y) f(y) d y+\epsilon
$$

where

$$
\begin{aligned}
& P(i, y)=\quad \text { particle size vs. penetration characteristics for stage } i . \\
& f(y)=\quad \text { paiticle size distribution }
\end{aligned}
$$




$$
\text { e }=\text { measurement error }
$$

This integral is expressed as a series of linear, simultaneous equations which relate the measured particle concentrations to quantized values of the size distribution and the stage penetration functions as follows:

$$
z(i)=z_{0} \sum_{i=1}^{J}\left(p_{i j} f_{f}\right)
$$

where

$$
\begin{array}{lll}
\mathrm{Z}_{\mathrm{i}} & = & \text { observed stage penetration } \\
\mathrm{Z}_{\mathrm{o}} & = & \text { total particle concentration } \\
\mathrm{I} & = & \text { number of DB stages } \\
\mathrm{J} & = & \text { number of size interval mid-points in the distribution } \\
\mathrm{p}_{\mathrm{ij}} & =\quad \text { penetration of } \mathrm{j}^{\text {th }} \text { particle size through } \mathrm{i}^{\text {th }} \text { stage }
\end{array}
$$

Realistic physical solutions are rarely produced and direct inversion methods yield oscillatory and sometimes negative solutions (Ramamurthi, 1989).

To overcome the difficulty in obtaining meaningful solutions, a non-linear, iterative perturbation technique was developed by Twomey (1975). There are still shortcomings in this method as the algorithm does not converge to any particular optimum solution, and an intelligent stopping criterion must be utilized to terminate the iterations when an acceptable solution to the algorithm is obtained (Ramamurthi, 1989).

Statistical methods, such as the Expectation-Maximization (EM) algorithm (Maher and Laird, 1985) provide a solution to some of the inherent problems in the Twomey algorithm as there is no danger of overiterating the algorithm. Statistical methods are able to obtain physical solutions from overdefined sets of equations where the number of data observations is greater than the number of parameters to be estimated. The EM method 
is based on the maximization of the likelihood or probability of observing the measured stage penetration data (Ramamurthi, 1989). The EM algorithm was derived for Poissondistributed data such as particle counts. The algorithm is a two step process where the Estep (expectation step) consists of using the observed data and estimate of the unknown parameters, $f(j)$, to estimate the unobservable data. The M-step (maximization step) maximizes the log-likelihood statistic using the estimated data in the E-step. The algorithm is iterated until there is no increase in the log-likelihood statistic or no significant change in the parameter estimates.

Maher and Laird (1985) presented the theory of the EM reconstruction algorithm and compared it to 3 better known reconstruction algorithms such as, least squares regression, ridge regression, and least squares with linear inequality constraints, to simulated diffusion battery data sets. They concluded that the EM algorithm was better than, or comparable to the other methods tested for ultrafine size distribution reconstructions. The algorithm does not require smoothing parameters or physical constraints and there is no possibility of obtaining negative size fraction estimates (Maher and Laird, 1985).

Ramamurthi and Hopke (1990) studied the E.M. and Twomey reconstruction algorithms using numerical simulations of various input size distributions. They performed simulations with different combinations of GSA stage progressions and different number of stages. It was found that the choice of GSA stages with $d_{p}(50 \%)$ diameters in geometric progression within the size range of interest aided the algorithm efficiency. The stage progression should also be chosen such that large areas of the distribution aren't collected by the first stage or penetrate past the last stage. Ramamurthi et al. (1990) also found it was beneficial to choose the stage $d_{p}(50 \%)$ diamet ars of the GSA stages 
approximately equal to the same as the mid-point diameters of the size intervals inferred, because the optimum number of GSA stages is ideally equal to or less than the number of size intervals inferred from the reconstruction algorithms. These principles allows an optimum choice of the size interval fractions to be inferred from the algorithms and the number and characteristics of the GSA stages.

The activity distribution measurements were performed on aerosols generated in the radon-aerosol chamber using radon in purified, compressed moist air, and trace concentrations of $\mathrm{SO}_{2}$. The radiolytic oxidation of $\mathrm{SO}_{2}$ to sulfuric acid vapor occurs and subsequent nucleation and coagulation yields sulfuric acid particles. Radioactivitiy is associated with the sulfuric acid particles as this process occurs in the vicinity of Po-218 atoms.

\subsection{Grab Sampling and The Total Alpha 3-Count Method}

To measure the activity disiributions a grab sampling system consisting of an openface filter for the ineasurement of the total radioactivity and a combination of single and multiple stacked screens of various mesh $(30,145,635)$ and a back up filter inside a filter holder were taken for 5 minute sampling intervals. The filters were analyzed for collected activity by the Tsivoglnu (Thomas, 1972) totals alpha 3-count tecnnique. This iechnique consists of counting the gross alpha emissions from Po-218 and Po-214 atoms collected on the filter following sampling. The screens were not analyzed due to the inherent alpha absorption loses in the screen weaves. Also, the activity on both sides of the screens cannot by analyzed simultaneously due to the $2 \pi$ detector geometry of the photomultiplier tubes. An implicilt assumption with this technique is that the concentration of radon progeny in air remain constant throughout the sampling period.

Tsivoglou et al. (1953) first proposed a technique for measuring radon progeriy 
concentrations in mine atmospheres using rate meters to determine alpha activity after sampling. The activities of the radon progeny are determined using simultaneous equations. Thomas (1972) optimized the count-interval 'iming to maximize measurement precision for a total measurement time of 35 minutes with counting from 2 to 5,6 to 20 , and 21 to 30 minutes after a 5 minute sampling.

Nazaroff (1984) reviewed past studies on the optimization of the total alpha 3count technique and developed a method which optimizes this technique for measuring low concentrations of radon progeny typically found in residences. He extended the total measurement time from 35 to 60 minutes, thereby improving measurement precision. The timing sequence for a one minute delay with a 5 minute sampling is 6 to 9,12 to 29,40 to 60 minute count intervals. Another method of improving the precision incorporates overlapped sampling and counting intervals; however, for our system this was not possible. Although measurement precision can be improved by increasing the sampling flow rate, high rates of air movement may perturb the evironment being measured (Holub et al, 1979). 


\section{CHAPTER 4}

\section{Experimental Design and Procedures}

The experimental apparati consisted of three main systems, the radon-aerosol chamber and associated operating equipment, the sampling and counting system and the Dionex Series 4000i Ion Chromatograph. The first two systems are described in detail in the Ph.D. thesis by Ramamurthi (Ramamurthi, 1989) so only a brief description will be given. Information on the Dionex Ion Chromatograph can be found in the operating manual for the instrument and only a brief description will also be given here.

\subsection{The Illinois-Clarkson Radon Chamber}

In Figure 4.1 shows a schematic representation of the chamber, flow system and operation controls. The radon chamber is operated using purified air, nitrogen carrier gas for the radon, humidified air, and various commercial trace gases. Compressed house air was initially passed through a Balston FT-IR air dryer (Type 75-60) for the removal of water vapor, trace organics and $\mathrm{CO}_{2}$. However, the house air system did not employ an aftercooler in line with the compressor and the dryer was initially unable to remove much of the water vapor in the humid summer months. To rectify this problem, a separate refrigerant aftercooler (Dayton Electrical Mfg.) was installed before the inlet of the Balston system.

The radon-aerosol chamber has dimensions of 6' $\times 4^{\prime}$ x 4' (approximately $2.4 \mathrm{~m}^{3}$ ) and is constructed from $1 / 8$ inch thick stainless steel. Gas mixtures are filtered through a $0.45 \mu \mathrm{m}$ mini-capsule filter (Gelman Sciences Inc.) for the removal of particlulate contamination prior to entering the chamber. It then enters the top of the chamber 


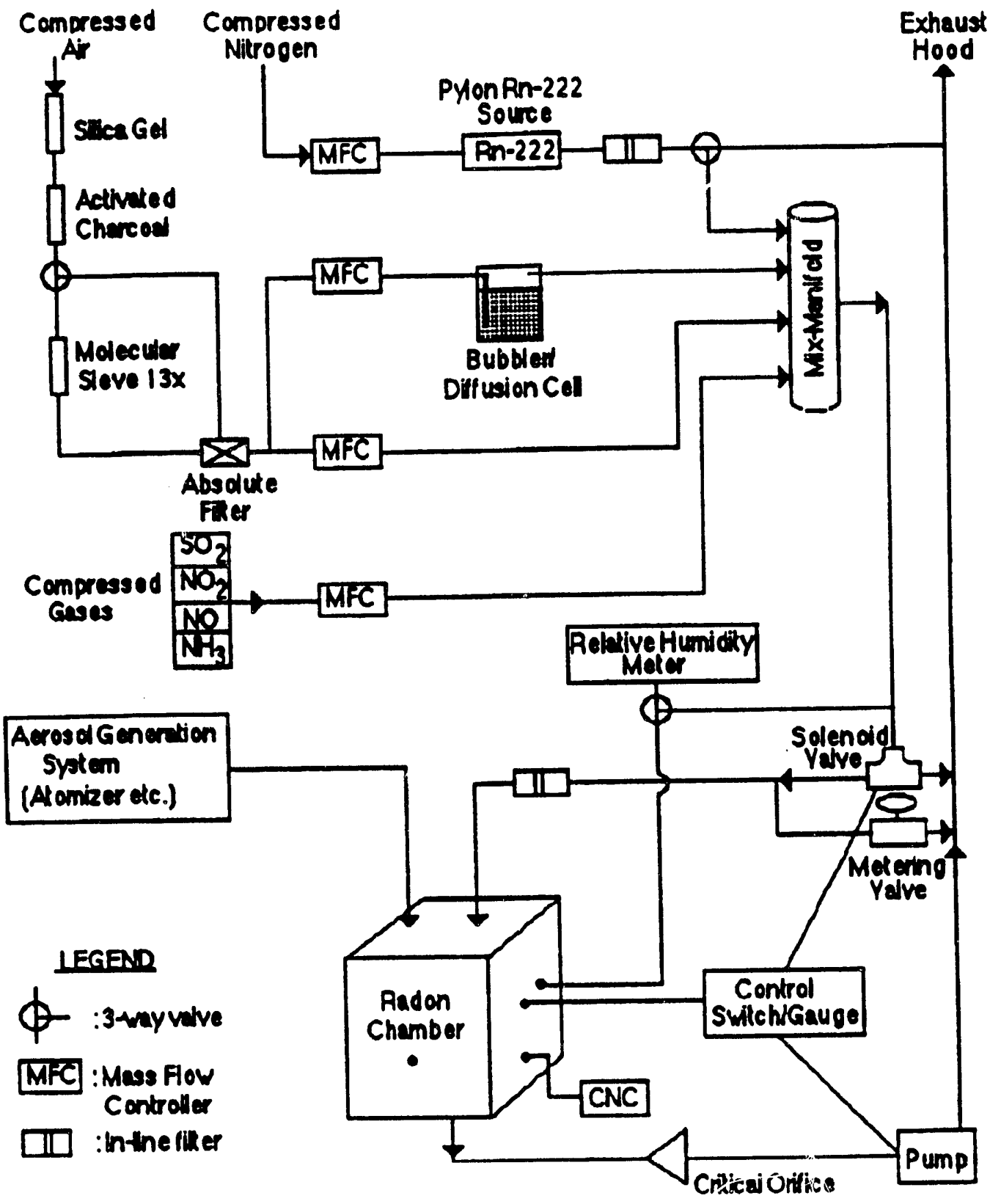

Figure 4.1 Set-up of the Illinois/Clarkson Radon-Aerosol Chamber (Ramamurthi, 1989) 
through 4 ports which help distribute the air throughout the chamber. Variable speed muffin fans (generally used on 40 volts, $780-800 \mathrm{rpm}$ ) are located at two bottom corners of the chamber to help provide a more homogeneous distribution of the gas mixture. The air flow into and out of the chamber could be varied from 9.0 to $20 \mathrm{lpm}$. For the experiments on the activity size distributions at $695 \mathrm{pCi} / 1$ radon the flow was held at 9.9 lpm. Experiments were performed at a flow of $17.9 \mathrm{lpm}$ giving $388 \mathrm{pCi} / 1$ radon, to study the mass conversion rate of $\mathrm{SO}_{2}$ to $\mathrm{H}_{2} \mathrm{SO}_{4}$. Activity size distribution measurments were also performed at this rate. All gases were metered and maintained using mass flow controllers (Tylan Equipment Co.).

Compressed nitrogen was used at a flow rate of $100 \mathrm{~cm}^{3} /$ minute as the carrier gas and entered two flow through type radon sources (Pylon Inc., Model RN-1025, $921 \mathrm{kBq}$ and $1,123 \mathrm{kBq}$ ) connected in parallel. By varying the flow of the compressed air that then mixed with the radon-laden nitrogen, the radon concentrations maintained inside the chamber could be varied from 695 to $348 \mathrm{pCi} / \mathrm{l}$ at flows from 10 to $20 \mathrm{lpm}$. Various trace gases $\left(\mathrm{SO}_{2}, \mathrm{NO}, \mathrm{NO}_{2}\right.$ etc..) could also be mixed with the air stream.

The air stream was humidified by passing purified, dry air through 2 bubblers immersed in a constant temperature water bath. A trap was installed in-line to prevent a backflow of water from entering the mass flow controllers or the radon sources. The air stream passed through a pleated membrane filter to remove any water droplets before entering the mixing manifold. By blending wet and dry air flows, the required humidity could be achieved and maintained. The relative humidity of the chamber was constantly monitored using a chilled platinum mirror dew point hygrometer (General Eastern Co., Model M1). All gases were combined at the mixing manifold before flowing into the 
chamber.

Positive pressure air input and negative pressure air removal was employed to insure uniform gas concentrations inside the chamber. This allowed sampling performed through a 5-inch diameter port in the chamber door to occur with minimum perturbation to the system and maximum safety to the individual. The chamber pressure was monitored and maintained around $1 \mathrm{~atm}$. A control system prevented the build-up of pressures either positive or negative in the chamber allowing unattended chamber operations.

The detectable particle number concentration in the chamber was constantly monitored using a ultrafine condensation nucleus counter (CNC) (TSI Inc., Model 3025). A vapor sheath technique is used to improve the instruments lower size sensitivities (Stolzenburg and McMurry, 1986). Submicrometer airborne particles that are larger the 3 $\mathrm{nm}$ in diameter are capable of being measured with a $50 \%$ detection efficiency at this level. The accuracy of the counter is $\pm 10 \%$. Supersaturated butanol vapor condenses onto the particles causing them to grow into larger droplets that are detected and counted by an optical detector. The particle detection range is from 0.01 particle/ $/ \mathrm{cm}_{3}$ to $9.99 \times 10^{4}$ particles $/ \mathrm{cm}^{3}$. The upper cut off range in our case was too low so filtered, compressed air was used to dillute the air sample taken from the chamber. The actual particle concentration inside the chamber was then calculated using the proper dillution factor.

\subsection{Sampling and Counting Equipment}

The sampling equipment consisted of open-face, stainless steel filter holders. The filter holders were attached by a quick connect fitting to a 4 arm probe that reached into the center of the chamber. This probe allowed the sampling of the more homogeneous distribution of gases to be made away from the influence of the chamber walls. Flow 
control was achieved by metering valves located on each probe arm so that 4 simultaneous samples could be taken at different flow rates. Radioactive particles were collected on membrane filters ( 0.8 um Millipore Type AA) for activity size distribution measurements. PTFE membrane Zefluor teflon filters (Gelman Sciences Inc., TF-200, $0.2 \mu \mathrm{m}$ ) were used to collect the radioactive sulfate aerosols. The sulfate was leached from the filters into solution and measured using the ion chromatograph. Sampling pumps used were oil-less, rotary vane pumps (Doerr Inc.) to prevent any contamination from the pump oil.

$\mathrm{ZnS}(\mathrm{Ag})$ coated mylar disks coupled to photomultiplier tubes (PMT) (Ludlum Inc., Model 182) were used to detect the alpha emissions from Po-218 and Po-214 collected on the grab sample filter. The detection efficiency of each PMT was measured regularly using a NBS-traceable alpha standard calibration source (Eberline Inc., Am-214, Pu-239, Th-230). Gross alpha analysis was performed on the filters by sending the output from the individual PMT's to a preamplifier (ORTEC, Model 113). The output from the preamplifier was sent to an amplifier (ORTEC, Model 855) and then routed into a timercounter (Ortec, Model 871) or through an 8 _input multiplier to a computer-based multichannel analyzer (ORTEC Model 918).

Activity size distribution measurements were performed using a manual graded screen array technique. Open face filter holders were utilized for grab sampling operations in the chamber. The filter holders were designed to minimize the plateout of ultrafine cluster particles onto surfaces other than the filter. The sampler "lip" - the distance between the top surface of the filter holder and the filter - was small $(1.5 \mathrm{~mm})$. A combination of one filter only sample and 4 samples taken with the filter downstream of various combinations of wire mesh screens were utilized to collect particles for activity size distributions. Figure 4.2 illustrates the various filter holder combinations used in the 

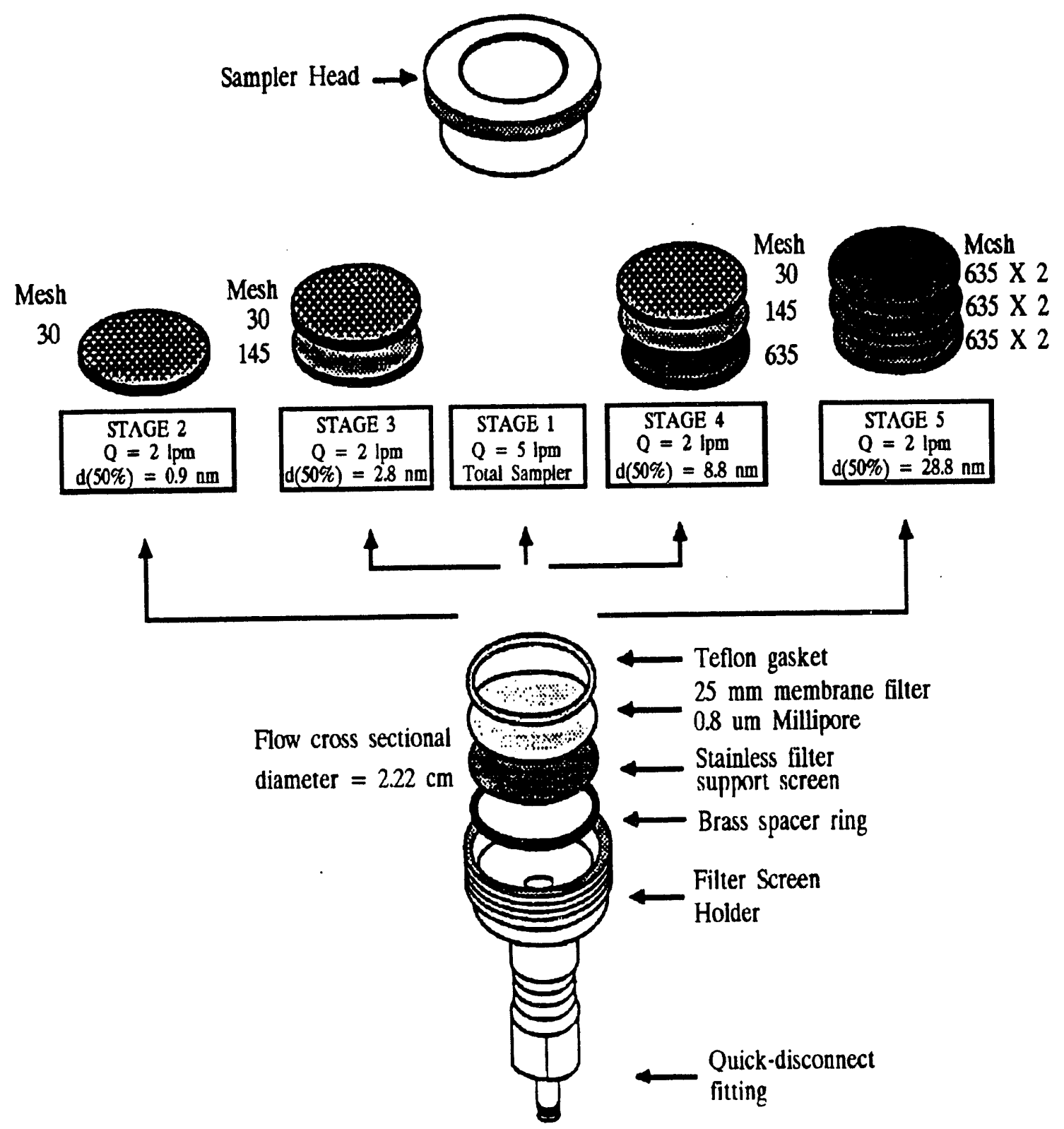

Figure 4.2 Sample holder and screen combinations used in activity size distribution measurements. 
measurement. The total alpha three count method described in chapter 3 was used to determine the concentrations of the decay products on the filters. Information regarding the radon progeny activity associated with the sulfate particles within each of the five inferred particles size intervals in the range of $0.5-150 \mathrm{~nm}$ is obtained using the EM or Twomey size reconstruction algorithms described in chapter 3 . The various characteristics such as sampling flow rate and lip distances are listed in Appendix C1.1.

\subsection{Ion Chromatography}

The amount of sulfate in the aerosols collected on the filter was determined using a Dionex Series 4000 i Ion Chromatograph. Ion chromatography (IC) is a liquid chromatographic technique based on ion exchange mechanisms and suppressed conductivity detection for the determination of cations and anions. Separation occurs due to differences in the equilibrium distribution of ions between the mobile and stationary phases. The ions migrate through the system when they are in the mobile phase at a velocity of migration that is a function of the equilibrium distribution. The components that have an affinity for the stationary phase migrate more slowly than those with an affinity for the mobile phase. Each type of ion will have a different equilibrium distribution and therefore a different velocity of migration. The mobility differences lead to the separation of the different types of components in the solution. The components of a typical IC are shown in Figure 4.3 and a review of the components follows.

The liquid mobile phase or eluent $\left(\mathrm{Na}_{2} \mathrm{CO}_{3} / \mathrm{NaHCO}_{3}\right)$ is propelled constantly through the column by a constant pressure/constant flow pump. A loop valve injector is used to introduce the sample into the column with a minimum disturbance of column packing. The injector loop holds a $50 \mu$ l volume. When the load valve opens, the sample 


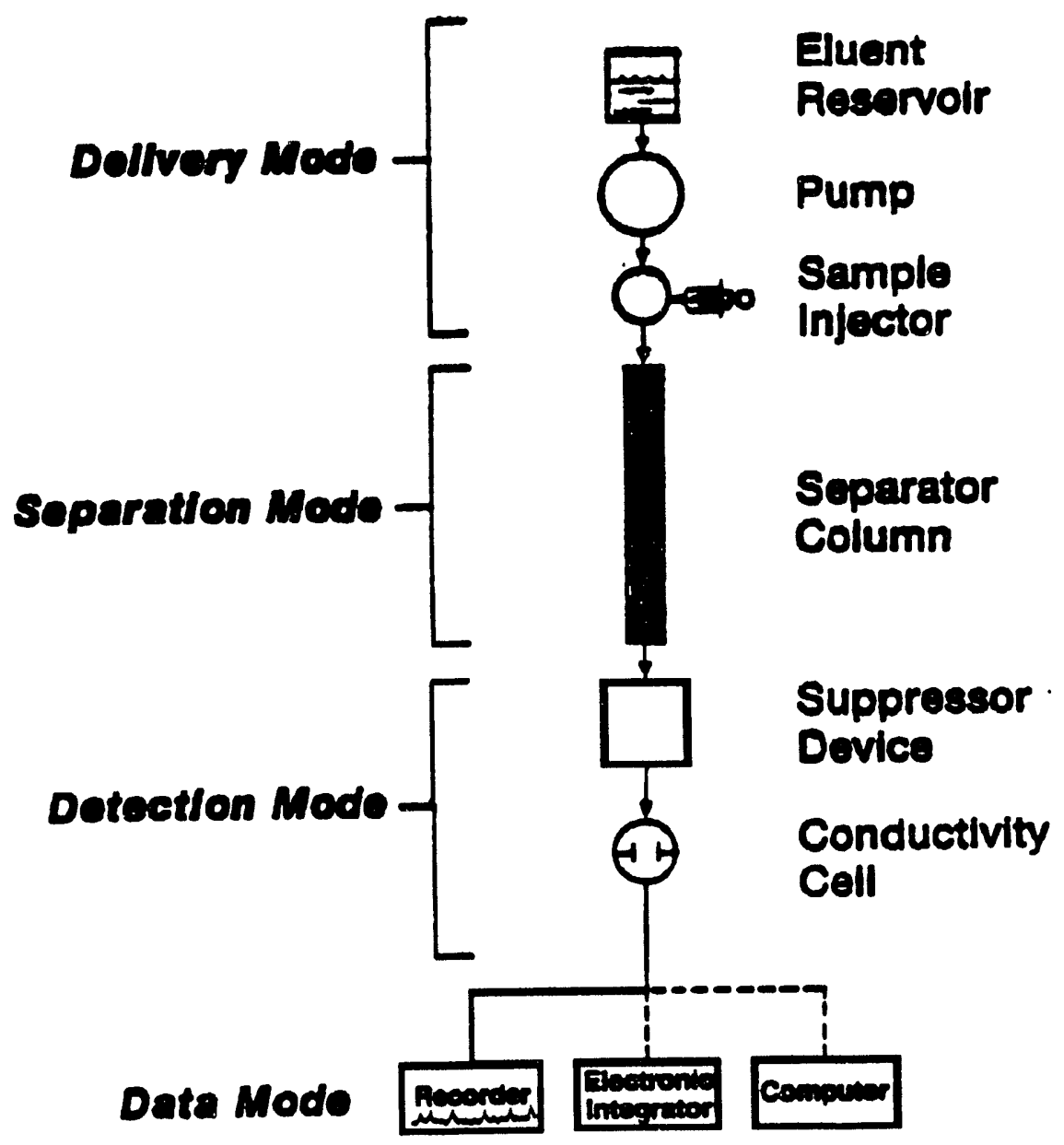

Figure 4.3 Typical Dionex Ion Chromatograph Configuration

is swept into the eluent stream and onto the column.

The column is the critical part of the ion chromatograph. The column chosen depends on the mode of separation employed. The system used in these experiments consited of a guard column (HPIC-AGS4A) and a separator column (HPIC-AS4A) chosen for inorganic anions. The guard column filters particulate maitter from the eluent and sample. The separator column used in High Performance Ion Chromatography (HPIC) works on the separation mode based on ion exchange and is packed with a low capacity pellicular ion exchange material (resin) see Figure 4.3. HPIC resins consist of inert 
polystyrene/divinylbenzene core. Attached to the surface of the bead is a sulfonic group that is also attached to a small totally porous, aminated, anion exchange bead. Attached to the bead are anion exchange particles with cationic sites that are responsible for the separation process. The anions in the solution from the sample and eluent compete for fixed cationic sites on the particle. The eluent ions exchanges with the sample ion thousands of times see Figure 4.4. The anions move through the column when they are not paired with the fixed cation. Separation occurs because of the different affinities the anions have for the fixed cationic sites. Equilibrium occurs between the mobile phase anion and the sample anions.

The eluent used for our system was $1.80 \mathrm{mM} \mathrm{Na}_{2} \mathrm{CO}_{3} / 1.70 \mathrm{mM} \mathrm{NaHCO}$ which gives the following equilibrium:

$$
\mathrm{SO}_{4}^{*}+\mathrm{HCO}_{3}^{-+} \mathrm{NR}_{4} \rightarrow \mathrm{Resin}=\mathrm{SO}_{4}^{=}{ }^{+} \mathrm{NR}_{4} \rightarrow \text { Resin }+\mathrm{HCO}_{3}^{-}
$$

Sulfate is more strongly attracted to the cationic sites on the ion exchanger then most inorganic anions due to the divalent charge and hence, has a longer retention time $\mathbf{5 . 0}$ $\min$ ).

The mode of detection utilized was suppressed conductivity detection. This inode is applicable for use with ions that have a $\mathrm{pK}_{\mathrm{A}}$ or $\mathrm{pK}_{\mathrm{B}}$ less than 7. The detection system consists of two parts: the suppressor column where chemical suppression of the eluent occurs, and the conductivity detector. The suppressor column contains a strongly acidic, cation-exchange membrane in the hydronium form. Highly conductive carbonate eluent ions are converted to a less conductive carbonic acid through ion exchange before detection by conductivity. The solute ions, in this case sulfate, are converted to acids which are highly conducting. Detector sensitivity is increased as the background 


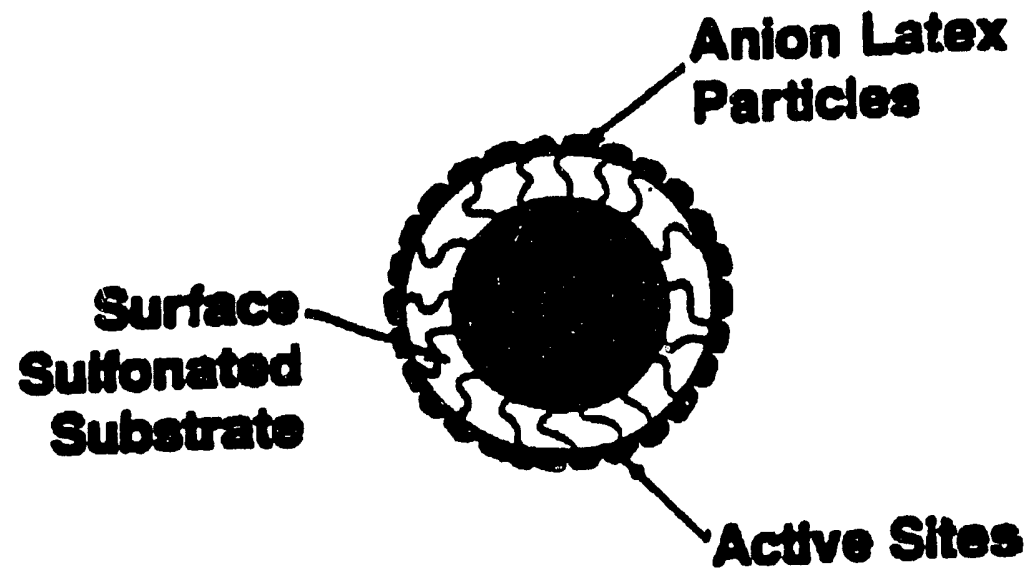

Anion Pellleular

\section{LATEX ANION EXCHANGE PARTICLE}

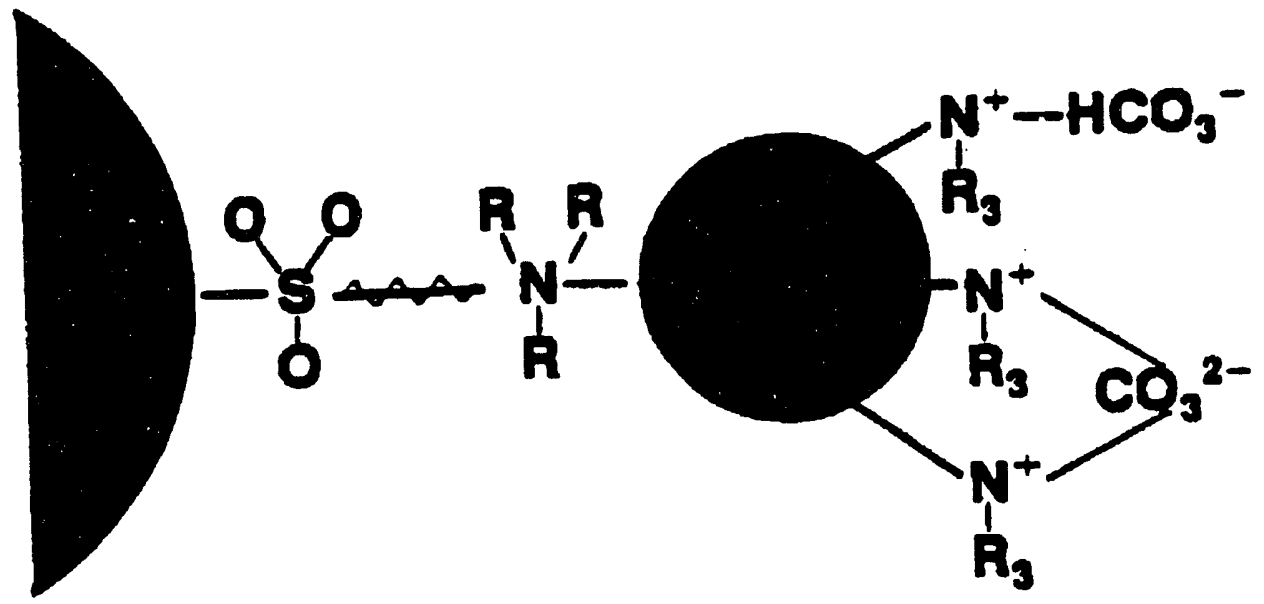

Figure 4.4 Pictorial Representation of Anion Separator Resin 


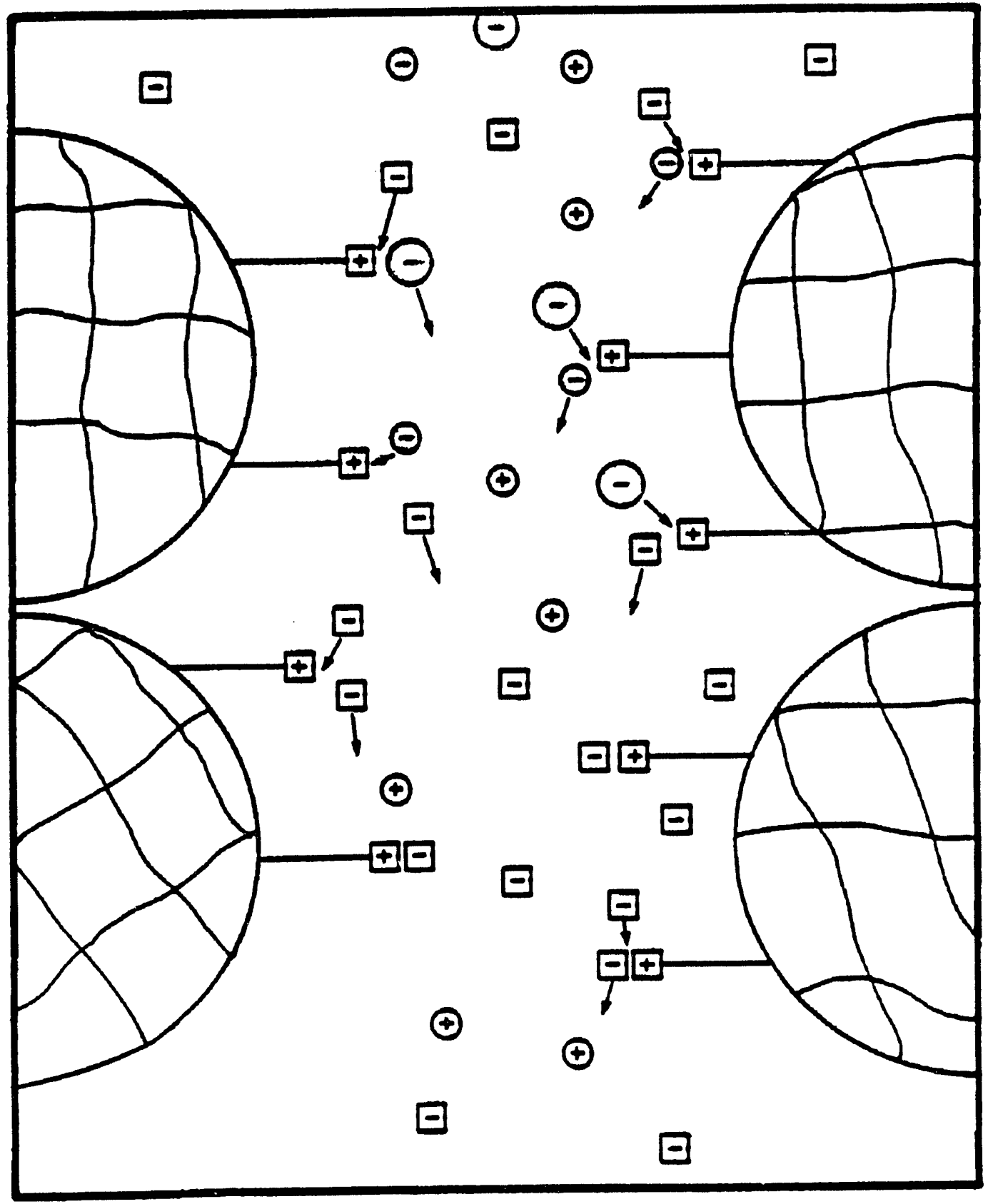

Figure 4.5 Pictorial Representation of Anion Exchange 
conductivity of the eluent is decreased. The reactions taking place in the suppressor follow:

$$
\begin{gathered}
2\left(\mathrm{H}^{+}-\text {-Resin }\right)+\mathrm{Na}_{2} \mathrm{CO}_{3} \rightarrow 2\left(\mathrm{Na}^{+}-- \text {Resin }\right)+\mathrm{H}_{2} \mathrm{CO}_{3} \\
\left(\mathrm{H}^{+}-\text {-Resin }\right)+\mathrm{NaHCO}_{3} \rightarrow\left(\mathrm{Na}^{+}-- \text {Resin }\right)+\mathrm{H}_{2} \mathrm{CO}_{3} \\
\left(\mathrm{H}^{+}-\text {-Resin }\right)+\text { Cation- } \mathrm{X}^{-} \rightarrow(\text { Cation-Resin })+\mathrm{H}^{+} \mathrm{X}^{-}
\end{gathered}
$$

The suppressor collects ions removed from the eluent stream and needs to be regenerated frequently. Continuous regeneration with $25 \mathrm{mN} \mathrm{H}_{2} \mathrm{SO}_{4}$ occurs throughout the fiber suppressor column.

A conductivity detector was used in our determinations of sulfate. Conductivity detection is based on the ability of ions in solution to conduct electricity when placed between 2 oppositely charged electrodes. The ions in solution complete the circuit and an electical current flows between the electrodes. Increasing the ionic character of a substance results in an increased detector response. The conductance of a solution is expressed in terms of the solution electrolytic resistance measured in reciprocal $\mu$ ohms or $\mu$ siemens. At low ionic concentration, solution conductance is proportional to ionic concentration and the mobility of each type of ion in solution. The detector has automatic offset capability which zeros the detector output from the background noise.

The detector output is sent to the electronic integrator which converts the signal into numeric form. The peak area or height and the retention time are automatically measured. The results are diplayed graphically and digitally on a strip chart recorder. The retention time is used to qualitatively identify a component through comparison with a known standard. The peak area or peak height are proportional to the concentration. 
Sulfate grab samples were collected for various lengths of time depending on the chamber conditions. To collect any measurable sulfate, the length of time ranged from approximately 40 hours for relatively high $\mathrm{SO}_{2}$ and relative humidity concentrations to over 80 hours for lower concentrations. An aliquot of distilled, dionized $\mathrm{H}_{2} \mathrm{O}$ was placed by pipette into sterile polystyrene culture tubes (Fisher Scientific) and the cap was replaced. The culture tube was placed in close proximity to the chamber, the pump was turned off, and the filter holder was removed from the probe. The filter was asceptically removed from the filter holder and placed in the culture tube by the use of stainless steel tweezers. The filter was placed in an ulirasonic bath for 1.0 minutes. The sample loop on the IC was only $50 \mu \mathrm{l}$ but tuberculin syringes, with graduations from $0.1 \mathrm{ml}$ to $1.0 \mathrm{ml}$, were used to inject the samples so roughly $0.2 \mathrm{ml}$ of the sample was injected into the IC even though this was more than needed. The method of calibration with external standards was employed. The standards were made from anhydrous $\mathrm{NaSO}_{4}$ that was dried in an oven at $120^{\circ} \mathrm{C}$, cooled in a desicator, weighed out as $1.479 \mathrm{~g}$, and made into a $1000 \mathrm{ppm}$ stock solution. Standards that enveloped the suspected range of the unknown sulfate samples were prepared through serial dillution and were injected multiple times to achieve statistical precision. The samples were injected multiple times as well.

The data obtained for the standard peak areas through the IC integrator were used to create a calibration curve of peak area vs. concentration. It is assummed that uncertainties in the peak areas are distributed as a Poisson distribution and is thus equal to the square root of the area. The intercept of the curve was statistically zero and the slope was used to calculate the concentration of unknown samples. The raw data was analyzed using LOTUS 1-2-3. A linear regression with a zero intercept was performed on the standards giving the coefficient of $\mathrm{x}$, the error in the coefficient, and the error in the 
peak area. The concentration of the samples were calculated from the calibration curve using linear regression analysis and the error in the samples was calculated as follows:

$$
\sigma_{\mathrm{X}}=\left[\left(\frac{\sigma_{\mathrm{y}}{ }^{2}+\sigma_{\mathrm{b}}{ }^{2}}{(y-b)^{2}}\right)+\left(\frac{\sigma_{\mathrm{m}}}{m}\right)^{2}\right]^{1 / 2} X
$$

$$
\begin{aligned}
& \text { where } \quad \begin{aligned}
X & =\text { calculated concentration of sulfate in sample } \\
\sigma_{\mathrm{y}} & =\text { error in the peak area, assumed to be } \sqrt{ } \mathrm{y} \\
\mathrm{y} & =\text { peak area } \\
\mathrm{b} & =\text { intercept of calibration curve } \\
\sigma_{\mathrm{b}} & =\text { intercept of calibration curve } \\
\mathrm{m} & =\text { slope of the calibration curve } \\
\sigma_{\mathrm{m}} & =\text { error in the slope of the calibration curve }
\end{aligned}
\end{aligned}
$$

Once the sulfate concentration in solution is known, it can be used to determine the airborne sulfate concentration by the following relationship:

$$
\left(\mathrm{H}_{2} \mathrm{SO}_{4}\right)=\frac{\left(\mathrm{H}_{2} \mathrm{O}\right)(X}{\left(Q_{\mathrm{s}} \cdot\right)(t)}
$$

$$
\begin{aligned}
& \mathrm{H}_{2} \mathrm{O}=\text { concentration of distilled, dionized water } \\
& \mathrm{X}=\text { concentration of sulfate in solution } \\
& \mathrm{Q}_{3} \quad=\text { flow rate of sample } \\
& \mathrm{t} \quad=\text { sampling time }
\end{aligned}
$$


The mass conversion rate of $\mathrm{SO}_{2}$ to $\mathrm{H}_{2} \mathrm{SO}_{4}$ can then be calculated by converting the amount of $\mathrm{SO}_{2}$ to the mass equivalent of $\mathrm{H}_{2} \mathrm{SO}_{4}$ that would theoretically have formed if $100 \%$ of the $\mathrm{SO}_{2}$ had converted as follows:

$$
\begin{gathered}
1 \mathrm{ppm}=4.09 \times 10^{-8} \mathrm{moles} / \mathrm{L} \\
25 \mathrm{ppm} \mathrm{SO}_{2}\left(4.09 \times 10^{-8} \mathrm{moles} / \mathrm{L}\right)\left(64.04 \times 10_{6} \mu \mathrm{g} / \mathrm{L}\right)=65.50 \mu \mathrm{g} / \mathrm{L} \mathrm{SO}_{2}
\end{gathered}
$$

The mass of $\mathrm{SO}_{2}$ must be converted to what would be an equivalent mass of $\mathrm{H}_{2} \mathrm{SO}_{4}$ :

$$
65.50 \mu \mathrm{g} / \mathrm{L} \mathrm{SO}_{2}\left(98.08 \mathrm{~g} \mathrm{H}_{2} \mathrm{SO}_{4} / 64.06 \mathrm{~g} \mathrm{SO}_{2}\right)=100.3 \mu \mathrm{g} / \mathrm{L} \mathrm{SO}_{2} \text { eq }
$$

The mass conversion rate is then calulated as the following ratio:

$$
\text { Mass conversion rate }=\left(\mathrm{H}_{2} \mathrm{SO}_{4} \mu \mathrm{g} / \mathrm{L}\right) /\left(\mathrm{SO}_{2} \mu \mathrm{g} / \mathrm{L}\right) \mathrm{eq}
$$

The $\mathrm{OH}$ radical concentration in molecules $/ \mathrm{cm}^{3}$ is estimated using the measured sulfate values, the concentration of $\mathrm{SO}_{2}$, the flow rate of gases into and out of the chamber, $\mathrm{Q}$, the volume of the chamber, $V_{\text {chamber }}$ and the known rate constant of $(1.1 \pm 0.2) \times 10^{-12}$ $\mathrm{cm}^{3} / \mathrm{sec}$ for the reaction of $\mathrm{OH}$ radicals with $\mathrm{SO}_{2}$ at atmospheric pressure (Barnes et al., 1986).

$$
\frac{d\left(\mathrm{SO}_{2}\right)}{d t}=\frac{Q\left(\mathrm{SO}_{2}\right)_{\text {in }}-Q\left(\mathrm{SO}_{2}\right)_{\text {out }}}{V_{\text {chamber }}}-k(\mathrm{OH})\left(\mathrm{SO}_{2}\right)
$$

At steady state,

$$
\begin{gathered}
\frac{d\left(\mathrm{SO}_{2}\right)}{d t}=0=\frac{Q}{V}\left[\left(\mathrm{SO}_{2}\right)_{\text {in }}-\left(\mathrm{SO}_{2}\right)_{\text {out }}\right]-k(\mathrm{OH})\left(\mathrm{SO}_{2}\right) \\
\frac{Q\left[\left(\mathrm{SO}_{2}\right)_{\text {in }}-\left(\mathrm{SO}_{2}\right)_{\text {out }}\right]}{V_{\text {chamber }}}=k(\mathrm{OH})\left(\mathrm{SO}_{2}\right) \\
\frac{\frac{64}{98}\left(\mathrm{SO}_{4}\right)_{\text {measured }}}{\mathrm{V}_{\text {chamber }}}=\frac{k}{Q}(\mathrm{OH})\left(\mathrm{SO}_{2}\right)
\end{gathered}
$$

The error in the $\mathrm{OH}$ concentration is determined by assuming the errors in the $\mathrm{SO}_{2}$ and 
the flow rate are negligable. The errors in the $\mathrm{H}_{2} \mathrm{SO}_{4}$ concentration and the error in the rate constant are propagated as follows:

$$
\sigma_{\mathrm{OH}}=[\mathrm{OH}] \sqrt{\left(\frac{\sigma_{\mathrm{k}}}{k}\right)^{2}+\left(\frac{\sigma_{\mathrm{SO}_{4}}}{\left[\mathrm{SO}_{4}^{3}\right]}\right)^{2}}
$$




\section{CHAPTER 5}

\section{Results and Discussion}

Activity size distributions were measured for various steady state conditions in which the amount of radon-222 was held at a constant $695 \mathrm{pCi} / 1$ or $388 \mathrm{pCi} / 1$ and the concentrations of $\mathrm{SO}_{2}$ and relative humidity were varied. These distributions will be discussed in relation to the general growth trends of sulfate particles and the amounts of radioactivity incorporated therein. The ion chromatographic results for the sulfate produced from the radiolytic oxidation of $\mathrm{SO}_{2}$ are listed in Appendices B1.1 through B1.6. From the measured concentration of sulfate in solution, the concentration of airborne sulfate was calculated. This value was then used to determine the mass conversion rate of $\mathrm{SO}_{2}$ to $\mathrm{H}_{2} \mathrm{SO}_{4}$. A rate constant was estimated for the steady state conversion of $\mathrm{SO}_{2}$ into $\mathrm{H}_{2} \mathrm{SO}_{4}$. Using the known rate constant for the reaction of $\mathrm{SO}_{2}$ with $\mathrm{OH}$ radicals to form $\mathrm{H}_{2} \mathrm{SO}_{4}$, and the concentrations of $\mathrm{SO}_{2}$ and $\mathrm{H}_{2} \mathrm{SO}_{4}$, the $\mathrm{OH}$ radical production rate was estimated.

\subsection{Activity Size Distributions}

Activity size distribution measurements were made at various concentrations of radon-222, $\mathrm{SO}_{2}$, and relative humidity. The results are shown in graphical form with the activity fraction of each decay product and PAEC (potential alpha energy concentration) versus the particle diameter $(\mathrm{nm})$. The concentrations of the reactants in the chamber are listed above the graphs. The algorithm used to calculate the distribution (either the E.M. or Twomey) is listed on the graph. The symbols used for each decay product and the PAEC are given in the key on the graph. The total number of particles was measured with the CNC (TSI Inc., Model 3025) and the measured value is listed on the graph with 
units of particles $/ \mathrm{cm}^{3}$. Some distributions are lacking the total particle count, as they were not measured. All of the distributions are given in Appendix A1.1. The wire screen parameters and flow rates used to measure the activity distribtuions are listed in Appendix D1.1. Only a few activity size distributions will be discussed here. These show the general trend of the activity size distribution to larger size particles as the relative humidity and the $\mathrm{SO}_{2}$ concentration increases.

In Figure 5.1, graph A, almost all of the activity was incorporated in particles with a diameter between $0.5-1.5 \mathrm{~nm}$. This result was expected as there was no $\mathrm{SO}_{2}$ present to form lower vapor pressure species that can then nucleate. The PAEC was the greatest in this traditionally defined "unattached" size range as lung deposition of these particles most effective. The residual humidity was due to the limits of the system to dry the house compressed air. Depending on the humidity of house air, the drying system employed could not completely dehumidify the air.

In graph $\mathrm{B}$, the relative humidity was negligibly lower but a trace amount $(0.5$ ppm) of $\mathrm{SO}_{2}$ was added. The $\mathrm{SO}_{2}$ was oxidized to $\mathrm{H}_{2} \mathrm{SO}_{4}$ and nucleation and particle growth occurs. The Po-218 was mostly associated with particles with diameters between $0.5-1.5 \mathrm{~nm}$, although there was about $18 \%$ found in the particle diameter size ranges of 1.5-5.0 $\mathrm{nm}$ and $50-150 \mathrm{~nm}$. Very little of the Po-218 was found in the $15-50 \mathrm{~nm}$ diameter size range. Approximately $50 \%$ of $\mathrm{Pb}-214$ and $\mathrm{Bi}-214$ activities were associated with the smallest diameter size range. However, since these decay products are formed 3 to 29 minutes after the formation of Po-218, the particles they were attached to have had time to grow. Therefore, it might be expected to find that the highest fraction of activity of Bi214 was associated with particles in the $5-15 \mathrm{~nm}$ diameter size range. The activity fraction of $\mathrm{Pb}-214$ was almost equally distributed between the $0.5-1.5 \mathrm{~nm}$ and $5.0-15 \mathrm{~nm}$ diameter 
A: $695 \mathrm{pCi} / \mathrm{Rn}, 7.0 \%$ R.H., $0.0 \mathrm{ppm}$ $\mathrm{SO}_{2}$

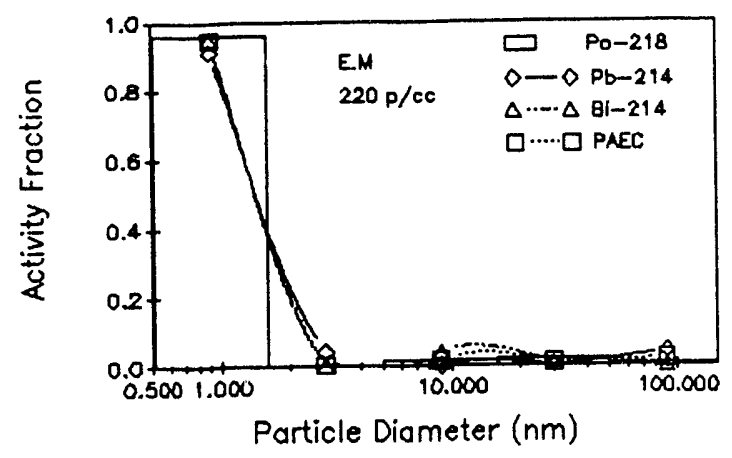

C: $695 \mathrm{pCi} / / \mathrm{Rn}, 5.5 \%$ R.H., $5.0 \mathrm{ppm}$ $\mathrm{SO}_{2}$

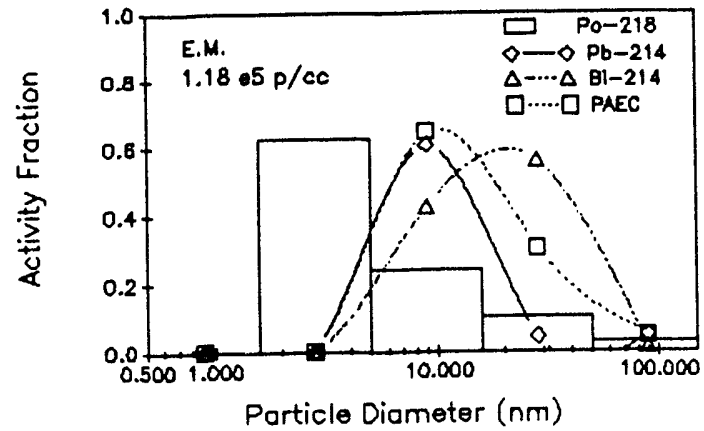

E: $695 \mathrm{pCi} / 1$ Radon, $30 \%$ Relative Humidity, 0.5 ppm SO2

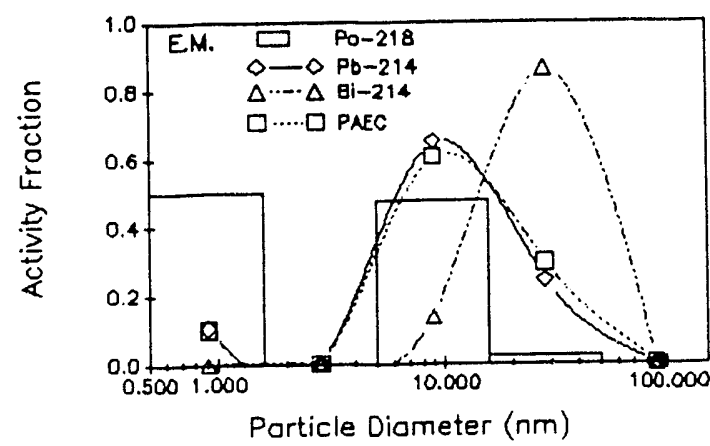

B: $695 \mathrm{pCi} / \mathrm{Rn}, 5.5 \%$ R.H., $0.5 \mathrm{ppm}$ $\mathrm{SO}_{2}$

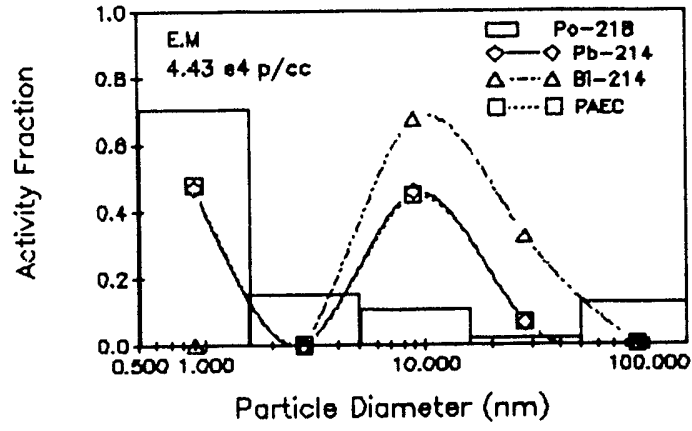

D: 695 pCi/l Rn, 30\% R.H., 0.5 ppm $\mathrm{SO}_{2}$

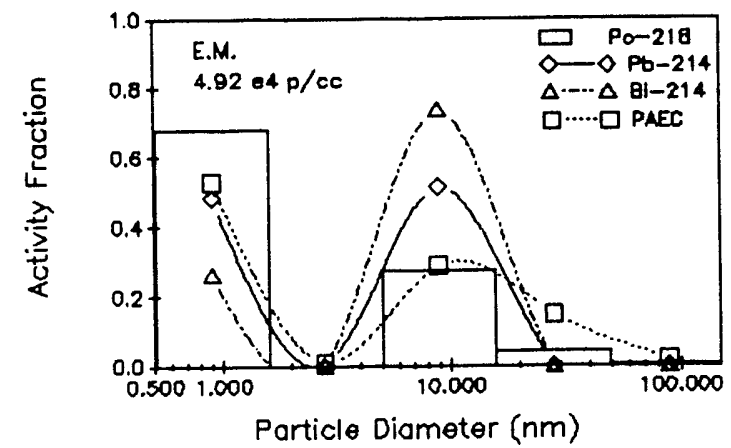

F: $695 \mathrm{pCi} / 1 \mathrm{Rn}, 33 \%$ R.H., $2.0 \mathrm{ppm} \mathrm{SO}$

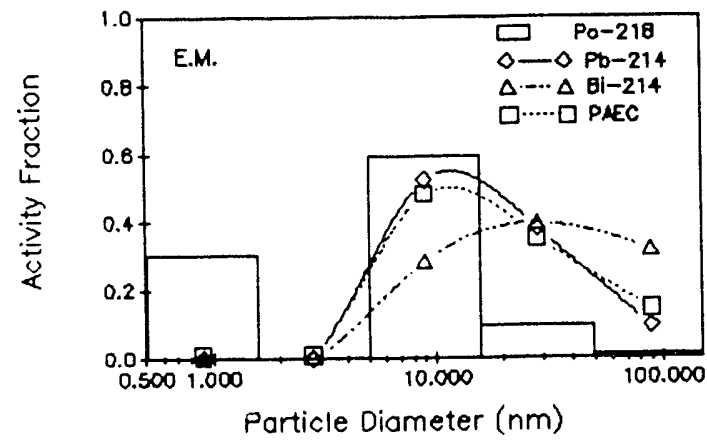

Figure 5.1 Activity size distributions at $695 \mathrm{pCi} / \mathrm{Rn}$, various \% R.H. and various $\mathrm{SO}_{2}$ concentrations. 
size ranges as the particle had less time to grow.

In graph $\mathrm{C}$, the addition of $5.0 \mathrm{ppm} \mathrm{SO}$ to the same relative humidity and $\mathrm{Rn}-222$ concentrations changed the activity size distribution significantly. There was no activity associated with the smallest diameter size range. $60 \%$ of the Po-218 was found associated with particles $1.5-5.0 \mathrm{~nm}$ diameter size range but $\mathrm{Pb}-214$ and $\mathrm{Bi}-214$ fractions were quite small in this range. The particle diameter size range from $5.0-15.0 \mathrm{~nm}$ had all three decay products associated with it. $\mathrm{Pb}-214$ was at a maximum in this range and $\mathrm{Bi}-214$ was at a maximum in the $15-50 \mathrm{~nm}$ range.

The relative humidity and $\mathrm{SO}_{2}$ concentrations were the same in graphs $\mathrm{D}$ and $\mathrm{E}$, but the activity size distributions were measured roughly 12 hours apart. In graph $\mathrm{D}, 70 \%$ of Po-218 was associated with $0.5-1.5 \mathrm{~nm}$ diameter particles and $30 \%$ was associated with 5.0-15 nm diameter particles as was most of the $\mathrm{Pb}-214$ and $\mathrm{Bi}-214$. In graph $\mathrm{E}$, taken 12 hours later, Po-218 is distributed equally between the two size ranges and $\mathrm{Bi}-214$ is now incorporated almost completely in the diameter size range greater than $15 \mathrm{~nm}$.

In graph $\mathrm{F}$, the $\mathrm{SO}_{2}$ concentration increased to $2.0 \mathrm{ppm}$ while the relative humidity stayed roughly the same. Here the activity fraction of Po-218 found in the smallest diameter range decreased and a increase in the $5.0-15 \mathrm{~nm}$ and $15-50 \mathrm{~nm}$ size range was observed.

In Figure 5.2 graph $A$, the relative humidity was on the average about $42 \%$ and the $\mathrm{SO}_{2}$ concentration was $0.5 \mathrm{ppm}$. Most of the Po-218 was still incorporated into the 0.5-1.5 nm diameter size range but there was enough humidity for particle growth to occur and shift the distribution to the larger size ranges. In graphs $B$ and $C$, the relative humidity was $30 \%$ and the $\mathrm{SO}_{2}$ was increased to $2.0 \mathrm{ppm}$. These measurements were taken on different days. In graph B, Po-218 was associated with both the $0.5-1.5 \mathrm{~nm}$, and 
A: $695 \mathrm{pCi} / \mathrm{Rn}, 38-45 \%$ R.H., $0.5 \mathrm{ppm}$ $\mathrm{SO}_{2}$

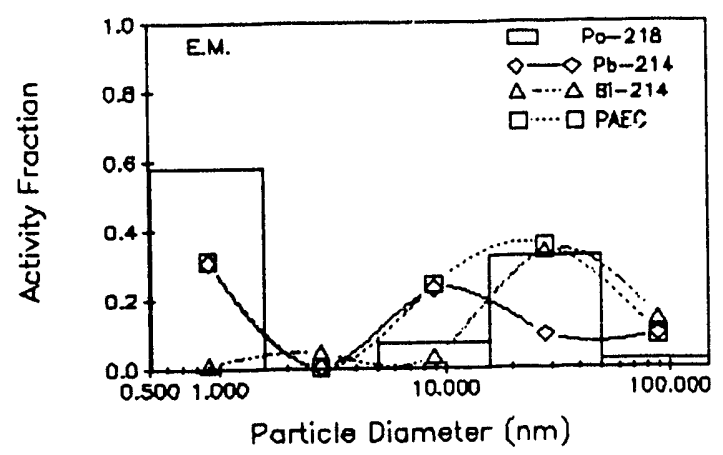

C: $695 \mathrm{pCi} / 1 \mathrm{Rn}, 30 \%$ R.H., $2.0 \mathrm{ppm}$ $\mathrm{SO}_{2}$

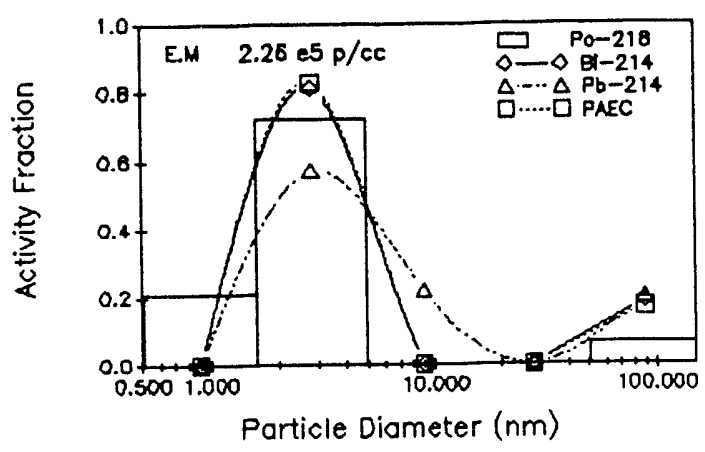

E: $388 \mathrm{pCi} / \mathrm{Rn}, 30 \%$ R.H., $20 \mathrm{ppm}$ $\mathrm{SO}_{2}$

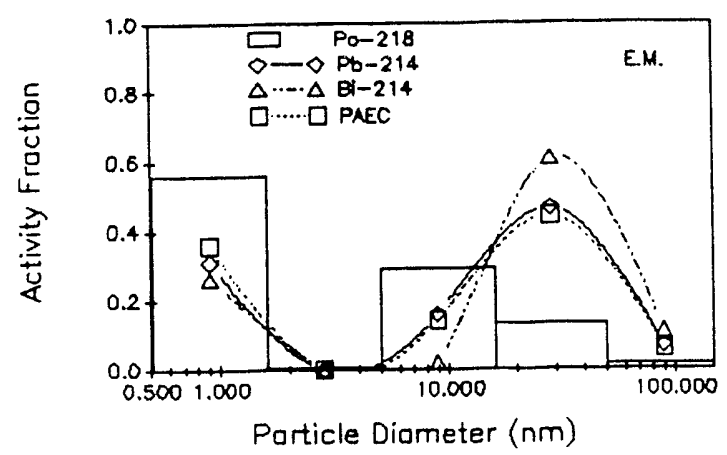

B: $695 \mathrm{pCi} / \mathrm{Rn}, 30 \%$ R.H., 2.0 ppm $\mathrm{SO}_{2}$

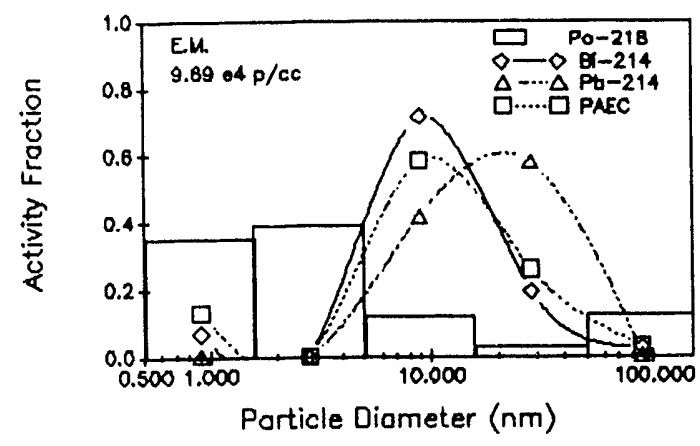

D: 388 pCi/ Rn, $30 \%$ R.H., 15 ppm $\mathrm{SO}_{2}$

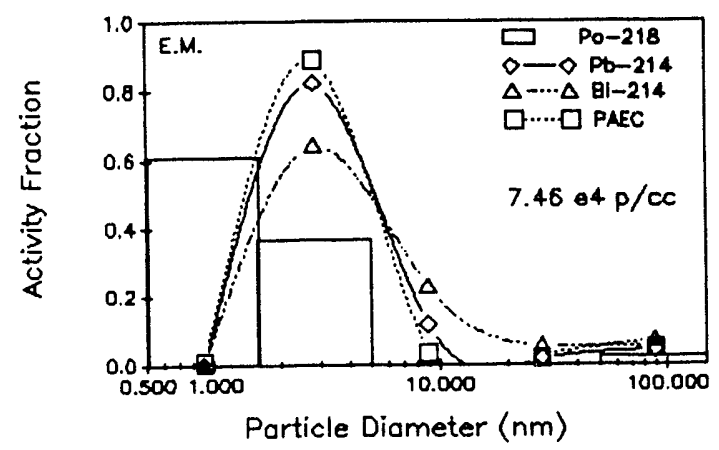

F: 388 pCi/ Rn, 27-30 \% R.H., 25 ppm $\mathrm{SO}_{2}$

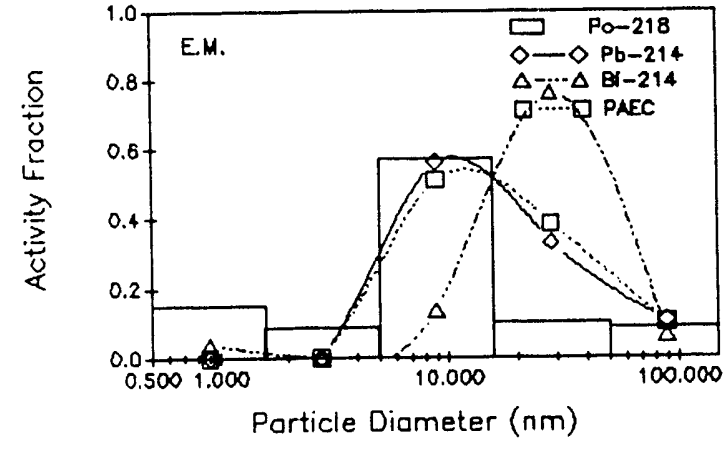

Figure 5.2 Activity size distributions at 695 and $388 \mathrm{pCi} / \mathrm{Rn}$, various $\% \mathrm{R} . \mathrm{H}$. and various $\mathrm{SO}_{2}$ concentrations. 
1.5-5.0 $\mathrm{nm}$ ranges almost equally and about $10 \%$ was associated with $5.0-15 \mathrm{~nm}$ and the 50-150 nm size ranges. Most of the $\mathrm{Pb}-214$ and $\mathrm{Bi}-214$ was found with the $1.5-15 \mathrm{~nm}$ diameter size range.

In graph $\mathrm{C}$, most of the activity was associated with the $1.5-5.0 \mathrm{~nm}$ diameter size range unlike graph B. Although the mass concentrations of the constituents in the chamber are constant at steady state, it appears that the aerosol dynamics of growth and coagulation occur and a constant activity size distribution for one set of conditions does not occur. A better method, given the time, would have been to take multiple distribution measurements and then averaged them or to have had multiple measurements to characterize the growth and coagulation processes occuring.

This oscillatory behavior of the size distribution of the aerosol produced in the chamber was also observed as part of the intercomparison measurements in the University of Illinios (now Clarkson ) $2.4 \mathrm{~m}^{3}$ chamber made in April 1988 (Hopke, 1991). Activity size distributions of various concentrations of $\mathrm{SO}_{2}$ and relative humidity with $200 \mathrm{pCi} / 1$ radon were measured using several different graded screen array systems. The particle size distributions were measured using the University of Vienna Differential Mobility Analyzer (DMA). Particle size distributions were taken in succession. Initially, the particle size distribution has a peak around $4-5 \mathrm{~nm}$. As time increases, the distributions shifts to a larger diameter and it appears that the smaller particles coagulate into the 10 to $12 \mathrm{~nm}$ size particles. Particles less than $3 \mathrm{~nm}$ are unobservable by the DMA but apparently coagulate into larger particles and the $4 \mathrm{~nm}$ mode becomes depleted from the distribution. The formation of 4 to $5 \mathrm{~nm}$ particles is no longer prevented and occurs as the larger mode coagulates to form fewer, larger particles. Eventually, the 4 to $5 \mathrm{~nm}$ size mode becomes dominant again. This study concurs with the results found in our activity 
size distribution measurements. Unfortunately, we do not have enough multiple measurements of the same set of conditions to quantitatively access the oscillations of the distributions.

In graphs $\mathrm{D}, \mathrm{E}$, and $\mathrm{F}$, the relative humidity was held roughly at $30 \%$ and the $\mathrm{SO}_{2}$ concentrations varied from 15 to $25 \mathrm{ppm}$. As the $\mathrm{SO}_{2}$ concentrations increased, the activity size distributions shifted toward increased particle diameter. It is difficult to determine the quantitative dependence of the relative humidity and $\mathrm{SO}_{2}$ concentration on the activity size distributions. As the relative humidity and $\mathrm{SO}_{2}$ concentrations increased, the activity size distributions generally shifted to larger particle sizes.

\subsection{Mass Conversion Rate Results}

The data used to calculate the mass conversion rate results and the $\mathrm{OH}$ concentration estimates for the steady state radiolytic oxidation of $\mathrm{SO}_{2}$ into $\mathrm{H}_{2} \mathrm{SC}_{4}$ are listed in Appendices B1.1 through B1.3. along with the results. The experimental conditions for each sample are listed in Appendix C1.1. The IC data for the samples are listed in Appendix E1.1 through E1.6. Analyzing sulfate on the Ion-Chromatograph(IC) incurred many difficulties due to problems with the instrument. Samples 1-25 were very difficult to analyze because the detector on the IC was deteriorating. Sulfate was not detected at all in samples 1-6. The $\mathrm{SO}_{2}$ concentration varied from 1.25 to $26.5 \mathrm{ppm}$, but sulfate detection was not possible. We were unaware at the time that the detector was the problem until it broke completely and was replaced. Samples $25-40$ then were measured on the IC with the new detector and sensitive resolutions were no problem. The IC column was rapidly deteriorating also, but since our samples were so clean with regards to other anions, the only noticable result was a decrease in retention time. Samples 29-32 were the last to be analyzed on the old column. Samples 33-40 were 
analyzed on the IC with both a new column and detector.

The mass conversion rate results are given in Figure 5.3 and are plotted as $\mathrm{SO}_{4}$ concentration versus the $\mathrm{SO}_{2}$ concentration at $30 \%$ relative humidity. There was not enough samples taken at constant relative humidity and various $\mathrm{SO}_{2}$ concentrations to study this relationship. Qualitatively, a linear relatioship exists between the concentration of $\mathrm{SO}_{2}$ and the concentration of sulfate produced. However, the errors are so large that a quanititative analysis is impossible. Many more data points are needed to assess the mass conversion rate as a function of relative humidity, but the long sampling times needed and the difficulty of measuring the sulfate on the particular Ion-Chromatograph employed, made our experiments difficult.

\subsection{The Estimate of the Amount of OH Produced.}

The results on the amount of $\mathrm{OH}$ produced and the error in the estimate are listed in Appendix B1.3. The $\mathrm{OH}$ concentration is given in numbers per $\mathrm{cm}^{-3}$. The error associated with these values at least twice the magnitude of the value. The large uncertainties are due to the uncertainty in the measured sulfate and the uncertainty in the rate constant used. Many additional measurements need to be made to assess this estimate quantitatively to study the $\mathrm{OH}$ concentration as a function of radon concentration and relative humidity. 
Mass Conversion Rate at SU\% Relative Hurindity

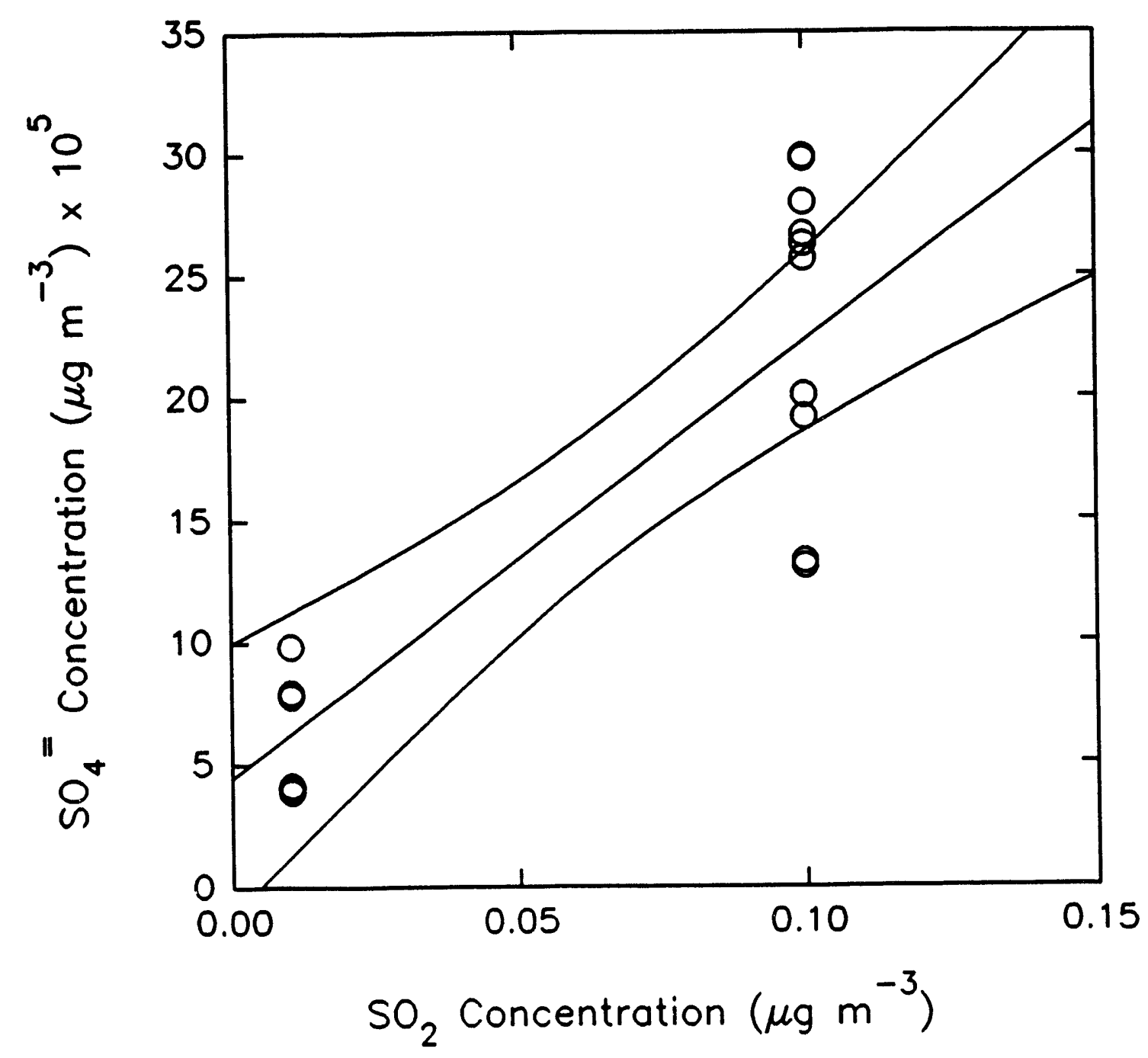

Figure 5.3 Mass Conversion Rate Results at 30\% Relative Humidity 


\section{CHAPTER 6}

\section{Conclusions}

The activity size distributions measurements show the dependence of $\mathrm{SO}_{2}$ and relative humidity on the particle size. As the $\mathrm{SO}_{2}$ concentration and relative humidity increased, the particle size increased. The activity fraction of Po-218 associated with each size range depends on the concentration of $\mathrm{SO}_{2}$ and relative humidity. Generally, as the amount of reactants increased the size range of the particles Po-218 was associated with increased. When there was none or very little $\mathrm{SO}_{2}$ in the chamber, most of the Po-218 was associated with the $0.5-1.5 \mathrm{~nm}$ diameter size range. The activity fraction of $\mathrm{Pb}-214$ and Bi-214 associated with the particles of a certain size range did not vary as much with the increase in reactants as Po-218 did. The general trend was still observed. When the reactants increased so did the particle diameter associated with these decay products as they were associated with particles that had been around long enough to grow through coagulation. Many additional measurements need to be performed to quantitatively assess the dependence of $\mathrm{SO}_{2}$ and relative humidity of particle size. The oscillatory behavior of the nucleation and growth of particles in the chamber needs to be studied further. Activity size distributions measurements on the same set of conditions vary depending on the time of sampling with respect to the initial flow of reactants into the chamber. To achieve a representative measurement of the distribution multiple samples should be measured and averaged.

The mass conversion rate results show the linear dependence of the amount of $\mathrm{H}_{2} \mathrm{SO}_{4}$ produced on the concentration of $\mathrm{SO}_{2}$ at $30 \%$ relative humidity. There were not enough measurements made to assess the amount of $\mathrm{H}_{2} \mathrm{SO}_{4}$ produced as a function of relative humidity or radon due to the difficulty in analyzing sulfate on the IC. 
The estimated $\mathrm{OH}$ concentration produced be radon radiolysis is inconclusive due to the large errors associated with the sulfate concentration measurements and the literature constant used. Many additional measurements of sulfate will be needed before the quantitative dependence of the $\mathrm{OH}$ concentration as a function of radon concentration and relative humidity can be determined. 


\section{REFERENCES}

Agarwal, J.K., and Sem, G.J. (1980) Continuous Flow, Single-Particle Counting Condensation Nucleus Counter. J. Aerosol Sci 11:343-357.

Chamberlain, A.C., Megaw, W.J., and Wiffen, R.D. (1957) Role of Condensation Nuclei as Carriers of Radioactive Particles. Geofisica Pura e Appl. 36:233.

Chan, L.Y.C. and Mohnen, V.A. (1980) Ion Nucleation Theory. J. Atmos. Sci 37:23232331.

Cheng, Y.S.; Keating, J.A. and Kanapilly, G.M. (1980) Theory and Calibration of a Screen-Type Diffusion Battery. J. Aerosol Sci 11:546-549.

Cheng, Y.S.; Yamada, Y.; Yeh, H.C.; Swift, D.L. (1988) Diffusional Deposition of Ultrafine Aerosols in a Human Nasal Cast. J. Aerosol Sci 19:741-751.

Cheng, Y.S. and Yeh, H.C. (1980) Theory of Screen Type Diffusion Battery. J. Aerosol Sci 11:313-319.

Chu, K.D.; Hopke, P.K.; Knutson, E.O.; Tu, K.W. and Holub, R.F. (1987) The induction of an Ultrafine Aerosol by Radon Radiolysis. In: Radon and its Decay Products:

Occurrence, Properties and Health Effects. Hopke, P.K., Ed., Washington D.D: American Chemical Society, pp. 365-376.

Chu, K.D. and Hopke, P.K. (1988) Neutralization Kinetics for Po-218. Environ. Sci Te:hnol. 22:711-717.

Diamond, G.L.; Iribarne, J.V.; and Corr, D.J. (1985) Ion-Induced Nucleation From Sulfur Dioxide. J. Aerosol Sci 16:43-55.

Holub, R.F.; Droullard, R.F,; Ho, W.L.; Hopke, P.K.; Parsley, R. and Stukel, J.J. (1979) The Reduction of Airborne Radon Daughter Concentrations by Plateout on an Air Mixing Fan. Health Phys. 36:497-504.

James, A.C. (1991) Dosimetry of Radon Exposures: Waht Does It Imply for Risk and Measurement of Indoor Exposure?., Columbus, OH. Proceedings of the 29th Hanford Symposium on Health and the Environment, Battelle Memorial Press.

Lind, S.C. (1961) Radiation Chemistry of Gases. ACS Monograph Series, Reinhold Publishing Corp., New York, NY.

Loeb, L.B. (1961) The Kinetic Theory of Gases. 3rd Ed. p554. New York: Dover Publications.

Megaw, W.J. and Wiffen, R.D. (1961) The Generation of Condensation Nuclei by 
Ionizing Radiation. Geofisica Pura e Appl. 50:118-128.

Maher, E.F. and Laird, N.M. (1986) EM Algorithm Reconstruction of Particle Size Distribution From Diffusion Battery Data. J. Aerosol Sci. 16:557-570.

NAS/NRC (1988) Health Risks of Radon and Other Internally Deposited Alpha-Emitters, National Academy Press, Washington, D.C.

NAS/NRC (1991) Dosimetric Extrapolation of BEIR IV Risks to the General Public, Washington, D.C., National Academy Press.

Nazaroff, W.W. (1984) Optimizing the Total-Alpha Three-Count Technique for Measuring Concentrations of Radon Progeny in Residences. Health Phys. 24:387-395.

Puskin, J.S.; Nelson, C.B. (1989) EPA's Perspective on Risks From Residential Radon Exposure. J. Air Waste Manage. Assoc., 39:915-920.

Porsendorfer, J.; Mercer, T.T. (1979) Influence of Electric Charge and Humidity Upon the Diffusion Coefficient of Radon Decay Products. Health Phys. 15:191-199.

Rabeony, H. and Mirabel, P. (1986) Vapor Nucleation on Ions. J. de Chemie Physique. 83:219-224.

Raes, F. and Janssens, A. (1985) Ion-Induced Aerosol Formation in a $\mathrm{H}_{2} \mathrm{O}-\mathrm{H}_{2} \mathrm{SO}_{4}$ SystemI. Extension of the Classical Theory and Search for Experimental Evidence. J. Aerosol Sci 16:217-227.

Ramamurthi, M. (1989) Detection and Measurement of the Activity Size Distributions $\left(d_{p}>0.5 \mathrm{~nm}\right)$ Associated with Radon Decay Products in Indoor Air. PhD. Thesis. University of Illinois at Urbana-Champaign.

Ramamurthi, M. and Hopke, P.K. (1989) On Improving the Validity of Wire Screen "Unattached" Fraction Rn Daughter Measurements. Health Phys. 56:189-194.

Ramamurthi, M. and Hopke, P.K. (1990) Simulation Studies of Reconstruction Algorithms for the Determination of Optimum Operating Parameters and Resolution of Graded Screen Array Sustems (Non-Conventional Diffusion Batteries). Aerosol Sci Technol. 12:700-710.

Ramamurthi, M.; Strydom, R.; Hopke, P.K. (1990) Assessment of Wire and Tube Penetration Theories Using a 218PoO Cluster Aerosol. J. Aerosol Sci. 21:203-211.

Reineking, A. and Porstendorfer, J. (1986) High-Volume Screen Diffusion Batteries and $\alpha$-Spectroscopy for Measurement of the Radon Daughter Activity Size Distributions in the Environment. J. Aerosol Sci. 17: 873-879. 
Scheibel, H.G. and Porstendorfer, J. (1986) Penetration Measurements in the Ultrafine Particle Size Range. J. Aerosol Sci. 15:549-556.

Strydom, R. (1989). Measurement of Initial Clustering of the Radon Decay Product Po218. Ph.D. Thesis. Potchefstroom University of Christian Higher Education.

Stolzenburg, M.R., and McMurry, P.H. (1986) Counting Efficiency of an Ultrafine Aerosol Condensation Nucleus Counter: Theory and Experiment. Aerosols: Formation and Reactivity, 2nd Inth Aerosol Conf. Berlin, Pergamon Press, New York. 786-789

Thomas, J.W. (1972) Measurements of Radon Daughters in Air. Health Phys. 23:783-789.

Tsivoglou, E.C.; Ayer, H.E. and Holaday D.A. (1953) Occurrence of Nonequilibrium Atmospheric Mixtures of Radon and its Daughters. Nucleonics. 11:40-xx.

Twomey, S. (1975) Comparison of Constrained Linear Inversion and an Iterative nonlinear Algorithm Applied to the Indirect Estimation of the Particle Size Distribution. $J$. J. Comput. Phys. 18: 188-200.

Van Dingenen, R. (1990) The Dynamics of Sub-Micron $\mathrm{H}_{2} \mathrm{O}-\mathrm{H}_{2} \mathrm{SO}_{4}$ Aerosols: A Smog Chamber Study. Ph.D. Thesis. Gent University.

Warnek,P. (1988) Chemistry of the Natural Atmosphere. International Geophysics Series. Vol. 41. Academic Press, Inc., New York, NY.

Wellisch, E.M. (1913) The Distribution of the Active Deposition of Radium in an Electric Field. II. Phi Mag. 6:623-635.

Wilson, C.T.R. (1897) Condensation of Water Vapor in the Presence of Dust-Free Air and Other Gases. Phil. Trans. Roy. Soc. London. A189. 265-274.

Yamada, Y.; Cheng, Y.S. and Yeh, H.C. (1988) Evaluation of Coarse Screens as

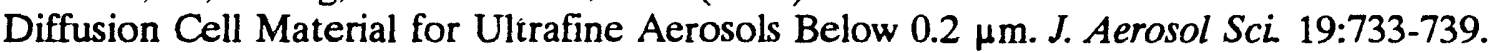




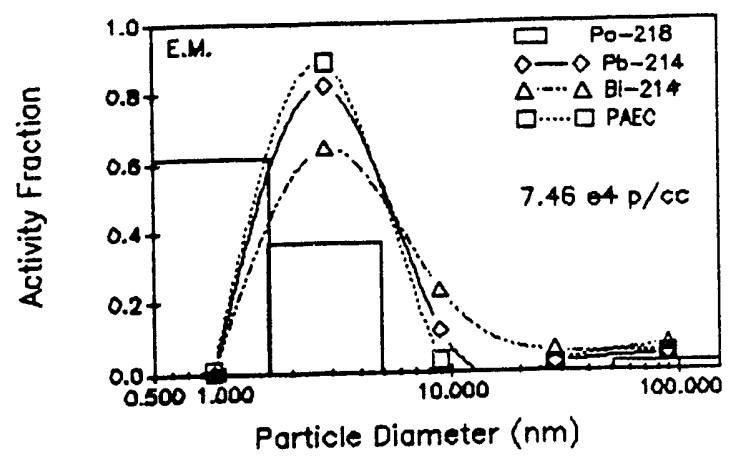

A: 388 pCi $/ \mathrm{Rn}, 30 \%$ R.H., 2.5 ppm $\mathrm{SO}_{2}$

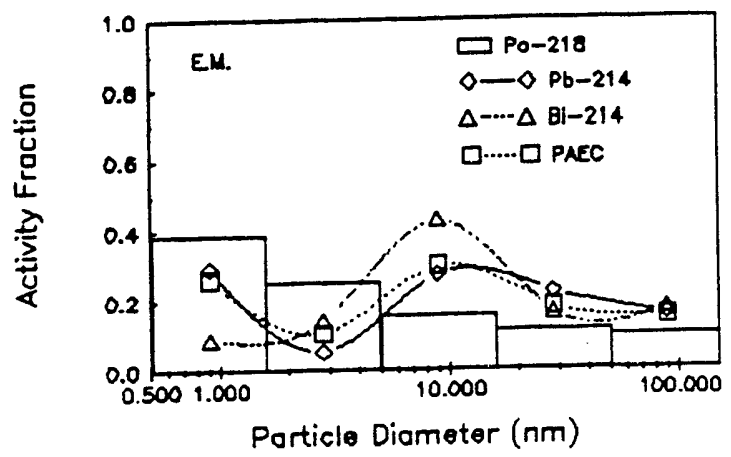

C: $388 \mathrm{pCi} / \mathrm{Rn}, 30 \%$ R.H., 5.0 ppm $\mathrm{SO}_{2}$

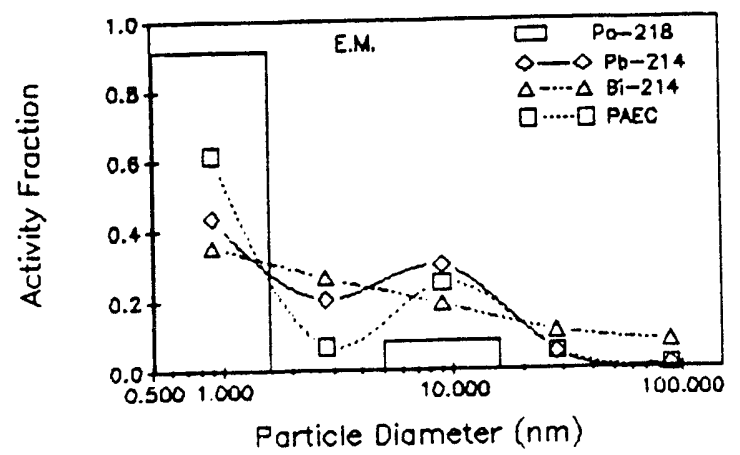

E: 388 pCin Rn, 30 \% R.H., 12 ppm $\mathrm{SO}_{2}$

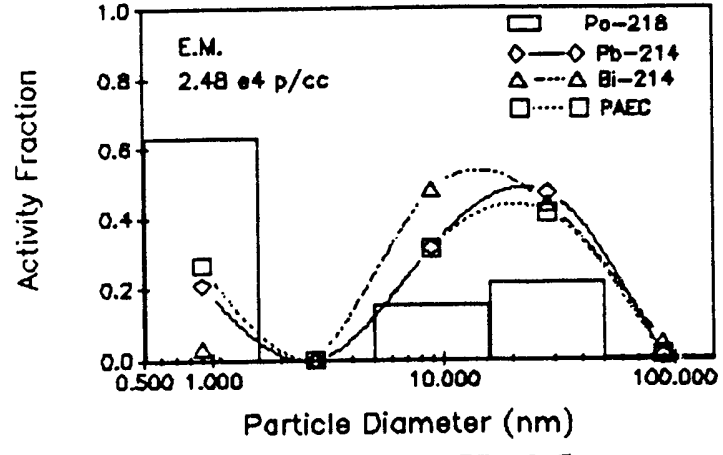

B: 388 pCi/ Rn, 33 \% R.H., 2.5 ppm $\mathrm{SO}_{2}$

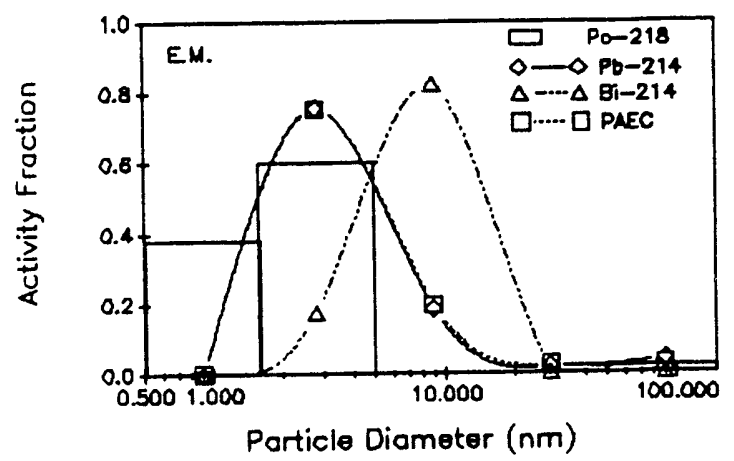

D: $388 \mathrm{pCi} / \mathrm{Rn}, 30$ \% R.H., 10 ppm $\mathrm{SO}_{2}$

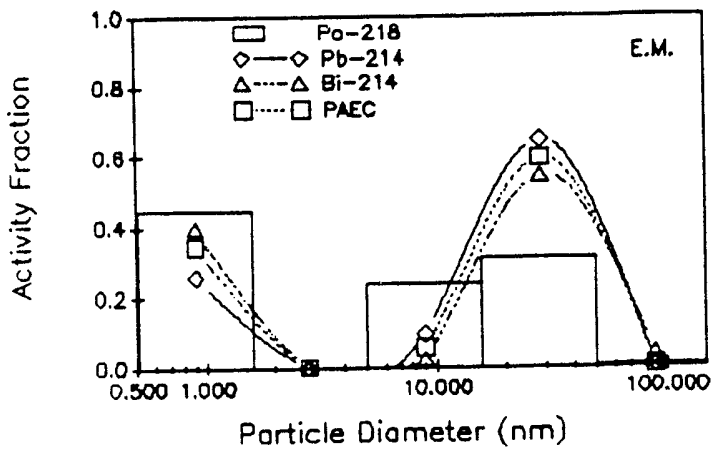

F: 388 pCi/l Rn, 30 \% R.H., 12.0 ppm $\mathrm{SO}_{2}$ 


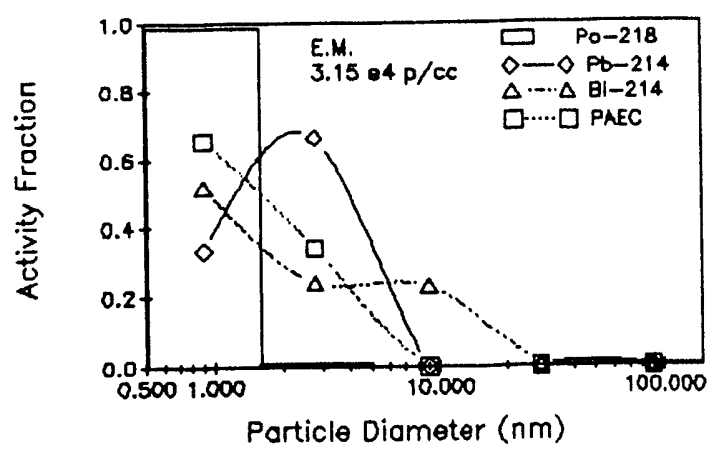

A: 388 pCi/l Rn, $18 \%$ R.H., 10 ppm SO

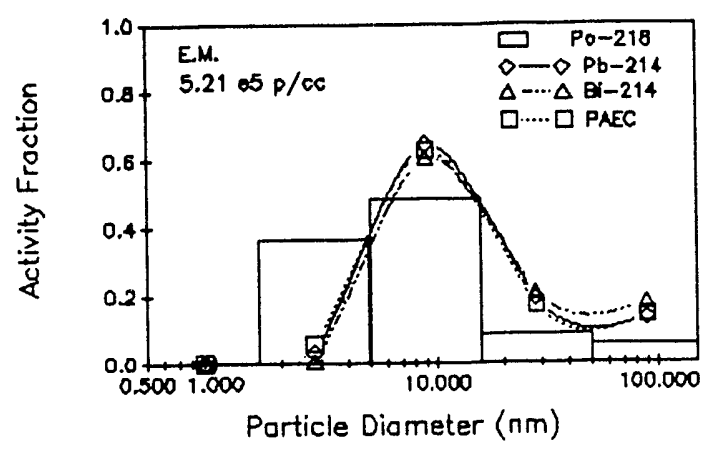

C: $388 \mathrm{pCi} / \mathrm{Rn}, 39-43 \%$ R.H., 22.3 ppm $\mathrm{SO}_{2}$

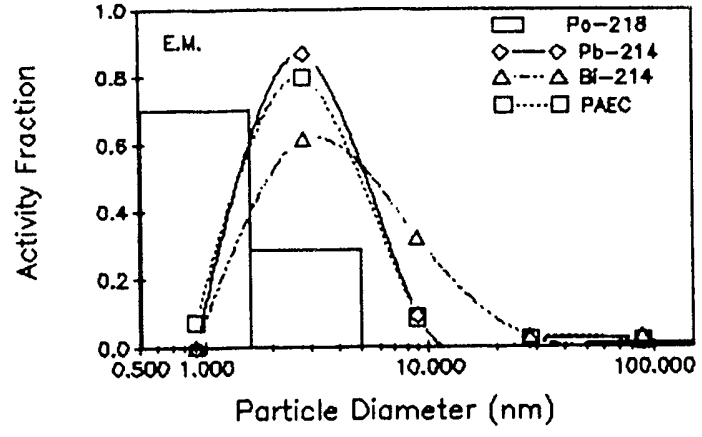

B: 388 pCi/l Rn, 35\% R.H., 20 ppm SO 2

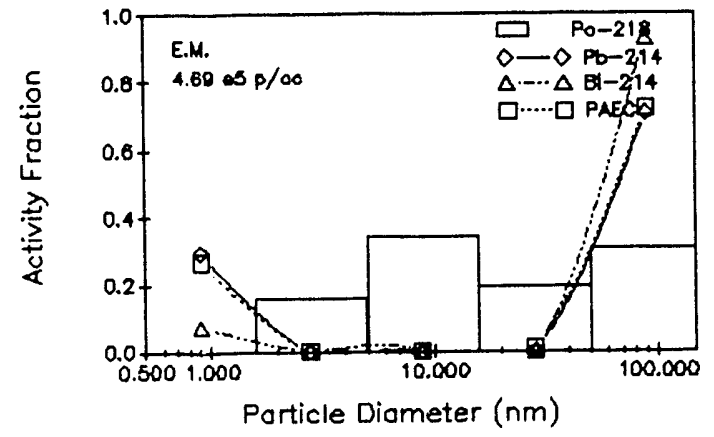

D: $388 \mathrm{pCi} / 1 \mathrm{Rn}, 39-44 \%$ R.H., $22.3 \mathrm{ppm}$ $\mathrm{SO}_{2}$

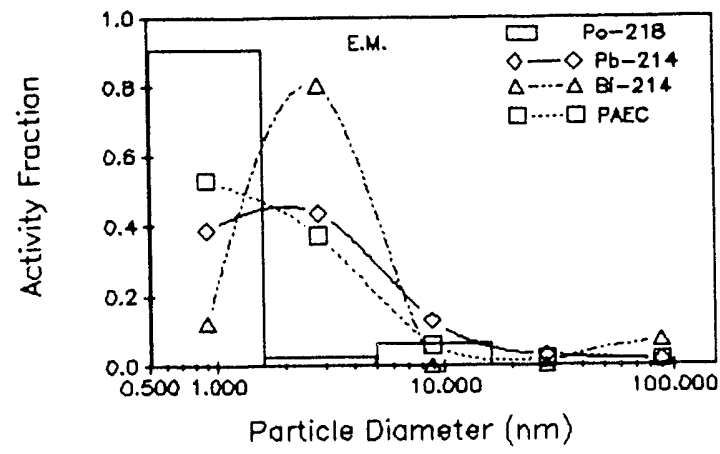

E: $388 \mathrm{pCi} / \mathrm{Rn}, 35 \%$ R.H., 25 ppm SO 

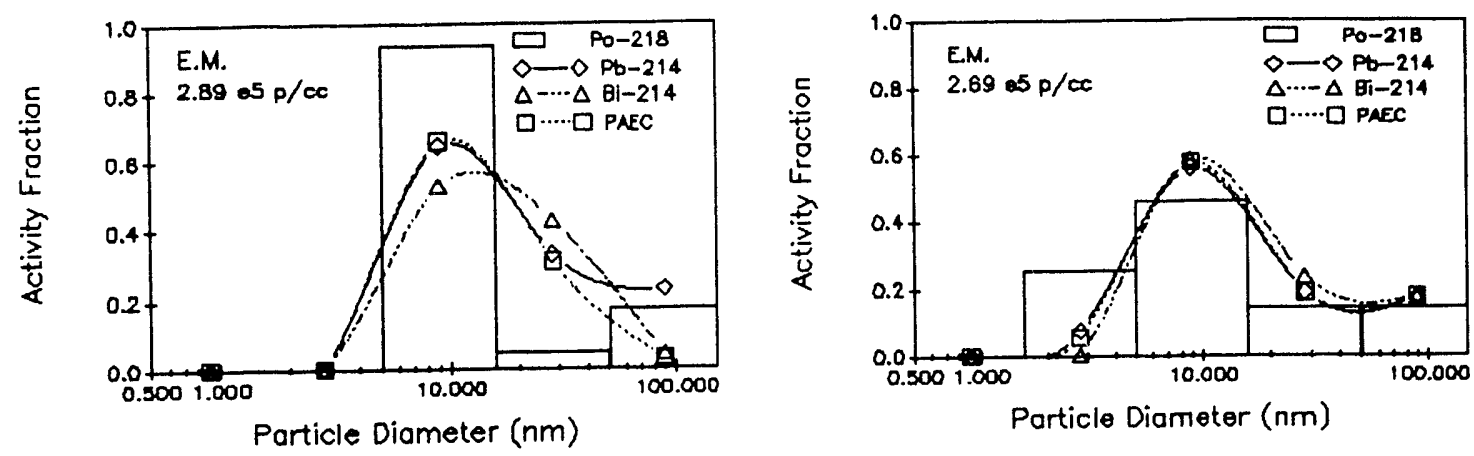

A: 388 pCi/ Rn, $42 \%$ R.H., 25 ppm $\mathrm{SO}_{2}$

B: $388 \mathrm{pCi} / \mathrm{l} \mathrm{Rn}, 42-45 \%$ R.H., 25 ppm $\mathrm{SO}_{2}$
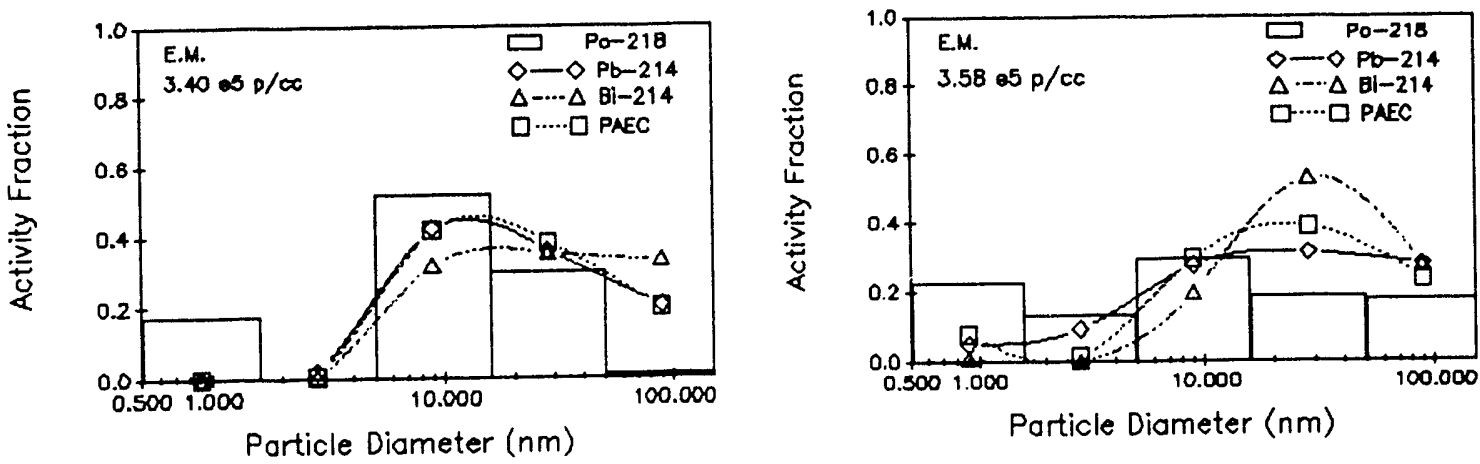

C: 388 pCi/ Rn, $42 \%$ R.H., 35.9 ppm $\mathrm{SO}_{2}$

D: $388 \mathrm{pCi} / \mathrm{Rn}, 42 \%$ R.H., 35.9 ppm SO

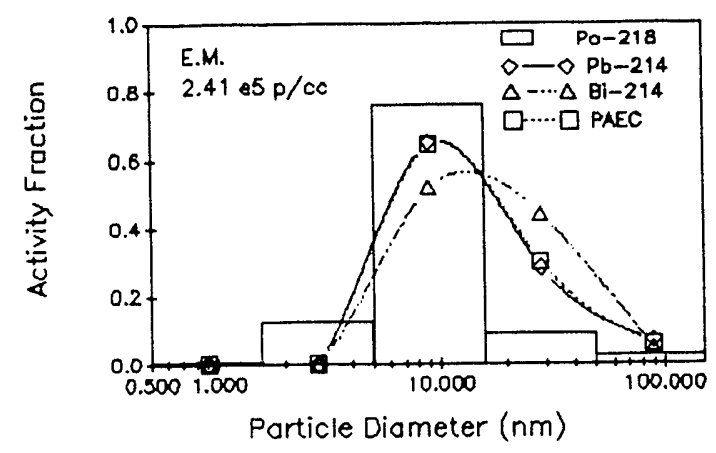

E: $388 \mathrm{pCi} / 1 \mathrm{Rn}, 42-45 \%$ R.H., 35.9 ppm

$\mathrm{SO}_{2}$ 


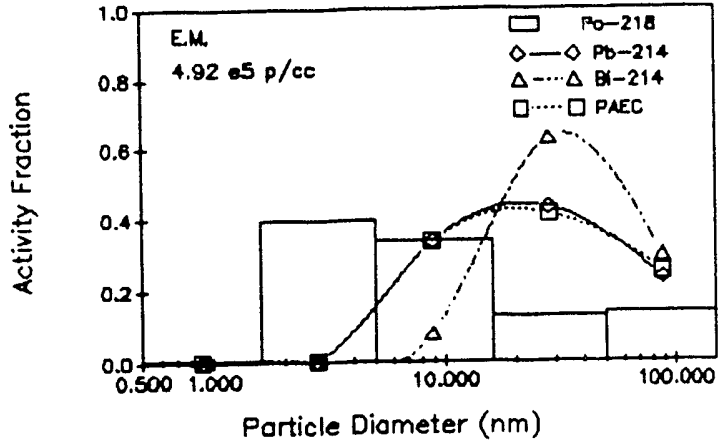

A: $388 \mathrm{pCi} / \mathrm{Rn}, 49-51 \%$ R.H., $34.5 \mathrm{ppm}$ $\mathrm{SO}_{2}$

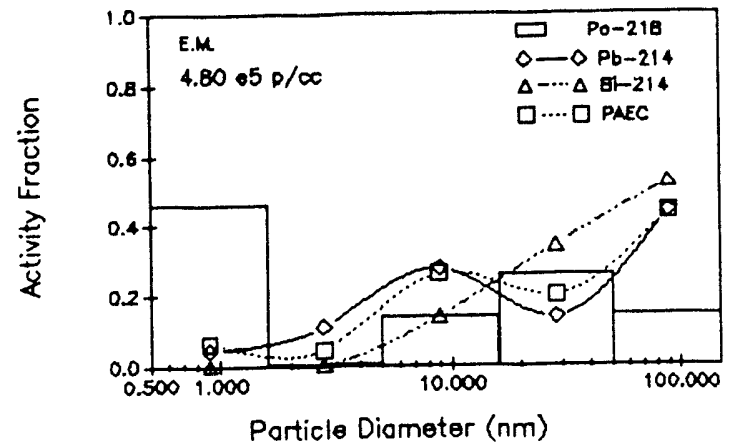

C: $388 \mathrm{pCi} / 1 \mathrm{Rn}, 60 \%$ R.H., $34.5 \mathrm{ppm}$ $\mathrm{SO}_{2}$

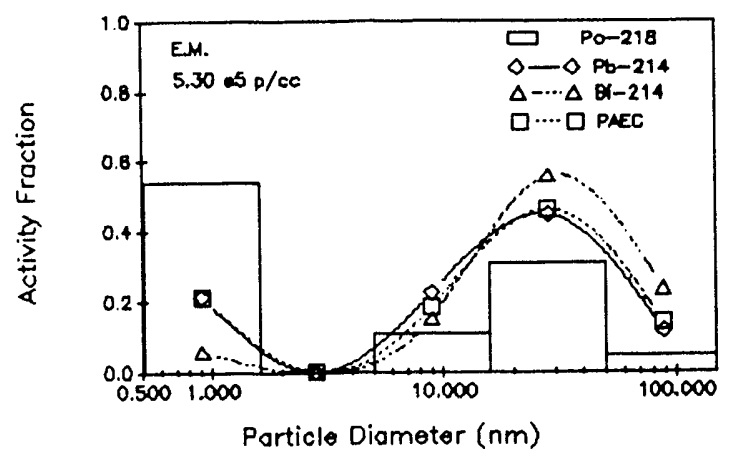

B: 388 pCi/ Rn, $60 \%$ R.H., 34.5 ppm $\mathrm{SO}_{2}$ 


\section{APPENDIX B1.1}

Data and Results

\begin{tabular}{|c|c|c|c|c|c|c|}
\hline Sample & $\mathrm{SO}_{4} \mathrm{sol}$ & $\begin{array}{l}\mathrm{SO}_{4} \\
\text { Error }\end{array}$ & $t \min$ & $\begin{array}{r}Q \\
\mathrm{lpm}\end{array}$ & $\begin{array}{l}\mathrm{SO}_{4} \text { air } \\
\mathrm{ug} / 1\end{array}$ & $\begin{array}{l}\mathrm{SO}_{4} \text { air err } \\
\mathrm{ug} / 1\end{array}$ \\
\hline a7 & 0.073 & 0.036 & 1462.00 & 5.01 & $3.99 \mathrm{e}-05$ & $3.60 \mathrm{e}-05$ \\
\hline b7 & 0.099 & 0.036 & 1462.00 & 5.01 & $5.41 \mathrm{e}-05$ & $3.60 \mathrm{e}-05$ \\
\hline a8 & 0.337 & 0.038 & 1500.00 & 5.01 & $1.79 \mathrm{e}-04$ & $3.80 \mathrm{e}-05$ \\
\hline b8 & 0.354 & 0.038 & 1500.00 & 5.01 & $1.88 \mathrm{e}-04$ & $3.80 \mathrm{e}-05$ \\
\hline a9 & 0.293 & 0.037 & 4240.00 & 5.01 & $5.52 \mathrm{e}-05$ & $3.70 \mathrm{e}-05$ \\
\hline b9 & 0.367 & 0.038 & 4240.00 & 5.01 & $6.91 \mathrm{e}-05$ & $3.80 \mathrm{e}-05$ \\
\hline $\mathrm{a} 10$ & 0.144 & 0.036 & 2820.00 & 5.01 & $4.08 \mathrm{e}-05$ & $3.60 \mathrm{e}-05$ \\
\hline $\mathrm{b} 10$ & 0.105 & 0.036 & 2820.00 & 5.01 & $2.97 \mathrm{e}-05$ & $3.60 \mathrm{e}-05$ \\
\hline $\mathrm{a} 15$ & 0.176 & 0.043 & 1805.00 & 5.01 & $7.78 e-05$ & $4.30 \mathrm{e}-05$ \\
\hline b15 & 0.179 & 0.043 & 1805.00 & 5.01 & $7.92 e-05$ & $4.30 \mathrm{e}-05$ \\
\hline c15 & 0.222 & 0.043 & 1805.00 & 5.01 & $9.82 \mathrm{e}-05$ & $4.30 \mathrm{e}-05$ \\
\hline $\mathrm{a} 16$ & 0.219 & 0.043 & 4345.00 & 5.01 & $4.02 \mathrm{e}-0.5$ & $4.30 \mathrm{e}-05$ \\
\hline b16 & 0.211 & 0.043 & 4345.00 & 5.01 & $3.88 \mathrm{e}-05$ & $4.30 \mathrm{e}-05$ \\
\hline $\mathrm{c} 16$ & 0.224 & 0.043 & 4345.00 & 5.01 & $4.12 \mathrm{e}-05$ & $4.30 \mathrm{e}-05$ \\
\hline $\mathrm{a} 17$ & 0.052 & 0.042 & 4460.00 & 5.01 & $9.31 \mathrm{e}-06$ & $4.20 \mathrm{e}-05$ \\
\hline b17 & 0.053 & 0.042 & 4460.00 & 5.01 & $9.49 \mathrm{e}-06$ & $4.20 \mathrm{e}-05$ \\
\hline c17 & 0.081 & 0.042 & 4460.00 & 5.01 & $1.45 \mathrm{e}-05$ & $4.20 \mathrm{e}-05$ \\
\hline $\mathrm{d} 17$ & 0.065 & 0.042 & 4460.00 & 5.01 & $1.16 \mathrm{e}-05$ & $4.20 \mathrm{e}-05$ \\
\hline a18 & 0.092 & 0.190 & 6313.00 & 5.01 & $1.16 \mathrm{e}-05$ & $1.90 \mathrm{e}-04$ \\
\hline b18 & 0.031 & 0.189 & 6313.00 & 5.01 & $3.92 \mathrm{e}-06$ & $1.89 \mathrm{e}-04$ \\
\hline $\mathrm{c} 18$ & 0.020 & 0.189 & 6313.00 & 5.01 & $2.53 \mathrm{e}-06$ & $1.89 \mathrm{e}-04$ \\
\hline a19 & 0.083 & 0.190 & 4326.00 & 5.01 & $1.53 \mathrm{e}-05$ & $1.90 \mathrm{e}-04$ \\
\hline b19 & 0.005 & 0.189 & 4326.00 & 5.01 & $9.23 e-07$ & $1.89 \mathrm{e}-04$ \\
\hline $\mathrm{a} 20$ & 0.060 & 0.190 & 4345.00 & 5.01 & $1.10 \mathrm{e}-05$ & $1.90 \mathrm{e}-04$ \\
\hline $\mathrm{a} 21$ & 0.024 & 0.189 & 5155.00 & 5.01 & $3.72 \mathrm{e}-06$ & $1.89 \mathrm{e}-04$ \\
\hline
\end{tabular}




\begin{tabular}{|c|c|c|c|c|c|c|}
\hline b21 & 0.022 & 0.189 & 5155.00 & 5.01 & $3.41 \mathrm{e}-06$ & $1.89 \mathrm{e}-04$ \\
\hline a22 & 0.042 & 0.189 & 4380.00 & 5.04 & $7.61 \mathrm{e}-06$ & $1.89 \mathrm{e}-04$ \\
\hline a23 & 0.176 & 0.080 & 7105.00 & 5.04 & $1.97 e-05$ & $8.00 \mathrm{e}-05$ \\
\hline a24 & 0.179 & 0.080 & 4320.00 & 5.04 & $3.29 \mathrm{e}-05$ & $8.00 \mathrm{e}-05$ \\
\hline a25 & 1.045 & 0.052 & 2957.00 & 5.04 & $2.80 \mathrm{e}-04$ & $5.20 \mathrm{e}-05$ \\
\hline b25 & 1.115 & 0.053 & 2957.00 & 5.04 & $2.99 \mathrm{e}-04$ & $5.30 \mathrm{e}-05$ \\
\hline c25 & 1.106 & 0.052 & 2957.00 & 5.04 & $2.97 \mathrm{e}-04$ & $5.20 \mathrm{e}-05$ \\
\hline a26 & 1.633 & 0.060 & 4323.00 & 5.88 & $2.57 \mathrm{e}-04$ & $6.00 \mathrm{e}-05$ \\
\hline b26 & 1.695 & 0.061 & 4323.00 & 5.88 & $2.67 \mathrm{e}-04$ & $6.10 \mathrm{e}-05$ \\
\hline c26 & 1.673 & 0.061 & 4323.00 & 5.88 & $2.63 e-04$ & $6.10 \mathrm{e}-05$ \\
\hline a27 & 0.811 & 0.049 & 2880.00 & 5.88 & $1.92 \mathrm{e}-04$ & 4.90e-05 \\
\hline b27 & 0.823 & 0.049 & 2880.00 & 5.88 & $1.94 \mathrm{e}-04$ & $4.90 \mathrm{e}-05$ \\
\hline c27 & 0.849 & 0.049 & 2880.00 & 5.88 & $2.01 \mathrm{e}-04$ & $4.90 \mathrm{e}-05$ \\
\hline a28 & 0.572 & 0.047 & 3245.00 & 5.40 & $1.31 \mathrm{e}-04$ & $4.70 \mathrm{e}-05$ \\
\hline b28 & 0.581 & 0.047 & 3245.00 & 5.40 & $1.33 e-04$ & 4.70e-05 \\
\hline c28 & 0.581 & 0.047 & 3245.00 & 5.40 & $1.33 \mathrm{e}-04$ & 4.70e-05 \\
\hline a29 & 2.840 & 0.087 & 4395.00 & 5.40 & $4.79 e-04$ & 8.70e-05 \\
\hline b29 & 2.863 & 0.088 & 4395.00 & 5.40 & $4.83 e-04$ & $8.80 \mathrm{e}-05$ \\
\hline c29 & 2.834 & 0.088 & 4395.00 & 5.40 & $4.78 \mathrm{e}-04$ & $8.80 \mathrm{e}-05$ \\
\hline d29 & 2.844 & 0.088 & 4395.00 & 5.40 & $4.79 \mathrm{e}-04$ & $8.80 \mathrm{e}-05$ \\
\hline a30 & 0.760 & 0.056 & 3125.00 & 5.40 & $1.80 \mathrm{e}-04$ & $5.60 \mathrm{e}-05$ \\
\hline b30 & 0.767 & 0.056 & 3125.00 & 5.40 & $1.82 \mathrm{e}-04$ & $5.60 \mathrm{e}-05$ \\
\hline $\mathrm{c} 30$ & 0.822 & 0.056 & 3125.00 & 5.40 & $1.95 \mathrm{e}-04$ & $5.60 \mathrm{e}-05$ \\
\hline $\mathrm{d} 30$ & 0.818 & 0.056 & 3125.00 & 5.40 & $1.94 \mathrm{e}-04$ & $5.60 \mathrm{e}-05$ \\
\hline a31 & 1.252 & 0.061 & 2585.00 & 5.11 & $3.79 e-04$ & $6.10 \mathrm{e}-05$ \\
\hline b31 & 1.248 & 0.061 & 2585.00 & 5.11 & $3.78 e-04$ & $6.10 \mathrm{e}-05$ \\
\hline c31 & 1.304 & 0.062 & 2585.00 & 5.11 & $3.95 \mathrm{e}-04$ & $6.20 \mathrm{e}-05$ \\
\hline $\mathrm{d} 31$ & 1.293 & 0.062 & 2585.00 & 5.11 & $3.92 \mathrm{e}-04$ & $6.20 \mathrm{e}-05$ \\
\hline a32 & 0.602 & 0.055 & 2723.00 & 5.11 & $1.73 e-04$ & $5.50 \mathrm{e}-05$ \\
\hline
\end{tabular}




\begin{tabular}{|c|c|c|c|c|c|c|}
\hline b32 & 0.591 & 0.055 & 2723.00 & 5.11 & $1.70 \mathrm{e}-04$ & $5.50 \mathrm{e}-05$ \\
\hline c32 & 0.598 & 0.055 & 2723.00 & 5.11 & $1.72 \mathrm{e}-04$ & $5.50 \mathrm{e}-05$ \\
\hline $\mathrm{d} 32$ & 0.590 & 0.055 & 2723.00 & 5.11 & $1.70 \mathrm{e}-04$ & $5.50 \mathrm{e}-05$ \\
\hline a33 & 1.056 & 0.041 & 3777.00 & 5.11 & $2.19 \mathrm{e}-04$ & $4.10 c-05$ \\
\hline b33 & 1.592 & 0.060 & 3777.00 & 5.11 & $3.30 \mathrm{e}-04$ & $6.00 \mathrm{e}-05$ \\
\hline c33 & 0.453 & 0.057 & 3777.00 & 5.11 & $9.39 \mathrm{e}-05$ & $5.70 \mathrm{e}-05$ \\
\hline a34 & 0.806 & 0.046 & 2512.00 & 5.11 & $2.51 \mathrm{e}-04$ & $4.60 \mathrm{e}-05$ \\
\hline b34 & 0.886 & 0.048 & 2512.00 & 5.11 & $2.76 \mathrm{e}-04$ & $4.80 \mathrm{e}-05$ \\
\hline c34 & 0.917 & 0.048 & 2512.00 & 5.11 & $2.86 \mathrm{e}-04$ & $4.80 \mathrm{e}-05$ \\
\hline $\mathrm{d} 34$ & 0.847 & 0.048 & 2512.00 & 5.11 & $2.64 \mathrm{e}-04$ & $4.80 \mathrm{e}-05$ \\
\hline a35 & 1.210 & 0.053 & 2835.00 & 5.11 & $3.34 \mathrm{e}-04$ & $5.30 \mathrm{e}-05$ \\
\hline b35 & 0.935 & 0.040 & 2835.00 & 5.11 & $2.58 \mathrm{e}-04$ & $4.00 \mathrm{e}-05$ \\
\hline c35 & 0.918 & 0.040 & 2835.00 & 5.11 & $2.53 e-04$ & $4.00 \mathrm{e}-05$ \\
\hline $\mathrm{d} 35$ & 0.963 & 0.040 & 2835.00 & 5.11 & $2.66 \mathrm{e}-04$ & $4.00 \mathrm{e}-05$ \\
\hline a36 & 1.009 & 0.041 & 4037.00 & 5.11 & $1.96 \mathrm{e}-04$ & $4.10 \mathrm{e}-05$ \\
\hline b36 & 1.098 & 0.042 & 4037.00 & 5.11 & $2.13 e-04$ & $4.20 \mathrm{e}-05$ \\
\hline c36 & 1.138 & 0.043 & 4037.00 & 5.11 & $2.21 \mathrm{e}-04$ & $4.30 \mathrm{e}-05$ \\
\hline $\mathrm{d} 36$ & 1.108 & 0.042 & 3037.00 & 5.11 & $2.86 \mathrm{e}-04$ & $4.20 \mathrm{e}-05$ \\
\hline a37 & 0.655 & 0.036 & 2633.00 & 5.11 & $1.95 \mathrm{e}-04$ & $3.60 \mathrm{e}-05$ \\
\hline b37 & 0.679 & 0.037 & 2633.00 & 5.11 & $2.02 \mathrm{e}-04$ & $3.70 \mathrm{e}-05$ \\
\hline c37 & 0.699 & 0.037 & 2633.00 & 5.11 & $2.08 \mathrm{e}-04$ & $3.70 e-05$ \\
\hline a38 & 1.152 & 0.043 & 2560.00 & 5.11 & $3.52 \mathrm{e}-04$ & $4.30 \mathrm{e}-05$ \\
\hline b38 & 1.154 & 0.043 & 2560.00 & 5.11 & $3.53 \mathrm{e}-04$ & $4.30 \mathrm{e}-05$ \\
\hline c38 & 1.152 & 0.043 & 2560.00 & 5.11 & $3.52 \mathrm{e}-04$ & $4.30 \mathrm{e}-05$ \\
\hline a39 & 1.074 & 0.042 & 2360.00 & 5.11 & $3.56 \mathrm{e}-04$ & $4.20 \mathrm{e}-05$ \\
\hline b39 & 1.129 & 0.043 & 2360.00 & 5.11 & $3.74 \mathrm{e}-04$ & $4.30 \mathrm{e}-05$ \\
\hline c39 & 1.189 & 0.043 & 2360.00 & 5.11 & $3.94 \mathrm{e}-04$ & $4.30 \mathrm{e}-05$ \\
\hline $\mathrm{a} 40$ & 0.750 & 0.037 & 2530.00 & 5.11 & $2.32 \mathrm{e}-04$ & $3.70 \mathrm{e}-05$ \\
\hline b40 & 0.804 & 0.038 & 2530.00 & 5.11 & $2.49 \mathrm{e}-04$ & $3.80 \mathrm{e}-05$ \\
\hline
\end{tabular}




\begin{tabular}{||l|l|l|l|l|l|l||}
\hline $\mathrm{c} 40$ & 0.695 & 0.037 & 2530.00 & 5.11 & $2.15 \mathrm{e}-04$ & $3.70 \mathrm{e}-05$ \\
\hline $\mathrm{d} 40$ & 0.757 & 0.038 & 2530.00 & 5.11 & $2.34 \mathrm{e}-04$ & $3.80 \mathrm{e}-05$ \\
\hline $\mathrm{e} 40$ & 0.754 & 0.038 & 2530.00 & 5.11 & $2.33 \mathrm{e}-04$ & $3.80 \mathrm{e}-05$ \\
\hline
\end{tabular}


APPENDIX B1.2

Data and Results

\begin{tabular}{|c|c|c|c|c|}
\hline Sample & $\mathrm{SO}_{4}$ moles $/ 1$ & $\begin{array}{l}\mathrm{SO}_{4} \text { error } \\
\text { Moles } 1\end{array}$ & $\mathrm{SO}_{2} \mathrm{ug} / 1$ & $\mathrm{SO}_{2}$ moles $/ 1$ \\
\hline a7 & $4.06 \mathrm{e}-13$ & $3.67 \mathrm{e}-13$ & $1.00 \mathrm{e}+02$ & $1.02 \mathrm{e}-06$ \\
\hline b7 & $5.51 \mathrm{e}-13$ & $3.67 \mathrm{e}-13$ & $1.00 \mathrm{e}+02$ & $1.02 \mathrm{e}-06$ \\
\hline $\mathrm{a} 8$ & $1.83 \mathrm{e}-12$ & $3.87 \mathrm{e}-13$ & $4.01 \mathrm{e}+01$ & $4.09 \mathrm{e}-07$ \\
\hline b8 & $1.92 \mathrm{e}-12$ & $3.87 \mathrm{e}-13$ & $4.01 \mathrm{e}+01$ & $4.09 \mathrm{e}-07$ \\
\hline a9 & $5.63 e-13$ & $3.77 \mathrm{e}-13$ & $2.01 \mathrm{e}+01$ & $2.04 e-07$ \\
\hline b9 & $7.05 e-13$ & $3.87 e-13$ & $2.01 \mathrm{e}+01$ & $2.04 \mathrm{e}-07$ \\
\hline a10 & $4.16 \mathrm{e}-13$ & $3.67 e-13$ & $2.01 \mathrm{e}+01$ & $2.04 \mathrm{e}-07$ \\
\hline b10 & $3.03 e-13$ & $3.67 \mathrm{e}-13$ & $2.01 \mathrm{e}+01$ & $2.04 \mathrm{e}-07$ \\
\hline a15 & $7.94 \mathrm{e}-13$ & $4.38 \mathrm{e}-13$ & $1.02 \mathrm{e}+01$ & $1.02 \mathrm{e}-07$ \\
\hline b15 & $8.07 \mathrm{e}-13$ & $4.38 \mathrm{e}-13$ & $1.02 \mathrm{e}+01$ & $1.02 \mathrm{e}-07$ \\
\hline c15 & $1.00 \mathrm{e}-12$ & $4.38 \mathrm{e}-13$ & $1.02 \mathrm{e}+01$ & $1.02 \mathrm{e}-07$ \\
\hline $\mathrm{a} 16$ & $4.10 \mathrm{e}-13$ & $4.38 \mathrm{e}-13$ & $1.02 \mathrm{e}+01$ & $1.02 \mathrm{e}-07$ \\
\hline b16 & $3.95 \mathrm{e}-13$ & $4.38 \mathrm{e}-13$ & $1.02 \mathrm{e}+01$ & $1.02 \mathrm{e}-07$ \\
\hline $\mathrm{c} 16$ & $4.20 \mathrm{e}-13$ & $4.38 \mathrm{e}-13$ & $1.02 \mathrm{e}+01$ & $1.02 \mathrm{e}-07$ \\
\hline $\mathrm{a} 17$ & $9.49 \mathrm{e}-14$ & $4.28 \mathrm{e}-13$ & $1.02 \mathrm{e}+01$ & $1.02 \mathrm{e}-07$ \\
\hline b17 & $9.67 e-14$ & $4.28 \mathrm{e}-13$ & $1.02 \mathrm{e}+01$ & $1.02 \mathrm{e}-07$ \\
\hline $\mathrm{c} 17$ & $1.48 \mathrm{e}-13$ & $4.28 \mathrm{e}-13$ & $1.02 \mathrm{e}+01$ & $1.02 \mathrm{e}-07$ \\
\hline $\mathrm{d} 17$ & $1.19 \mathrm{e}-13$ & $4.28 \mathrm{e}-13$ & $1.02 \mathrm{e}+01$ & $1.02 \mathrm{e}-07$ \\
\hline $\mathrm{a} 18$ & $1.19 \mathrm{e}-13$ & $1.94 \mathrm{e}-12$ & $4.01 \mathrm{e}+01$ & $1.02 \mathrm{e}-07$ \\
\hline b18 & $4.00 \mathrm{e}-14$ & $1.93 \mathrm{e}-12$ & $4.01 \mathrm{e}+01$ & $1.02 e-07$ \\
\hline $\mathrm{c} 18$ & $2.58 \mathrm{e}-14$ & $1.93 \mathrm{e}-12$ & $4.01 \mathrm{e}+01$ & $4.09 e-07$ \\
\hline a19 & $1.56 \mathrm{e}-13$ & $1.94 \mathrm{e}-12$ & $4.01 \mathrm{e}+01$ & $4.09 \mathrm{e}-07$ \\
\hline b19 & $9.41 \mathrm{e}-15$ & $1.93 \mathrm{e}-12$ & $4.01 \mathrm{e}+01$ & $4.09 \mathrm{e}-07$ \\
\hline $\mathrm{a} 20$ & $1.12 \mathrm{e}-13$ & $1.94 \mathrm{e}-12$ & $4.00 \mathrm{e}+01$ & $4.09 \mathrm{e}-07$ \\
\hline a21 & $3.79 \mathrm{e}-14$ & $1.93 \mathrm{e}-12$ & $2.01 \mathrm{e}+01$ & $2.04 \mathrm{e}-07$ \\
\hline
\end{tabular}




\begin{tabular}{|c|c|c|c|c|}
\hline b21 & $3.47 \mathrm{e}-14$ & $1.93 \mathrm{e}-12$ & $2.01 \mathrm{e}+01$ & $2.04 \mathrm{e}-07$ \\
\hline a22 & $7.76 \mathrm{e}-14$ & $1.93 \mathrm{e}-12$ & $4.00 \mathrm{e}+01$ & $4.09 \mathrm{e}-07$ \\
\hline a23 & $2.00 \mathrm{e}-13$ & $8.16 \mathrm{e}-13$ & $2.01 \mathrm{e}+01$ & $2.04 \mathrm{e}-07$ \\
\hline a24 & $3.35 \mathrm{e}-13$ & $8.16 \mathrm{e}-13$ & $2.01 \mathrm{e}+01$ & $2.04 \mathrm{e}-07$ \\
\hline a25 & $2.86 \mathrm{e}-12$ & $5.30 \mathrm{e}-13$ & $1.00 \mathrm{e}+02$ & $1.02 \mathrm{e}-06$ \\
\hline b25 & $3.05 \mathrm{e}-12$ & $5.40 \mathrm{e}-13$ & $1.00 \mathrm{e}+02$ & $1.02 \mathrm{e}-06$ \\
\hline c25 & $3.03 \mathrm{e}-12$ & $5.30 \mathrm{e}-13$ & $1.00 \mathrm{e}+02$ & $1.02 \mathrm{e}-06$ \\
\hline a26 & $2.62 \mathrm{e}-12$ & $6.12 \mathrm{e}-13$ & $1.00 \mathrm{e}+02$ & $1.02 e-06$ \\
\hline b26 & $2.72 \mathrm{e}-12$ & $6.22 \mathrm{e}-13$ & $1.00 \mathrm{e}+02$ & $1.02 \mathrm{e}-06$ \\
\hline c26 & $2.68 \mathrm{e}-12$ & $6.22 \mathrm{e}-13$ & $1.00 \mathrm{e}+02$ & $1.02 \mathrm{e}-06$ \\
\hline a27 & $1.95 \mathrm{e}-12$ & $5.00 \mathrm{e}-13$ & $1.00 \mathrm{e}+02$ & $1.02 \mathrm{e}-06$ \\
\hline b27 & $1.98 \mathrm{e}-12$ & $5.00 \mathrm{e}-13$ & $1.00 \mathrm{e}+02$ & $1.02 \mathrm{e}-06$ \\
\hline c27 & $2.04 \mathrm{e}-12$ & $5.00 \mathrm{e}-13$ & $1.00 \mathrm{e}+02$ & $1.02 \mathrm{e}-06$ \\
\hline a28 & $1.33 \mathrm{e}-12$ & $4.79 e-13$ & $1.00 \mathrm{e}+02$ & $1.02 \mathrm{e}-06$ \\
\hline b28 & $1.35 \mathrm{e}-12$ & $4.79 \mathrm{e}-13$ & $1.00 \mathrm{e}+02$ & $1.02 \mathrm{e}-06$ \\
\hline c28 & $1.35 \mathrm{e}-12$ & $4.79 \mathrm{e}-13$ & $1.00 \mathrm{e}+02$ & $1.02 \mathrm{e}-06$ \\
\hline a29 & $4.88 \mathrm{e}-12$ & $8.87 e-13$ & $1.00 \mathrm{e}+02$ & $1.02 \mathrm{e}-06$ \\
\hline b29 & $4.92 \mathrm{e}-12$ & $8.97 \mathrm{e}-13$ & $1.00 \mathrm{e}+02$ & $1.02 \mathrm{e}-06$ \\
\hline c29 & $4.87 \mathrm{e}-12$ & $8.97 \mathrm{e}-13$ & $1.00 \mathrm{e}+02$ & $1.02 \mathrm{e}-06$ \\
\hline d29 & $4.89 \mathrm{e}-12$ & $8.97 \mathrm{e}-13$ & $1.00 \mathrm{e}+02$ & $1.02 \mathrm{e}-06$ \\
\hline $\mathrm{a} 30$ & $1.84 \mathrm{e}-12$ & $5.71 \mathrm{e}-13$ & $1.00 \mathrm{e}+02$ & $9.81 \mathrm{e}-07$ \\
\hline b30 & $1.85 \mathrm{e}-12$ & $5.71 \mathrm{e}-13$ & $1.00 \mathrm{e}+02$ & $9.81 \mathrm{e}-07$ \\
\hline $\mathrm{c} 30$ & $1.99 \mathrm{e}-12$ & $5.71 \mathrm{e}-13$ & $1.00 \mathrm{e}+02$ & $9.81 \mathrm{e}-07$ \\
\hline $\mathrm{d} 30$ & $1.98 \mathrm{e}-12$ & $5.71 \mathrm{e}-13$ & $1.00 \mathrm{e}+02$ & $9.81 \mathrm{e}-07$ \\
\hline a31 & $3.87 \mathrm{e}-12$ & $6.22 \mathrm{e}-13$ & $1.44 \mathrm{e}+02$ & $1.47 \mathrm{e}-06$ \\
\hline b31 & $3.85 \mathrm{e}-12$ & $6.22 \mathrm{e}-13$ & $1.44 \mathrm{e}+02$ & $1.47 \mathrm{e}-06$ \\
\hline c31 & $4.03 \mathrm{e}-12$ & $6.32 \mathrm{e}-13$ & $1.44 \mathrm{e}+02$ & $1.47 \mathrm{e}-06$ \\
\hline $\mathrm{d} 31$ & $3.99 \mathrm{e}-12$ & $6.32 \mathrm{e}-13$ & $1.44 \mathrm{e}+02$ & $1.47 \mathrm{e}-06$ \\
\hline a32 & $1.76 \mathrm{e}-12$ & $5.61 \mathrm{e}-13$ & $1.44 \mathrm{e}+02$ & $1.47 \mathrm{e}-06$ \\
\hline
\end{tabular}




\begin{tabular}{|c|c|c|c|c|}
\hline b32 & $1.73 \mathrm{e}-12$ & $5.61 \mathrm{e}-13$ & $1.44 \mathrm{e}+02$ & $1.47 e-06$ \\
\hline c32 & $1.75 \mathrm{e}-12$ & $5.61 \mathrm{e}-13$ & $1.44 \mathrm{e} \div \mathrm{J} 2$ & $1.47 e-06$ \\
\hline d32 & $1.73 e-12$ & $5.61 \mathrm{e}-13$ & $1.44 e+02$ & $1.47 \mathrm{e}-06$ \\
\hline a33 & $2.23 \mathrm{e}-12$ & $4.18 e-13$ & $1.44 \mathrm{e}+02$ & $1.47 e-06$ \\
\hline b33 & $3.36 \mathrm{e}-12$ & $6.12 e-13$ & $1.44 e+02$ & $1.47 \mathrm{e}-06$ \\
\hline c33 & $9.57 e-13$ & $5.81 \mathrm{e}-13$ & $1.44 e+02$ & $1.47 \mathrm{e}-06$ \\
\hline a34 & $2.56 \mathrm{e}-12$ & $4.69 \mathrm{e}-13$ & $1.42 \mathrm{e}+02$ & $1.45 e-06$ \\
\hline b34 & $2.81 \mathrm{e}-12$ & $4.89 e-13$ & $1.42 \mathrm{e}+02$ & $1.45 \mathrm{e}-06$ \\
\hline c34 & $2.91 \mathrm{e}-12$ & $4.89 e-13$ & $1.42 e+02$ & $1.45 e-06$ \\
\hline d34 & $2.69 \mathrm{e}-12$ & $4.89 e-13$ & $1.42 e+02$ & $1.45 \mathrm{e}-06$ \\
\hline a35 & $3.41 \mathrm{e}-12$ & $5.40 \mathrm{e}-13$ & $1.42 e+02$ & $1.45 \mathrm{e}-06$ \\
\hline b35 & $2.63 e-12$ & $4.08 \mathrm{e}-13$ & $1.42 e+02$ & $1.45 e-06$ \\
\hline c35 & $2.58 \mathrm{e}-12$ & $4.08 \mathrm{e}-13$ & $1.42 e+02$ & $1.45 e-06$ \\
\hline $\mathrm{d} 35$ & $2.71 \mathrm{e}-12$ & $4.08 \mathrm{e}-13$ & $1.42 e+02$ & $1.45 e-06$ \\
\hline a36 & $1.99 \mathrm{e}-12$ & $4.18 e-13$ & $1.42 e+02$ & $1.45 e-06$ \\
\hline b36 & $2.17 e-12$ & $4.28 \mathrm{e}-13$ & $1.42 e+02$ & $1.45 \mathrm{e}-06$ \\
\hline c36 & $2.25 \mathrm{e}-12$ & $4.38 \mathrm{e}-13$ & $1.42 e+02$ & $1.45 \mathrm{e}-06$ \\
\hline $\mathrm{d} 36$ & $2.91 \mathrm{e}-12$ & $4.28 \mathrm{e}-13$ & $1.42 e+02$ & $1.45 e-06$ \\
\hline a37 & $1.99 \mathrm{e}-12$ & $3.67 t-1.3$ & $1.42 \mathrm{e}+02$ & $1.45 \mathrm{e}-06$ \\
\hline b37 & $2.06 \mathrm{e}-12$ & $3.77 e-13$ & $1.42 e+72$ & $1.45 e-06$ \\
\hline c37 & $2.12 \mathrm{e}-12$ & $3.77 e-13$ & $1.42 e+02$ & $1.45 e-06$ \\
\hline a38 & $3.59 e-12$ & $4.38 \mathrm{e}-13$ & $1.42 e+02$ & $i .45 e-06$ \\
\hline b38 & $3.60 \mathrm{e}-12$ & $4.38 \mathrm{e}-13$ & $1.42 \mathrm{e}+02$ & $1.45 e-06$ \\
\hline $\mathrm{c} 38$ & $3.59 \mathrm{e}-12$ & $4.38 \mathrm{e}-13$ & $1.42 e+02$ & 1.45 e 06 \\
\hline a39 & $3.63 e-12$ & $4.28 \mathrm{e}-13$ & $1.42 e+02$ & $1.45 \mathrm{e}-06$ \\
\hline b39 & $3.82 \mathrm{e}-12$ & $4.38 \mathrm{e}-13$ & $1.42 e+02$ & $1.45 e-06$ \\
\hline c39 & $4.02 \mathrm{e}-12$ & $4.38 \mathrm{e}-13$ & $1.42 e+02$ & $1.45 \mathrm{e}-06$ \\
\hline $\mathrm{a} 40$ & $2.37 e-12$ & $3.77 \mathrm{e}-13$ & $1.42 \mathrm{e}+02$ & $1.45 \mathrm{e}-06$ \\
\hline b40 & $2.54 c-12$ & $3.87 c-13$ & $1.42 e+02$ & $1.45 e-06$ \\
\hline
\end{tabular}




\begin{tabular}{|l|l|l|l|l|}
\hline $\mathrm{c} 40$ & $2.19 \mathrm{e}-12$ & $3.77 \mathrm{e}-13$ & $1.42 \mathrm{e}+02$ & $1.45 \mathrm{e}-06$ \\
\hline $\mathrm{d} 40$ & $2.39 \mathrm{e}-12$ & $3.87 \mathrm{e}-13$ & $1.42 \mathrm{e}+02$ & $1.45 \mathrm{e}-06$ \\
\hline $\mathrm{c} 40$ & $2.38 \mathrm{e}-12$ & $3.87 \mathrm{e}-13$ & $1.42 \mathrm{e}+02$ & $1.45 \mathrm{e}-06$ \\
\hline
\end{tabular}




\section{APPENDIX B1.3}

\section{Data and Results}

\begin{tabular}{|c|c|c|c|c|}
\hline Sample & $\begin{array}{l}\text { Mass Conv. } \\
\text { Rate } \\
\end{array}$ & $\mathrm{H}_{2} \mathrm{O}$ moles $/ 1$ & $\begin{array}{c}\text { OH Estimate } \\
\mathrm{cm}^{-3}\end{array}$ & $\begin{array}{l}\text { OH ERROR } \\
\mathrm{cm}^{-3}\end{array}$ \\
\hline a7 & $3.97 \mathrm{e}-07$ & $2.09 \mathrm{e}-04$ & $4.90 \mathrm{e}-01$ & $8.92 e+00$ \\
\hline b7 & $5.39 \mathrm{e}-07$ & $2.09 \mathrm{e}-04$ & $6.65 \mathrm{e}-01$ & $1.21 \mathrm{e}+01$ \\
\hline $\mathrm{a} 8$ & 4.47e-06 & $3.36 \mathrm{e}-04$ & $5.50 \mathrm{e}+00$ & $1.00 \mathrm{e}+02$ \\
\hline b8 & $4.70 \mathrm{e}-06$ & $3.36 \mathrm{e}-04$ & $5.78 \mathrm{e}+00$ & $1.05 e+02$ \\
\hline a9 & $2.75 e-06$ & $2.91 \mathrm{e}-04$ & $3.39 \mathrm{e}+00$ & $6.17 e+01$ \\
\hline b9 & $3.45 \mathrm{e}-06$ & $2.91 \mathrm{e}-04$ & $4.25 e+00$ & $7.73 e+01$ \\
\hline a10 & $2.03 e-06$ & $3.86 \mathrm{e}-04$ & $2.51 e+00$ & $4.56 \mathrm{e}+01$ \\
\hline b10 & $1.48 \mathrm{e}-06$ & $3.86 \mathrm{e}-04$ & $1.83 e+00$ & $3.33 e+01$ \\
\hline ai5 & $7.61 \mathrm{e}-06$ & $2.91 \mathrm{e}-04$ & $9.57 \mathrm{e}+00$ & $1.74 \mathrm{e}+02$ \\
\hline b15 & $7.74 \mathrm{e}-06$ & $2.91 \mathrm{e}-04$ & $9.73 e+00$ & $1.77 e+02$ \\
\hline c15 & $9.60 \mathrm{e}-06$ & $2.91 \mathrm{e}-04$ & $1.21 \mathrm{e}+01$ & $2.20 \mathrm{e}+02$ \\
\hline $\mathrm{a} 16$ & $3.93 e-06$ & $2.91 \mathrm{e}-04$ & $4.95 e+00$ & $9.01 e+01$ \\
\hline b16 & $3.79 e-06$ & $2.91 \mathrm{e}-04$ & $4.77 e+00$ & $8.68 e+01$ \\
\hline c16 & $4.02 \mathrm{e}-06$ & $2.91 \mathrm{e}-04$ & $5.06 \mathrm{e}+00$ & $9.22 e+01$ \\
\hline a17 & $9.10 \mathrm{e}-07$ & $3.10 \mathrm{e}-04$ & $1.14 \mathrm{e}+00$ & $2.14 \mathrm{e}+01$ \\
\hline b17 & $9.27 \mathrm{e}-07$ & $3.10 \mathrm{e}-04$ & $1.17 e+00$ & $2.18 e+01$ \\
\hline c17 & $1.42 \mathrm{e}-06$ & $3.10 \mathrm{e}-04$ & $1.78 \mathrm{e}+00$ & $3.28 \mathrm{e}+01$ \\
\hline d17 & $1.14 \mathrm{e}-06$ & $3.10 \mathrm{e}-04$ & $1.43 e+00$ & $2.65 e+01$ \\
\hline a18 & $2.90 \mathrm{e}-07$ & $1.43 \mathrm{e}-04$ & $1.43 e+00$ & $3.50 \mathrm{e}+01$ \\
\hline b18 & $9.77 \mathrm{e}-08$ & $1.43 \mathrm{e}-04$ & $4.82 \mathrm{e}-01$ & $2.48 \mathrm{e}+01$ \\
\hline $\mathrm{c} 18$ & $6.31 \mathrm{e}-08$ & $1.43 \mathrm{e}-04$ & $7.76 e-02$ & $5.96 \mathrm{e}+00$ \\
\hline a19 & $3.82 \mathrm{e}-07$ & $4.39 \mathrm{e}-04$ & $4.70 \mathrm{e}-01$ & $1.03 e+01$ \\
\hline b19 & $2.30 \mathrm{e}-08$ & $4.39 \mathrm{e}-04$ & $2.83 \mathrm{e}-02$ & $5.82 \mathrm{e}+00$ \\
\hline $\mathrm{a} 20$ & $2.76 \mathrm{e}-07$ & $1.48 \mathrm{e}-04$ & $3.38 \mathrm{e}-01$ & $8.47 \mathrm{e}+00$ \\
\hline 221 & $1.85 \mathrm{e}-07$ & $1.48 \mathrm{e}-04$ & $2.29 \mathrm{e}-01$ & $1.23 e+01$ \\
\hline
\end{tabular}




\begin{tabular}{|c|c|c|c|c|}
\hline b21 & $1.70 \mathrm{e}-07$ & $1.48 \mathrm{e}-04$ & $2.09 \mathrm{e}-01$ & $1.22 \mathrm{e}+01$ \\
\hline a22 & $1.90 \mathrm{e}-07$ & $1.48 \mathrm{e}-04$ & $2.33 e-01$ & $7.18 e+00$ \\
\hline a23 & $9.80 \mathrm{e}-07$ & $1.48 \mathrm{e}-04$ & $1.21 \mathrm{e}+00$ & $2.25 \mathrm{e}+01$ \\
\hline a24 & $1.64 \mathrm{e}-06$ & $1.48 \mathrm{e}-04$ & $2.02 e+00$ & $3.71 e+01$ \\
\hline a25 & $2.80 \mathrm{e}-06$ & $2.86 e-04$ & $3.45 e+00$ & $6.27 e+01$ \\
\hline b25 & $2.98 \mathrm{e}-06$ & $2.86 \mathrm{e}-04$ & $3.68 \mathrm{e}+00$ & $6.69 e+01$ \\
\hline $\mathrm{c} 25$ & $2.96 \mathrm{e}-06$ & $2.86 \mathrm{e}-04$ & $3.65 \mathrm{e}+00$ & $6.64 e+01$ \\
\hline a26 & $2.56 e-06$ & $3.10 \mathrm{e}-04$ & $3.16 \mathrm{e}+00$ & $5.74 e+01$ \\
\hline b26 & $2.66 \mathrm{e}-06$ & $3.10 \mathrm{e}-04$ & $3.28 \mathrm{e}+00$ & $5.96 \mathrm{e}+01$ \\
\hline c26 & $2.62 e-06$ & $3.10 \mathrm{e}-04$ & $3.24 \mathrm{e}+00$ & $5.89 e+01$ \\
\hline a27 & $1.91 \mathrm{e}-06$ & $3.10 \mathrm{e}-04$ & $2.36 \mathrm{e}+00$ & $4.28 \mathrm{e}+01$ \\
\hline b27 & $1.94 e-06$ & $3.10 \mathrm{e}-04$ & $2.39 e+00$ & $4.35 \mathrm{e}+01$ \\
\hline c27 & $2.00 \mathrm{e}-06$ & $3.10 \mathrm{e}-04$ & $2.47 \mathrm{e}+00$ & $4.48 \mathrm{e}+01$ \\
\hline a28 & $1.30 \mathrm{e}-06$ & $2.19 \mathrm{e}-04$ & $1.61 \mathrm{e}+00$ & $2.92 e+01$ \\
\hline b28 & $1.32 \mathrm{e}-06$ & $2.19 \mathrm{e}-04$ & $1.63 e+00$ & $2.97 e+01$ \\
\hline c28 & $1.32 \mathrm{e}-06$ & $2.19 \mathrm{e}-04$ & $1.63 e+00$ & $2.97 e+01$ \\
\hline a29 & 4.77e-06 & $3.82 \mathrm{e}-04$ & $5.89 e+00$ & $1.07 e+02$ \\
\hline b29 & $4.81 \mathrm{e}-06$ & $3.82 \mathrm{e}-04$ & $5.93 e+00$ & $1.08 \mathrm{e}+02$ \\
\hline c29 & $4.76 \mathrm{e}-06$ & $3.82 \mathrm{e}-04$ & $5.87 \mathrm{e}+00$ & $1.07 e+02$ \\
\hline d29 & $4.78 \mathrm{e}-06$ & $3.82 \mathrm{e}-04$ & $5.89 e+00$ & $1.07 e+02$ \\
\hline a30 & $1.80 \mathrm{e}-06$ & $3.82 \mathrm{e}-04$ & $2.30 \mathrm{e}+00$ & $4.19 e+01$ \\
\hline b30 & $1.81 \mathrm{e}-06$ & $3.82 \mathrm{e}-04$ & $2.32 e+00$ & $4.23 e+01$ \\
\hline c30 & $1.94 \mathrm{e}-06$ & $3.82 \mathrm{e}-04$ & $2.49 \mathrm{e}+00$ & $4.53 e+01$ \\
\hline $\mathrm{d} 30$ & $1.93 \mathrm{e}-06$ & $3.82 \mathrm{e}-04$ & $2.48 \mathrm{e}+00$ & $4.51 \mathrm{e}+01$ \\
\hline a31 & $2.63 e-06$ & $3.91 \mathrm{e}-04$ & $3.23 e+00$ & $5.88 \mathrm{e}+01$ \\
\hline b31 & $2.62 e-06$ & $3.91 \mathrm{e}-04$ & $3.22 e+00$ & $5.86 e+01$ \\
\hline c31 & $2.74 \mathrm{e}-06$ & $3.91 \mathrm{e}-04$ & $3.37 e+00$ & $6.13 e+01$ \\
\hline $\mathrm{d} 31$ & $2.72 e-06$ & $3.91 \mathrm{e}-04$ & $3.34 e+00$ & $6.07 e+01$ \\
\hline a32 & $1.20 \mathrm{e}-06$ & $4.01 \mathrm{e}-04$ & $1.48 \mathrm{e}+00$ & $2.68 \mathrm{e}+01$ \\
\hline
\end{tabular}




\begin{tabular}{|c|c|c|c|c|}
\hline b32 & $1.18 \mathrm{e}-06$ & $4.01 \mathrm{e}-04$ & $1.45 e+00$ & $2.64 \mathrm{e}+01$ \\
\hline c32 & $1.19 \mathrm{e}-06$ & $4.01 \mathrm{e}-04$ & $1.47 \mathrm{e}+00$ & $2.67 e+01$ \\
\hline $\mathrm{d} 32$ & $1.18 e-06$ & $4.01 \mathrm{e}-04$ & $-45 e+00$ & $2.63 e+01$ \\
\hline a33 & $1.52 e-06$ & $4.01 \mathrm{e}-04$ & $1.87 e+00$ & $3.39 e+01$ \\
\hline b33 & $2.29 \mathrm{e}-06$ & $4.01 \mathrm{e}-04$ & $2.81 e+00$ & $5.12 e+01$ \\
\hline c33 & $6.52 e-07$ & $4.01 \mathrm{e}-04$ & $8.01 \mathrm{e}-01$ & $1.46 \mathrm{e}+01$ \\
\hline a34 & $1.77 \mathrm{e}-06$ & $4.01 \mathrm{e}-04$ & $2.17 e+00$ & $3.95 \mathrm{e}+01$ \\
\hline b34 & $1.94 \mathrm{e}-06$ & $4.01 \mathrm{e}-04$ & $2.39 e+00$ & $4.34 \mathrm{e}+01$ \\
\hline c34 & $2.01 \mathrm{e}-06$ & $4.01 \mathrm{e}-04$ & $2.47 e+00$ & $4.49 e+01$ \\
\hline $\mathrm{d} 34$ & $1.86 \mathrm{e}-06$ & $4.01 \mathrm{e}-04$ & $2.28 \mathrm{e}+00$ & $4.15 \mathrm{e}+01$ \\
\hline a35 & $2.35 \mathrm{e}-06$ & $4.67 \mathrm{e}-04$ & $2.89 e+00$ & $5.25 \mathrm{e}+01$ \\
\hline b35 & $1.82 \mathrm{e}-06$ & $4.67 \mathrm{e}-04$ & $2.23 e+00$ & $4.06 \mathrm{e}+01$ \\
\hline c35 & $1.79 e-06$ & $4.67 \mathrm{e}-04$ & $2.19 e+00$ & $3.99 e+01$ \\
\hline $\mathrm{d} 35$ & $1.87 \mathrm{e}-06$ & 4.67e-04 & $2.30 \mathrm{e}+00$ & $4.18 \mathrm{e}+01$ \\
\hline a36 & $1.38 \mathrm{e}-06$ & $4.74 \mathrm{e}-04$ & $1.69 \mathrm{e}+00$ & $3.08 \mathrm{e}+01$ \\
\hline b36 & $1.50 \mathrm{e}-06$ & $4.74 \mathrm{e}-04$ & $1.84 \mathrm{e}+00$ & $3.35 e+01$ \\
\hline c36 & $1.55 \mathrm{e}-06$ & $4.74 \mathrm{e}-04$ & $1.91 \mathrm{e}+00$ & $3.47 \mathrm{e}+01$ \\
\hline $\mathrm{d} 36$ & $2.01 \mathrm{e}-06$ & $4.74 \mathrm{e}-04$ & $2.47 \mathrm{e}+00$ & $4.49 \mathrm{e}+01$ \\
\hline a37 & $1.37 \mathrm{e}-06$ & $4.74 \mathrm{e}-04$ & $1.68 \mathrm{e}+00$ & $3.06 \mathrm{e}+01$ \\
\hline b37 & $1.42 \mathrm{e}-06$ & $4.74 \mathrm{e}-04$ & $1.75 \mathrm{e}+00$ & $3.17 e+01$ \\
\hline c37 & $1.46 \mathrm{e}-06$ & $4.74 \mathrm{e}-04$ & $1.80 \mathrm{e}+00$ & $3.27 e+01$ \\
\hline a38 & $2.48 \mathrm{e}-06$ & $5.72 \mathrm{e}-04$ & $3.05 \mathrm{e}+00$ & $5.54 \mathrm{e}+01$ \\
\hline b38 & $2.48 \mathrm{e}-06$ & $5.72 \mathrm{e}-04$ & $3.05 \mathrm{e}+00$ & $5.55 e+01$ \\
\hline c38 & $2.48 \mathrm{e}-06$ & $5.72 \mathrm{e}-04$ & $3.05 \mathrm{e}+00$ & $5.54 \mathrm{e}+01$ \\
\hline a39 & $2.51 \mathrm{e}-06$ & $5.72 \mathrm{e}-04$ & $3.08 \mathrm{e}+00$ & $5.60 \mathrm{e}+01$ \\
\hline b39 & $2.64 \mathrm{e}-06$ & $5.72 \mathrm{e}-04$ & $3.24 \mathrm{e}+00$ & $5.89 e+01$ \\
\hline c39 & $2.78 \mathrm{e}-06$ & $5.72 \mathrm{e}-04$ & $3.41 \mathrm{e}+00$ & $6.20 \mathrm{e}+01$ \\
\hline $\mathrm{a} 40$ & $1.63 \mathrm{e}-06$ & $5.72 \mathrm{e}-04$ & $2.01 \mathrm{e}+00$ & $3.65 \mathrm{e}+01$ \\
\hline b40 & $1.75 \mathrm{e}-06$ & $5.72 \mathrm{e}-04$ & $2.15 e+00$ & $3.91 \mathrm{e}+01$ \\
\hline
\end{tabular}




\begin{tabular}{|l|l|l|l|l|}
\hline $\mathrm{c} 40$ & $1.51 \mathrm{e}-06$ & $5.72 \mathrm{e}-04$ & $1.86 \mathrm{e}+00$ & $3.38 \mathrm{e}+01$ \\
\hline $\mathrm{d} 40$ & $1.65 \mathrm{e}-06$ & $5.72 \mathrm{e}-04$ & $2.03 \mathrm{e}+00$ & $3.68 \mathrm{e}+01$ \\
\hline $\mathrm{e} 40$ & $1.64 \mathrm{e}-06$ & $5.72 \mathrm{e}-04$ & $2.02 \mathrm{e}+00$ & $3.67 \mathrm{e}+01$ \\
\hline
\end{tabular}




\section{APPENDIX D1.1}

\section{Graded Screen Parameters}

\begin{tabular}{|c|c|c|}
\hline Sample & Flow Rate (1pm) & Lip Thickness (mm) \\
\hline Average Total Filter & 5.00 & 2.80 \\
\hline Average 30 Mesh Filter & 2.00 & 4.10 \\
\hline Average $30 \times 145$ Filter & 1.98 & 6.80 \\
\hline Average $30 \times 145 \times 635$ Filter & 1.94 & 7.30 \\
\hline Average $635 \times 6$ Filter & 1.90 & 5.20 \\
\hline
\end{tabular}

These are the various characteristics of the manual graded screen array used to measure the activity size distributions. The lip thickness is the distance form the sampler head to the filter and varies with the number and types of screens. 


\section{APPENDIX E1.1}

\section{August 1990 IC Results}

\begin{tabular}{|c|c|c|c|c|}
\hline $\begin{array}{l}\text { STD Peak } \\
\text { Area } \\
\end{array}$ & $\begin{array}{l}\text { STD Conc. } \\
\text { ppm }\end{array}$ & $\begin{array}{l}\text { Unk Peak } \\
\text { Area }\end{array}$ & $\begin{array}{l}\text { Unk Conc. } \\
\text { ppm }\end{array}$ & Sigma Unk \\
\hline 801873 & $1.00 \mathrm{e}+00$ & 28073 & 0.073 & 0.036 \\
\hline 821266 & $1.00 e+00$ & 50330 & 0.099 & 0.036 \\
\hline 855540 & $1.00 \mathrm{e}+00$ & 249197 & 0.337 & 0.038 \\
\hline 557591 & $7.50 \mathrm{e}-01$ & 263014 & 0.354 & 0.038 \\
\hline 592832 & $7.50 \mathrm{e}-01$ & 212372 & 0.293 & 0.037 \\
\hline 563361 & $7.50 \mathrm{e}-01$ & 274078 & 0.367 & 0.038 \\
\hline 353877 & $5.00 \mathrm{e}-01$ & 87346 & 0.144 & 0.036 \\
\hline 363962 & $5.00 \mathrm{e}-01$ & 54903 & 0.105 & 0.036 \\
\hline 376144 & $5.00 \mathrm{e}-01$ & & & \\
\hline 215943 & $2.50 \mathrm{e}-01$ & & & \\
\hline 198888 & $2.50 \mathrm{e}-01$ & & & \\
\hline 179096 & $2.50 \mathrm{e}-01$ & & & \\
\hline
\end{tabular}

\begin{tabular}{||l|c||}
\hline \multicolumn{2}{|c||}{ Regression Output: } \\
\hline Constant & 0 \\
\hline Std Err of Y Est & 29959.96281 \\
\hline R Squared & 0.98650306 \\
\hline No. of Observations & 12 \\
\hline Degrees of Freedom & 10 \\
\hline X Coefficient(s) & 836540.9333 \\
\hline Std Err of Coef. & 30942.51653 \\
\hline
\end{tabular}




\section{APPENDIX E1.2}

\section{September 1990 IC Results}

\begin{tabular}{|c|c|c|c|c|}
\hline $\begin{array}{l}\text { STD Peak } \\
\text { Area }\end{array}$ & $\begin{array}{l}\text { STD Conc } \\
\mathrm{ppm}\end{array}$ & $\begin{array}{l}\text { UNK Peak } \\
\text { Area }\end{array}$ & $\begin{array}{l}\text { UNK Conc. } \\
\text { ppm }\end{array}$ & Sigma UNK \\
\hline 762780 & $1.00 e+00$ & 142988 & 0.176 & 0.043 \\
\hline 663210 & $1.00 \mathrm{e}+00$ & 145666 & 0.179 & 0.043 \\
\hline 739801 & $1.00 \mathrm{e}+00$ & 176117 & 0.222 & 0.043 \\
\hline 597779 & $7.50 \mathrm{e}-01$ & 173638 & 0.219 & 0.043 \\
\hline 538906 & $7.50 \mathrm{e}-01$ & 168190 & 0.211 & 0.043 \\
\hline 562740 & $7.50 \mathrm{e}-01$ & 177442 & 0.224 & 0.043 \\
\hline 371285 & $5.00 \mathrm{e}-01$ & 54995 & 0.052 & 0.042 \\
\hline 374706 & $5.00 \mathrm{e}-01$ & 55452 & 0.053 & 0.042 \\
\hline 374448 & $5.00 \mathrm{e}-01$ & 75223 & 0.081 & 0.042 \\
\hline 218148 & $2.50 \mathrm{e}-01$ & 63863 & 0.065 & 0.042 \\
\hline 181349 & $2.50 \mathrm{e}-01$ & & & \\
\hline 176569 & $2.50 \mathrm{e}-01$ & & & \\
\hline
\end{tabular}

\begin{tabular}{|c|c|c|}
\hline \multicolumn{3}{|c|}{ Regression Output: } \\
\hline Constant & & 17796.66667 \\
\hline Std Err of Y Est & & 30167.84992 \\
\hline R Squared & & 0.981266539 \\
\hline No. of Observations & & 12 \\
\hline Degrees of Freedom & & 10 \\
\hline X Coefficient(s) & 713088.1333 & \\
\hline Std Err of Coef. & 31157.22143 & \\
\hline
\end{tabular}


APPENDIX E1.3

\section{January 1991 IC Results}

\begin{tabular}{|c|c|c|c|c|}
\hline $\begin{array}{l}\text { STD Peak } \\
\text { Area }\end{array}$ & $\begin{array}{l}\text { STD Conc. } \\
\text { ppm }\end{array}$ & $\begin{array}{l}\text { UNK Peak } \\
\text { Area }\end{array}$ & $\begin{array}{l}\text { UNK Conc. } \\
\text { ppm }\end{array}$ & Sigma UNK \\
\hline 803098 & $1.00 \mathrm{e}+00$ & 37682 & 0.092 & 0.190 \\
\hline 903492 & $1.00 \mathrm{e}+00$ & 81674 & 0.031 & 0.189 \\
\hline 824165 & $1.00 \mathrm{e}+00$ & 118564 & 0.020 & 0.189 \\
\hline 584642 & $7.50 \mathrm{e}-01$ & 44406 & 0.083 & 0.190 \\
\hline 594963 & $7.50 \mathrm{e}-01$ & 107830 & 0.005 & 0.189 \\
\hline 663949 & $7.50 \mathrm{e}-01$ & 147830 & 0.060 & 0.190 \\
\hline 407630 & $5.00 \mathrm{e}-01$ & 86878 & 0.024 & 0.189 \\
\hline 368495 & $5.00 \mathrm{e}-01$ & 119974 & 0.022 & 0.189 \\
\hline 443270 & $5.00 \mathrm{e}-01$ & 74243 & 0.042 & 0.189 \\
\hline 608429 & $5.00 \mathrm{e}-01$ & & & \\
\hline 258824 & $2.50 \mathrm{e}-01$ & & & \\
\hline 357687 & $2.50 \mathrm{e}-01$ & & & \\
\hline 710144 & $2.50 \mathrm{e}-01$ & & & \\
\hline 178435 & $2.50 \mathrm{e}-01$ & & & \\
\hline 290360 & $2.50 \mathrm{e}-01$ & & & \\
\hline 61958 & $1.50 \mathrm{e}-01$ & & & \\
\hline 92111 & $1.50 \mathrm{e}-01$ & & & \\
\hline
\end{tabular}

\begin{tabular}{||l|c||}
\hline \multicolumn{2}{|c||}{ Regression Output: } \\
\hline Constant & 104357.3252 \\
\hline Std Err of Y Est & 137170.4518 \\
\hline R Squared & 0.734907069 \\
\hline No. of Observations & 17 \\
\hline Degrees of Freedom & 15 \\
\hline
\end{tabular}




\begin{tabular}{|l|l||}
\hline X Coefficient(s) & 724724.7127 \\
\hline Std Err of Coef. & 112385.5053 \\
\hline
\end{tabular}


APPENDIX E1.4

1 March 1991 IC Results

\begin{tabular}{|c|c|c|c|c|}
\hline $\begin{array}{l}\text { STD Peak } \\
\text { Area }\end{array}$ & $\begin{array}{l}\text { STD Conc. } \\
\text { ppm }\end{array}$ & $\begin{array}{l}\text { UNK Conc. } \\
\text { ppm }\end{array}$ & $\begin{array}{l}\text { UNK Conc. } \\
\text { ppm }\end{array}$ & Sigma UNK \\
\hline 1231386 & $1.50 \mathrm{e}+00$ & 832055 & 1.045 & 0.052 \\
\hline 1220362 & $1.50 \mathrm{e}+00$ & 889237 & 1.115 & 0.053 \\
\hline 1260379 & $1.50 \mathrm{e}+00$ & 881499 & 1.106 & 0.052 \\
\hline 764641 & $1.00 \mathrm{e}+00$ & 1313179 & 1.633 & 0.060 \\
\hline 757451 & $1.00 \mathrm{e}+00$ & 1363454 & 1.695 & 0.061 \\
\hline 752089 & $1.00 \mathrm{e}+00$ & 1346174 & 1.673 & 0.061 \\
\hline 559017 & $7.50 \mathrm{e}-01$ & 640096 & 0.811 & 0.049 \\
\hline 586695 & $7.50 \mathrm{e}-01$ & 650240 & 0.823 & 0.049 \\
\hline 554930 & $7.50 \mathrm{e}-01$ & 671055 & 0.849 & 0.049 \\
\hline 381145 & $5.00 \mathrm{e}-01$ & 444965 & 0.572 & 0.047 \\
\hline 452027 & $5.00 \mathrm{e}-01$ & 451682 & 0.581 & 0.047 \\
\hline 347549 & $5.00 \mathrm{e}-01$ & 451862 & 0.581 & 0.047 \\
\hline 368105 & $5.00 \mathrm{e}-01$ & & & \\
\hline 123928 & $1.50 \mathrm{e}-01$ & & & \\
\hline 125531 & $1.50 \mathrm{e}-01$ & & & \\
\hline 124071 & $1.50 \mathrm{e}-01$ & & & \\
\hline
\end{tabular}

\begin{tabular}{||l|c||}
\hline \multicolumn{2}{|c||}{ Regression Output: } \\
\hline Constant & 0 \\
\hline Std Err of Y Est & 36517.19442 \\
\hline R Squared & 0.991373215 \\
\hline No. of Observations & 16 \\
\hline Degrees of Freedom & 14 \\
\hline$X$ Coefficient(s) & 818485.4567 \\
\hline
\end{tabular}


\begin{tabular}{|l|l|}
\hline Std Err of Coef. & 20405.76282 \\
\hline
\end{tabular} 
APPENDIX E1.5

16 April 1991 IC Results

\begin{tabular}{|c|c|c|c|c|}
\hline $\begin{array}{l}\text { STD Peak } \\
\text { Area } \\
\end{array}$ & $\begin{array}{l}\text { STD Conc. } \\
\text { ppm }\end{array}$ & $\begin{array}{l}\text { UNK Peak } \\
\text { Area } \\
\end{array}$ & $\begin{array}{l}\text { UNK Conc. } \\
\text { ppm }\end{array}$ & Sigma UNK \\
\hline 1624167 & $2.00 e+00$ & 2301863 & 2.804 & 0.087 \\
\hline 1598651 & $2.00 \mathrm{e}+00$ & 2328417 & 2.836 & 0.088 \\
\hline 1606535 & $2.00 \mathrm{e}+00$ & 2326508 & 2.834 & 0.088 \\
\hline 1302783 & $1.50 \mathrm{e}+00$ & 2335108 & 2.844 & 0.088 \\
\hline 1306576 & $1.50 e+00$ & 619519 & 0.760 & 0.056 \\
\hline 1251494 & $1.50 \mathrm{e}+00$ & 625617 & 0.767 & 0.056 \\
\hline 1273528 & $1.50 \mathrm{e}+00$ & 670390 & 0.822 & 0.056 \\
\hline 792218 & $1.00 \mathrm{e}+00$ & 667082 & 0.818 & 0.056 \\
\hline 787992 & $1.00 \mathrm{e}+00$ & 1024641 & 1.252 & 0.061 \\
\hline 781325 & $1.00 e+00$ & 1021564 & 1.248 & 0.061 \\
\hline 809255 & $1.00 \mathrm{e}+00$ & 1067163 & 1.304 & 0.062 \\
\hline 809156 & $1.00 \mathrm{e}+00$ & 1058085 & 1.293 & 0.062 \\
\hline 594401 & $7.50 \mathrm{e}-01$ & 489626 & 0.602 & 0.055 \\
\hline 535437 & $7.50 \mathrm{e}-01$ & 480869 & 0.591 & 0.055 \\
\hline 586147 & $7.50 \mathrm{e}-01$ & 486235 & 0.598 & 0.055 \\
\hline 432995 & $5.00 \mathrm{e}-01$ & 480004 & 0.590 & 0.055 \\
\hline 433269 & $5.00 \mathrm{e}-01$ & & & \\
\hline 446665 & $5.00 \mathrm{e}-01$ & & & \\
\hline
\end{tabular}

\begin{tabular}{||l|c||}
\hline \multicolumn{2}{|c||}{ Regression Output: } \\
\hline Constant & -5880.40815 \\
\hline Std Err of Y Est & 43288.9312 \\
\hline R Squared & 0.990297264 \\
\hline No. of Observations & 18 \\
\hline
\end{tabular}




\begin{tabular}{|c|c|c|}
\hline Degrees of Freedom & & 16 \\
\hline X Coefficient(s) & 823057.4143 & \\
\hline Std Err of Coef. & 20367.34683 & \\
\hline
\end{tabular}


APPENDIX E1.6

16 May 1991 IC Results

\begin{tabular}{|c|c|c|c|c|}
\hline $\begin{array}{l}\text { STD Peak } \\
\text { Area } \\
\end{array}$ & $\begin{array}{l}\text { STD Conc. } \\
\text { ppm }\end{array}$ & $\begin{array}{l}\text { UNK Peak } \\
\text { Area }\end{array}$ & $\begin{array}{l}\text { UNK Conc. } \\
\text { ppm }\end{array}$ & Sigma UNK \\
\hline 1186333 & $1.50 \mathrm{e}+00$ & 815654 & 1.056 & 0.041 \\
\hline 1192654 & $1.50 \mathrm{e}+00$ & 891935 & 1.592 & 0.060 \\
\hline 1208230 & $1.50 \mathrm{e}+00$ & 814066 & 1.453 & 0.057 \\
\hline 768304 & $1.00 \mathrm{e}+00$ & 451597 & 0.806 & 0.046 \\
\hline 761689 & $1.00 \mathrm{e}+00$ & 496102 & 0.886 & 0.048 \\
\hline 771354 & $1.00 \mathrm{e}+00$ & 513787 & 0.917 & 0.048 \\
\hline 776962 & $1.00 \mathrm{e}+00$ & 474524 & 0.847 & 0.047 \\
\hline 771186 & $1.00 \mathrm{e}+00$ & 678099 & 1.210 & 0.053 \\
\hline 506626 & $7.50 \mathrm{e}-01$ & 712336 & 0.935 & 0.040 \\
\hline 526005 & $7.50 \mathrm{e}-01$ & 698064 & 0.918 & 0.040 \\
\hline 578787 & $7.50 \mathrm{e}-01$ & 736949 & 0.963 & 0.040 \\
\hline 613529 & $7.50 \mathrm{e}-01$ & 776301 & 1.009 & 0.041 \\
\hline 526318 & $7.50 \mathrm{e}-01$ & 852326 & 1.098 & 0.042 \\
\hline 556842 & $7.50 \mathrm{e}-01$ & 885831 & 1.138 & 0.043 \\
\hline 313049 & $5.00 \mathrm{e}-01$ & 860350 & 1.108 & 0.042 \\
\hline 333480 & 5.003e-0i & 473601 & 0.655 & 0.036 \\
\hline 398468 & $5.00 \mathrm{e}-01$ & 494118 & 0.679 & 0.037 \\
\hline \multirow[t]{7}{*}{328234} & $5.00 \mathrm{e}-01$ & 511019 & 0.699 & 0.037 \\
\hline & & 898179 & 1.152 & 0.043 \\
\hline & & 899975 & 1.154 & 0.043 \\
\hline & & 898283 & 1.152 & 0.043 \\
\hline & & 831570 & 1.074 & 0.042 \\
\hline & & 878366 & 1.129 & 0.043 \\
\hline & & 929750 & 1.189 & 0.043 \\
\hline
\end{tabular}




\begin{tabular}{|l|l|l|}
\hline 554926 & 0.750 & 0.037 \\
\hline 600674 & 0.804 & 0.038 \\
\hline 507876 & 0.695 & 0.037 \\
\hline 560235 & 0.757 & 0.038 \\
\hline 558283 & 0.754 & 0.038 \\
\hline
\end{tabular}

\begin{tabular}{||l|c||}
\hline \multicolumn{2}{|c||}{ Regression Output: } \\
\hline Constant & -86560.6934 \\
\hline Std Err of Y Est & 28148.25641 \\
\hline R Squared & 0.990963396 \\
\hline No. of Observations & 18 \\
\hline Degrees of Freedom & 16 \\
\hline X Coefficient(s) & 854758.9051 \\
\hline Std Err of Coef. & 20405.98031 \\
\hline
\end{tabular}



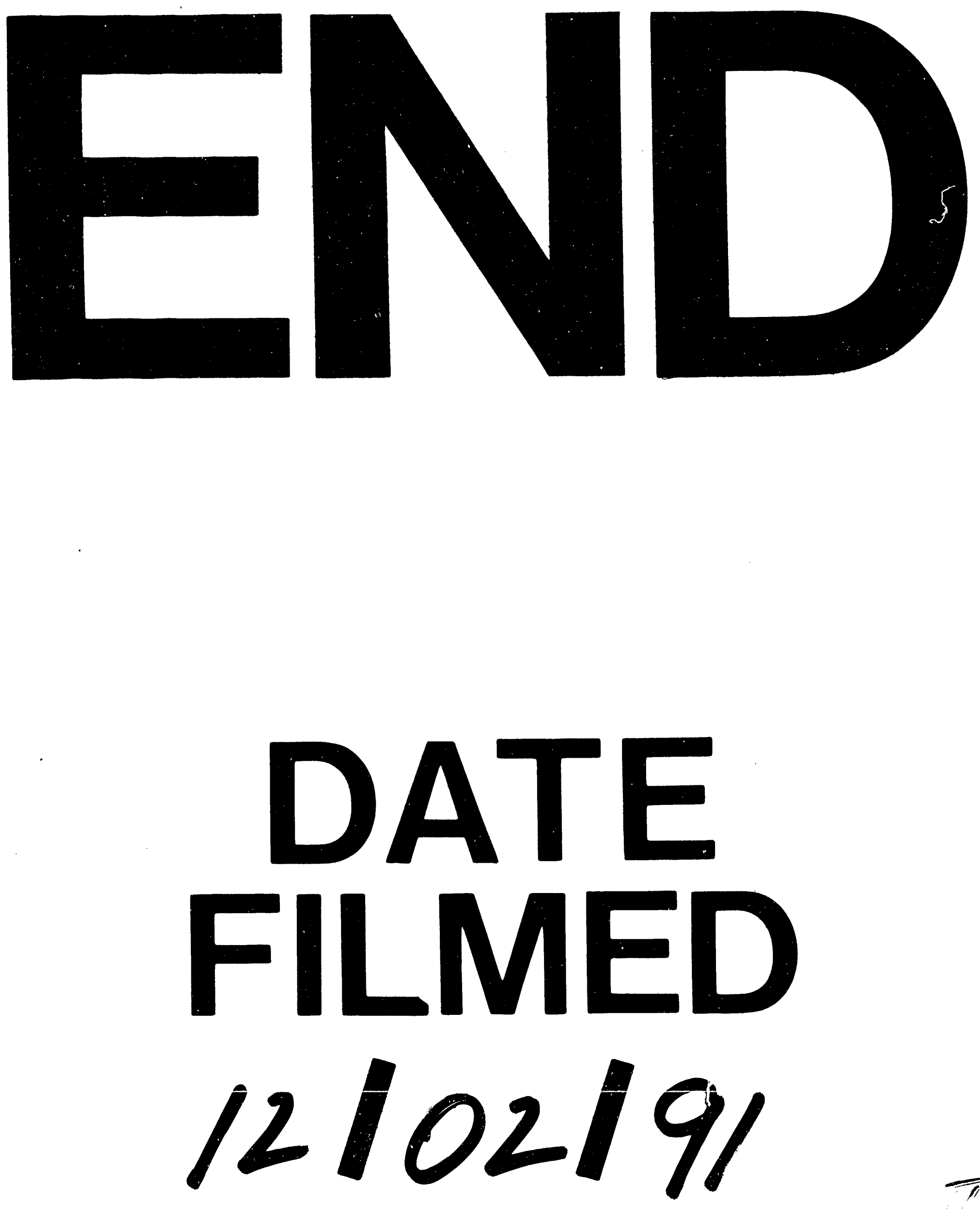

$\bar{I}$ 


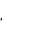

